\title{
PSCAD MODELING AND STABILITY ANALYSIS OF A MICROGRID
}

\author{
A Thesis \\ presented to \\ the Faculty of California Polytechnic State University,
}

San Luis Obispo

In Partial Fulfillment

of the Requirements for the Degree

Master of Science in Electrical Engineering

by

Kyle Hasan

June 2017 
(C) 2017

Kyle Hasan

ALL RIGHTS RESERVED 


\section{COMMITTEE MEMBERSHIP}

TITLE: PSCAD Modeling and Stability Analysis of a Microgrid

AUTHOR: Kyle Hasan

DATE SUBMITTED: June 2017

COMMITTEE CHAIR: Taufik, Ph. D.

Professor of Electrical Engineering

COMMITTEE MEMBER: Ahmad Nafisi, Ph. D.

Professor of Electrical Engineering

COMMITTEE MEMBER: Ali O. Shaban, Ph. D.

Professor of Electrical Engineering 


\section{ABSTRACT \\ PSCAD Modeling and Stability Analysis of a Microgrid \\ Kyle Hasan}

As power systems are evolving, engineers are facing, and will continue to face, new challenges with respect to maintaining the system in terms of stable operation. Many different forms of generation are becoming prevalent, including; small synchronous generators, photovoltaic generation, and energy storage techniques in the form of battery and ultracapacitor systems. One of the evolutions occurring in the power system is the emergence of microgrids, small power systems capable of isolating from the major power grid in the form of islands. Microgrids use distributed generation to provide power to small communities, and they come with several advantages and disadvantages. This thesis shows the design process employed to model a microgrid, which contains a variety of distributed resources, in PSCAD, as well as investigate the transient instability of the microgrid when transitioning to islanded operation. Modeling techniques for both grid-connected and islanded operation of the microgrid are considered in this study. In addition to modeling techniques, the effectiveness of proper control of energy storage assets in a microgrid is demonstrated through the implementation and comparison between real \& reactive power regulation and voltage $\&$ frequency regulation. 


\section{ACKNOWLEDGMENTS}

I would like to thank all of my friends and family for their endless support. I especially would like to thank a few special people. Without the help of my parents, Ken and Janie, I would not have been able to achieve many of my recent accomplishments. My brother and sister, Erik and Yvette, have always been a source of support that I am truly grateful for. Of course, much of my appreciation is owed to my loving girlfriend, Youlen, not only for her support, but for dealing with the distance along with long hours and nights spent working as I finished the Master's Program at Cal Poly. I am also highly indebted to Dr. Taufik for his guidance and support during my graduate education. Without Dr. Taufik, this Thesis would truly not have been possible. 


\section{TABLE OF CONTENTS}

\section{Page}

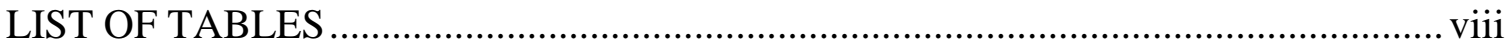

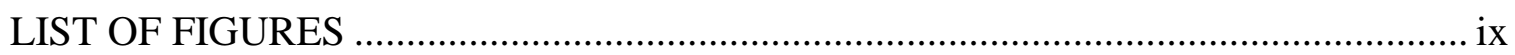

\section{CHAPTER}

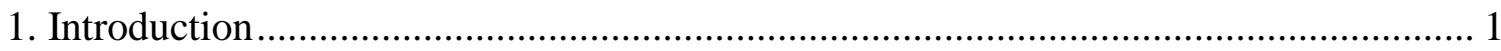

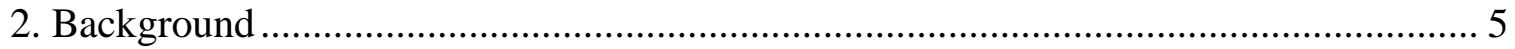

2.1: Composition of a Microgrid .............................................................................. 5

2.2: Complications within Microgrids ............................................................. 9

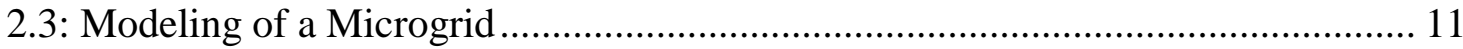

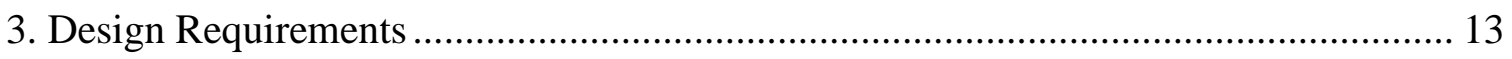

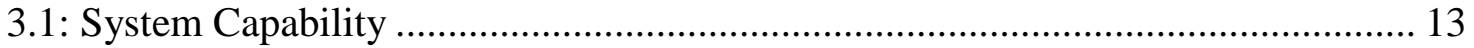

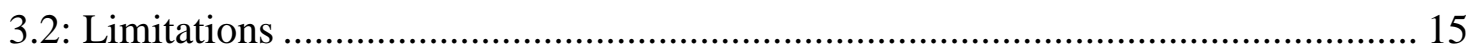

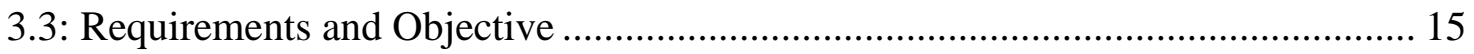

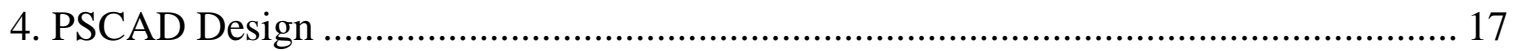

4.1: Diesel Generators .................................................................................... 17

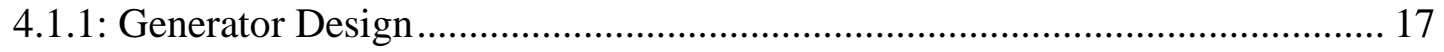

4.1.2: Synchronous Machine Design and Configuration..................................... 20

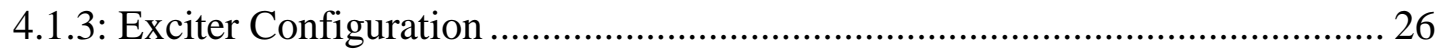

4.1.4: IC Diesel Engine Model Design ........................................................ 28

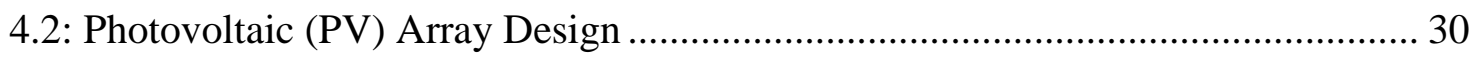

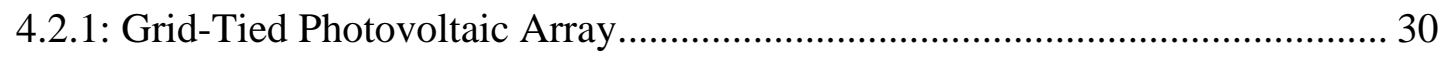

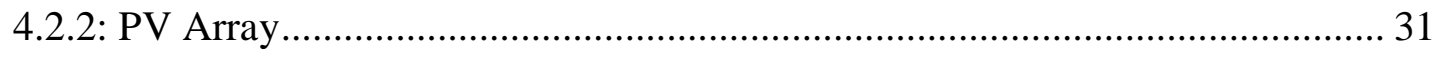




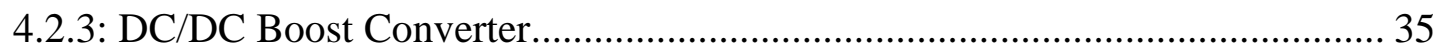

4.2.4: VSC (Voltage Source Converter) ………………........................................... 39

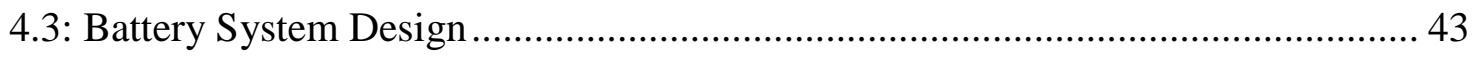

4.3.1: Grid-Tied Battery System........................................................................... 43

4.3.2: Battery Equivalent Module........................................................................... 46

4.3.3: Buck/Boost DC/DC Converter ...................................................................... 48

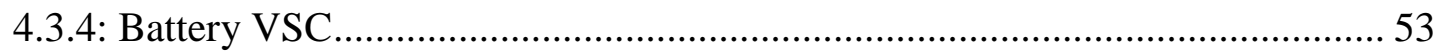

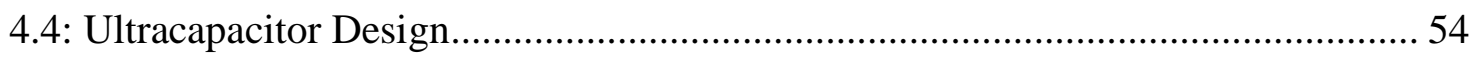

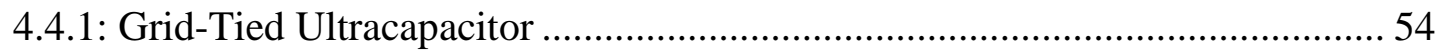

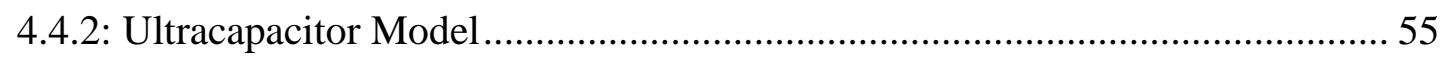

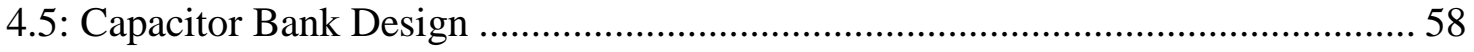

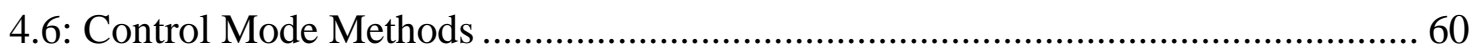

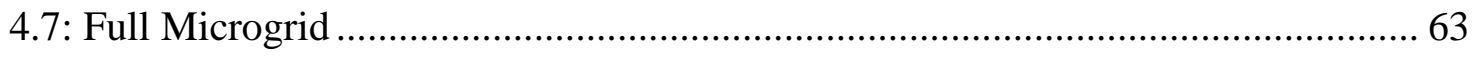

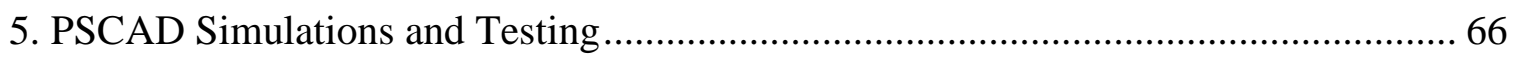

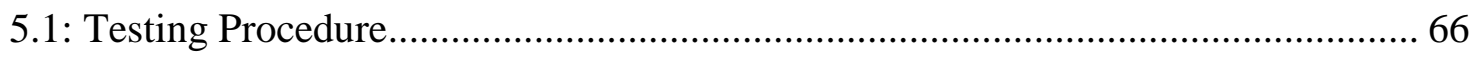

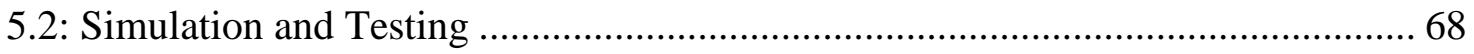

5.2.1: Test 1 - High Active Power Load Imbalance ……………………………..... 68

5.2.2: Test 2 - High Reactive Power Load Imbalance .............................................. 71

5.2.3: Test 3 - Low Reactive Power Load Imbalance ................................................. 74

5.2.4: Test 4 - High Active and Reactive Power Load Imbalance............................. 77

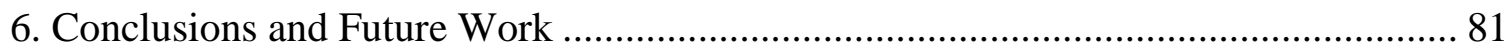

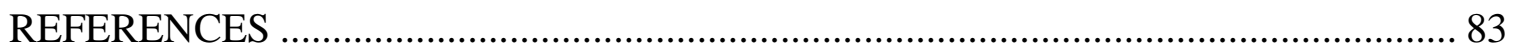




\section{LIST OF TABLES}

Table

Page

2-1: Basic Storage Device Characteristics .................................................................. 8

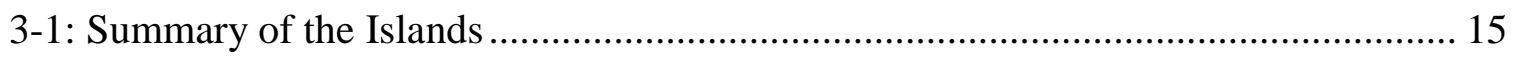

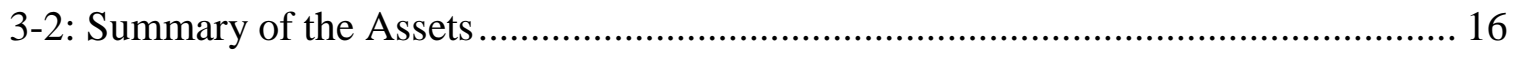

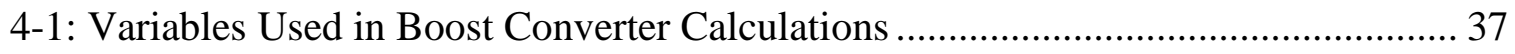

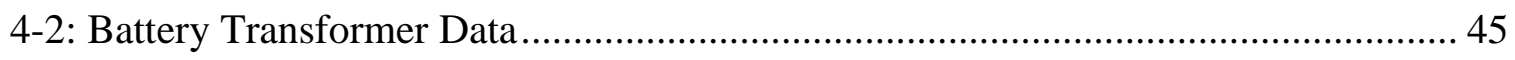

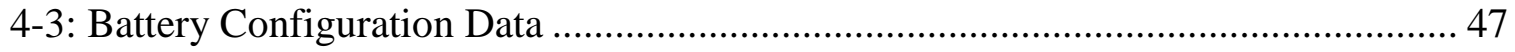

4-4: Variables Used in Buck Converter Calculations ................................................... 51

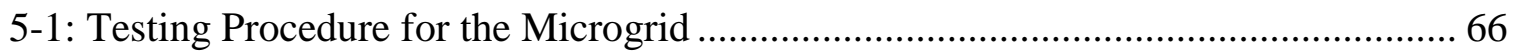




\section{LIST OF FIGURES}

Figure

Page

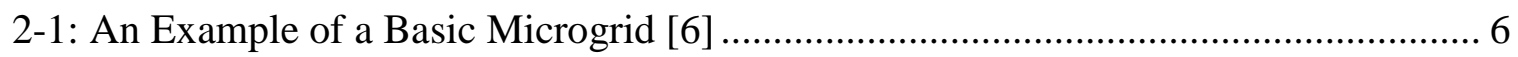

3-1: High Level Representation of the microgrid ................................................ 13

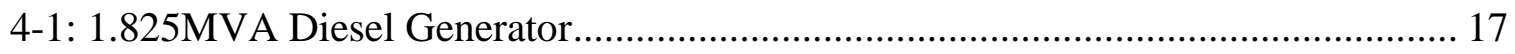

4-2: Phase-to-Ground Voltages and Line Currents Output from Diesel Generators ........ 18

4-3: Diesel Generator Speed (W), Real Power (Pg), Reactive Power (Qg), and Line-to-

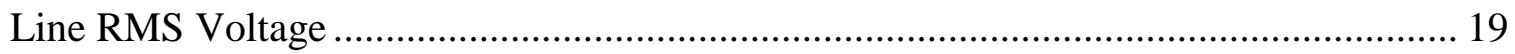

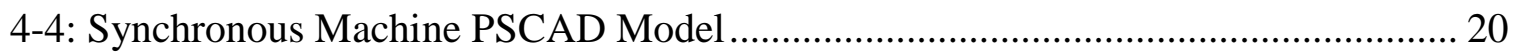

4-5: Synchronous Machine PSCAD Model Configuration Settings .............................. 21

4-6: Synchronous Machine PSCAD Model Variable Initialization Settings ................... 22

4-7: Diesel Generator Real Power (Pg), Reactive Power (Qg), and Line-to-Line RMS

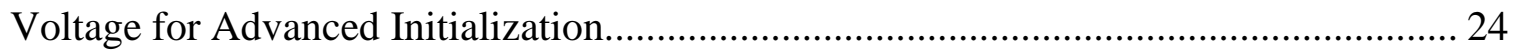

4-8: Synchronous Machine PSCAD Model Basic Data Settings.................................. 25

4-9: Synchronous Machine PSCAD Model Generator Data Format Settings ............. 26

4-10: Exciter (ST6B) for the PSCAD Diesel Generator Model ................................... 27

4-11: Diesel Internal Combustion Engine Model ................................................... 28

4-12: Diesel Internal Combustion Engine Model Configuration Settings ....................... 29

4-13: PV Array with DC/DC Converter and VSC ................................................ 30

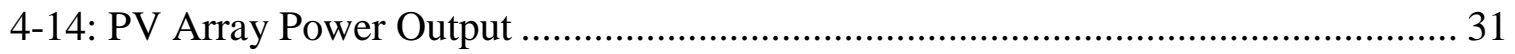

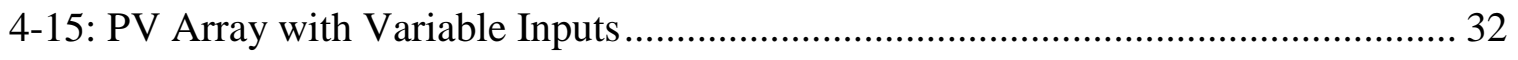

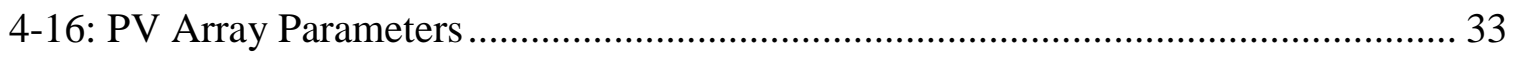




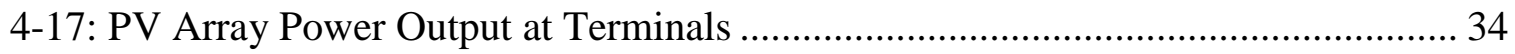

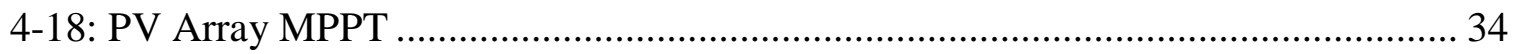

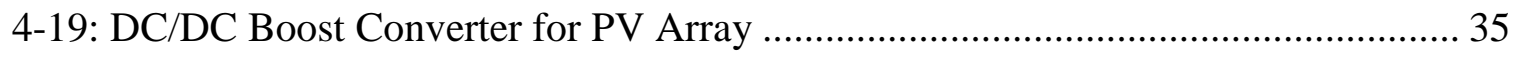

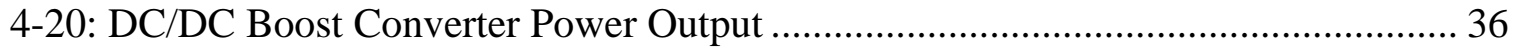

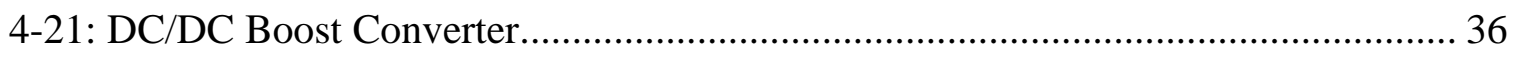

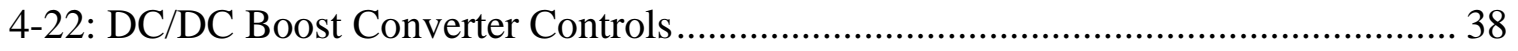

4-23: VSC Connected to Equivalent Power Grid ....................................................... 39

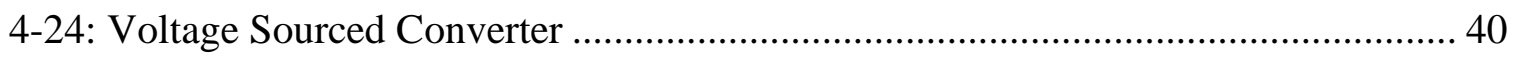

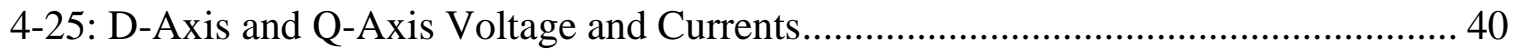

4-26: Regulation of DC Voltage, Reactive Power, and D/Q-Axis Parameters ............... 41

4-27: Generation of Reference A, B, and C Waveforms ........................................... 42

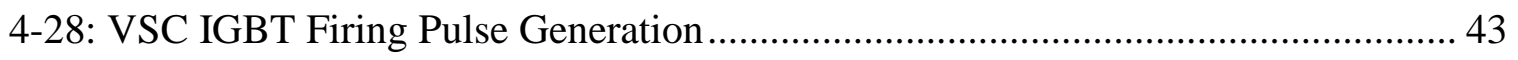

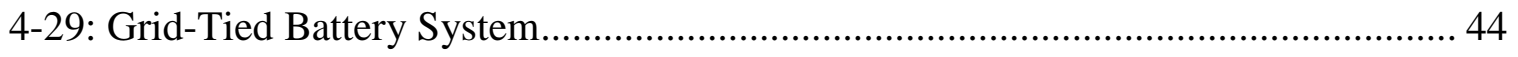

4-30: Battery System 1 Real and Reactive Power Curves ........................................... 44

4-31: Battery System 2 Real and Reactive Power Curves ......................................... 45

4-32: Battery Module for PSCAD Battery Systems ................................................. 46

4-33: Battery Equivalent Used for the Battery Systems ......................................... 47

4-34: State of Charge of Battery System for Discharge and Charging ........................... 48

4-35: Buck/Boost Converter Module for Battery Systems ........................................ 48

4-36: Buck/Boost Converter for Battery Systems ..................................................... 49

4-37: Buck/Boost Converter On/Off and Mode Controls........................................... 50

4-38: Buck Converter Controls for Battery Systems ............................................ 52

4-39: Boost Converter Controls for Battery System ................................................ 52 
4-40: LCL Filter for Battery Systems

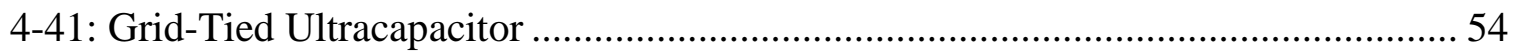

4-42: Ultracapacitor Module Power Output .............................................................. 55

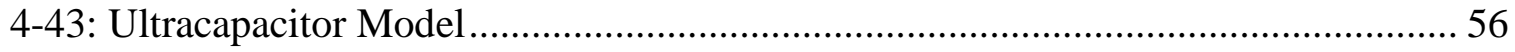

4-44: Ultracapacitor Power, Energy, and Voltage ................................................... 57

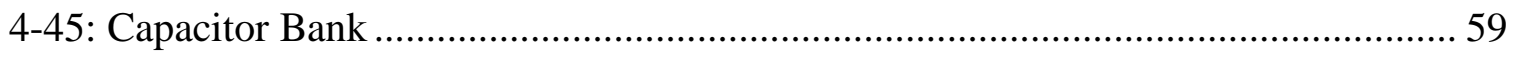

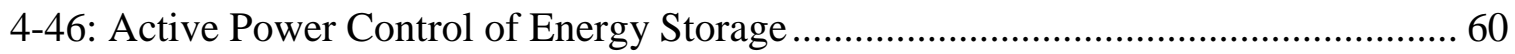

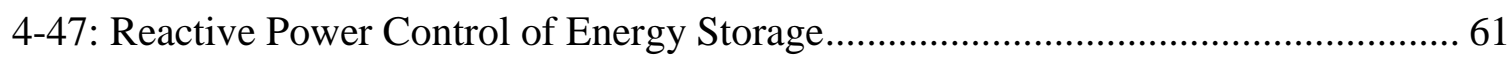

4-48: Frequency Regulation of Active Power Control of Energy Storage ...................... 62

4-49: System Voltage Regulation of Reactive Power Control of Energy Storage ........... 62

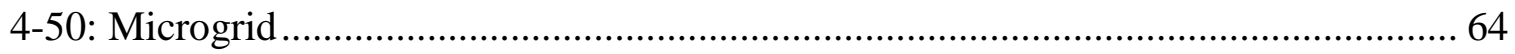

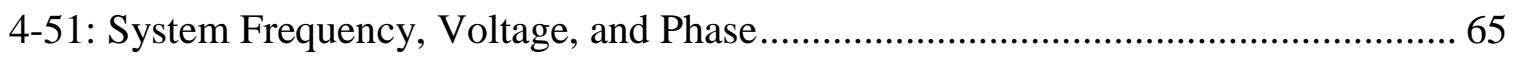

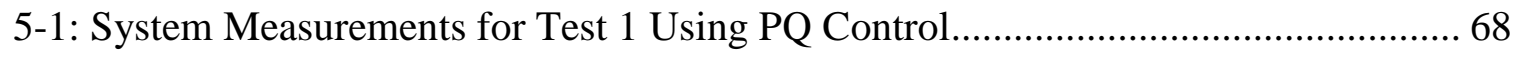

5-2: System Measurements for Test 1 Using VF Control.......................................... 69

5-3: Generator P and Q Measurements for Test 1 Using PQ Control ............................ 70

5-4: Generator P and Q Measurements for Test 1 Using VF Control ............................ 70

5-5: System Measurements for Test 2 Using PQ Control......................................... 72

5-6: System Measurements for Test 2 Using VF Control........................................... 73

5-7: Generator P and Q Measurements for Test 2 Using PQ Control ........................... 74

5-8: Generator P and Q Measurements for Test 2 Using VF Control ........................... 74

5-9: System Measurements for Test 3 Using PQ Control....................................... 75

5-10: System Measurements for Test 3 Using VF Control....................................... 76

5-11: Generator P and Q Measurements for Test 3 Using PQ Control .......................... 77 
5-12: Generator P and Q Measurements for Test 3 Using VF Control

5-13: System Measurements for Test 4 Using PQ Control.............................................. 78

5-14: System Measurements for Test 4 Using VF Control............................................. 79

5-15: Generator P and Q Measurements for Test 4 Using PQ Control ............................ 80

5-16: Generator P and Q Measurements for Test 4 Using VF Control ............................. 80 


\section{Chapter 1. Introduction}

Electricity is a utility that people in developed areas have come to expect to be always readily available at the flip of a switch. Most consumers don't normally consider where their electricity is coming from unless a power outage occurs due to a disturbance or system failure. Of course the only reason that Americans have power at all is due to the existence of electric utility power systems. Electric utilities include investor-owned, publicly-owned, cooperatives, and federal utilities. These power providers are responsible for the generation and distribution of electricity. Without a readily available supply of power, consumers would not only be inconvenienced by the absence of electricity, but most businesses would also be unable to function and could experience significant costs due to a power outage. As a result, improving the reliability and stability of the power system is of utmost importance to electric utilities.

The need for a reliable and stable power system is the reason that the field of power system protection exists. There are a variety of devices and methods used for power system protection. According to reference [1], the primary considerations for any power system protection scheme are: reliability, selectivity, speed, economy (or cost), and simplicity. The most common, and most simple, of devices used for power system protection are fuses. A fuse serves as an overcurrent protection device that melts when heated from high currents and then severs the electrical connection. Fuses, however, are not ideal for all protection purposes due to the lack of control they offer, as well as the fact that they take a relatively large amount of time to replace once blown. A power system needs to come back online as soon as possible in order to mitigate losses, especially when the initial failure is temporary. For improved control and recovery time, electromechanical relays and circuit breakers are 
used. Electromechanical relays started getting major use in system protection in the early 1920 s and are proven to be very sturdy and many engineers elect to use them due to their reliable performance and low cost. There are several kinds of electromechanical relays that improve the level of control and selectivity an engineer has for power system protection such as overcurrent and directional relays. Overcurrent relays operate like fuses, where they will interrupt the flow of current when the current is detected to be too high. The directional relay measures both voltage and current to determine the direction that current is flowing. Another popular type of relay that came about in the 1960s is static relays. Static relays have no moving parts and are used for improved sensitivity, speed, and repeatability in electrical design. Static relays can be used for most relay applications, but are highly susceptible to transients, which requires more care for shielding the installation. The advancement of solid state electronics, however, paved the way for the next generation of protective relays; digital relays. Digital relays became prominent in system protection during the 1980s and allows for adaptive settings that can be changed as the system conditions change. Digital relays are currently dominant in the market due to the fact that they are more flexible and reduces the need for many different types of relays. In many cases, only a software change will need to be made, rather than completely changing the hardware design of a system. The field of system protection is currently in the process of moving into a future generation; the integration of protection, metering, control, and communications into a protection system for a complete substation. This implies the use of many processors in a distributed environment with need for central control and surveillance. 
System protection is not only changing due to advancements in protective devices, but the power system itself is also constantly evolving, which in turn calls for updates to protection techniques. In recent years, many methods of power generation have emerged and become prominent in the power system, particularly variable resources. "Variable resources differ from conventional and fossil-fired resources in a fundamental way: their fuel source (wind, sunlight, and moving water) cannot presently be controlled or stored. Unlike coal or natural gas, which can be extracted from the earth, delivered to plants thousands of miles away, and stockpiled for use when needed, variable fuels must be used when and where they are available" [2]. Unfortunately these variable fuels are often either very abundant during times of low customer demand, or extremely lacking during times of need. Solar Energy, for example, is not available when the sun is down, so energy storage techniques must be incorporated in order to supply any energy after sunset.

One of the emerging methods for the improvement of reliability in the power system that incorporates advanced flexibility and energy storage is microgrids. A microgrid is a separate power system that utilizes smaller distributed energy sources, as opposed to large centralized generation, and incorporates its own methods of demand management and energy storage. Microgrids are capable of operating in parallel with, or entirely separate from the larger power system. As described in [3], during disturbances the generation and corresponding load can disconnect and run independently from the power system without impairing the transmission grid integrity. Furthermore, disconnecting from the larger power system allows for local control, rather than rely on central dispatch. Microgrids have become more relevant due to the emergence of smaller distributed generators and renewable resources like solar panels. In areas that these types 
of generation are used, microgrids have a much more limited range of loads to supply for, which allows for the effective management of variable fuels. Depending on the sources of fuel and how the energy requirements are managed, a microgrid can run indefinitely. A microgrid provides backup for the grid in the event of an emergency, while also allowing for the potential to cut costs, or even connect to a local resource that is too small or unreliable [4]. Of course, for microgrids to be beneficial the microgrids themselves must be reliable so that, when they are disconnected in the form of intentional islanding, power can still be delivered as expected. Furthermore for scalability and adoptability, microgrids can come in a range of designs and sizes ranging from a single facilities to much larger communities, may be grid-tied or entirely off-the-grid, and may operate in AC or DC power distribution system. 


\section{Chapter 2. Background}

\section{1: Composition of a Microgrid}

All of the elements contained within a microgrid comes with advantages and disadvantages that contribute to the overall quality of any individual microgrid. One quality that is common across all microgrids is the use of distributed generation (DG) sources. "Distributed generation is an approach that employs small-scale technologies to produce electricity close to the end users of power. DG technologies often consist of modular (and sometimes renewable-energy) generators, and they offer a number of potential benefits. In many cases, distributed generations can provide lower-cost electricity and higher power supply reliability and security with fewer environmental consequences than the traditional power generators [5]. The current power system is dominated by centralized power plants which have certain disadvantages such as the necessity for long transmission line and the use of fossil-based fuels including coal, oil, natural gas, and nuclear energy. The long transmission lines cause inefficiencies due to power loss introduced by line loss, and security related issues. The use of fossil fuels impose environmental concerns since they contribute to greenhouse gas emission. Microgrids offer the opportunity to overcome the aforementioned issues since they provide an excellent method of incorporating the various types of distributed generation. An example of a basic microgrid system is shown in Figure 2-1 [6]. Some common elements found in microgrids include photovoltaic (PV) systems, wind turbines, and storage systems. 


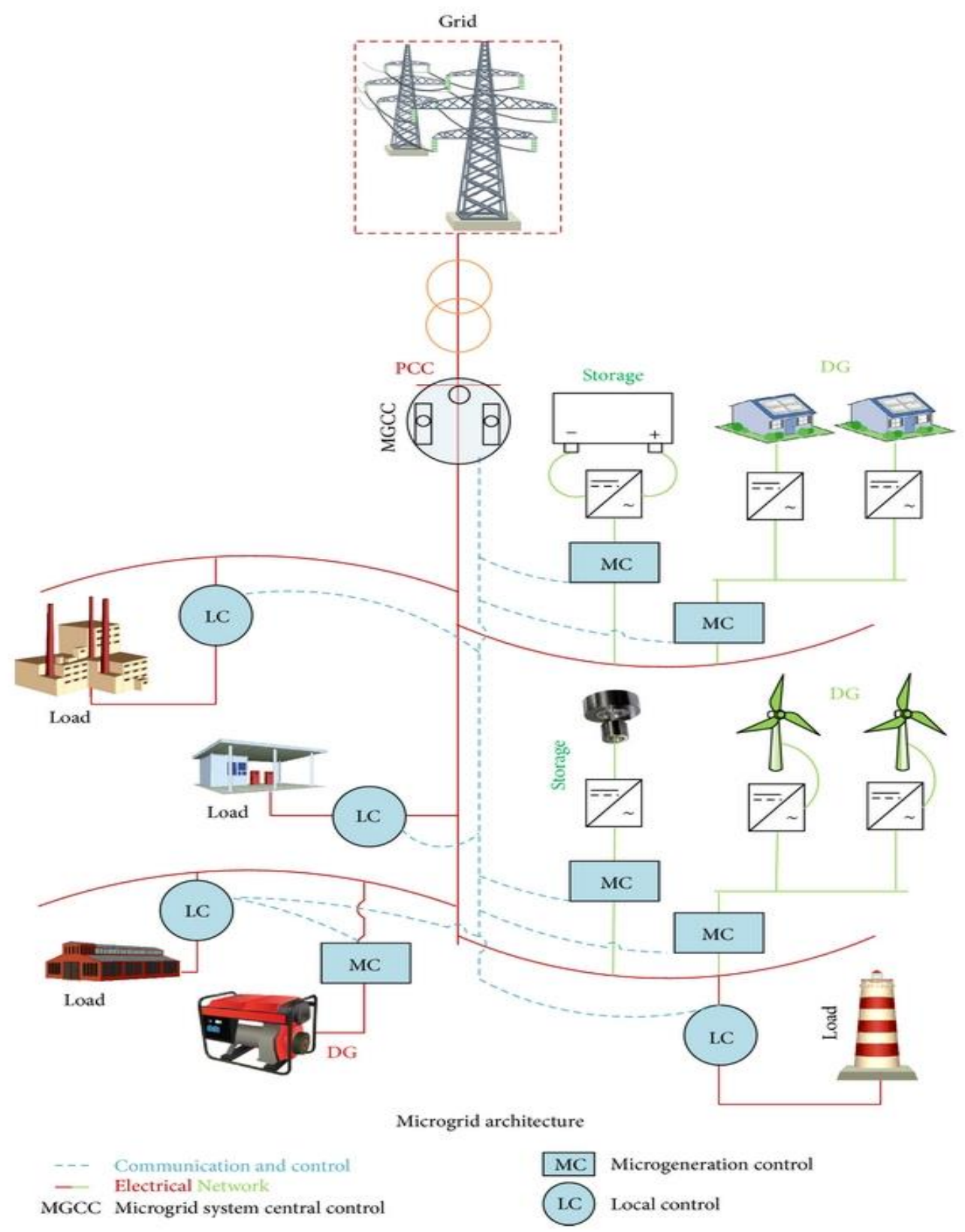

Figure 2-1: An example of a Basic Microgrid [6]

Arguably the most common and most well-known form of DG in the United States is in the form of Photovoltaics (PV). PV system technologies are continuously progressing to improve PV's efficiency and operating life. PV modules are scalable in the sense that they can be used for relatively small applications, such as powering a single home, or they 
can be constructed into a large utility-scale multi-MegaWatt solar farm. However, PV has the obvious drawback of requiring plentiful sunlight in order to generate large amounts of energy. Furthermore, PV modules inherently produce DC energy which implies the need for converting the energy to AC for use by residential homes and to connect to the grid. The recent increase in the use of PV systems, specifically pertaining to microgrid, has also been observed to cause some concerns which include alterations to infrastructure and voltage regulation [7].

Another widely used form of distributed generation come from harnessing wind energy through wind turbines. Very much like solar energy, wind energy is limited in its use due to the significant amounts of wind needed to produce large amounts of energy. In addition, wind is not as widely available as the solar energy and it is more difficult to incorporate in certain areas especially when massive wind turbines are needed to generate energy. Wind energy also presents certain grid integration challenges, specifically with regards to protection, voltage control, low-voltage ride through (LVRT), and active power control [8].

A mandatory requirement to a successful microgrid operation is the inclusion of one or more types of energy storage. Storage systems help to create a cohesive form of energy generation with the aforementioned generation methods. When a new load comes online, the system frequency is susceptible to change depending on the size of the new load [6]. Some form of energy storage is needed in a microgrid with multiple sources of generation to ensure balance. A study presented in [6] states that in the case of some microgrid sources that have large time constants, anywhere from 10 to 200 seconds, storage devices are needed to provide balance to the power system in the event of a disturbance 
and/or significant load changes. In such a case, the storage devices can act as an AC voltage source. Of course all storage devices have limited energy storage capacity, and as a result it is always wise to include backup storage devices to ensure that power is always provided as needed. Examples of suitable storage devices for a microgrid are batteries, flywheel, and supercapacitors. Table 2-1 shows some of the basic characteristics of these storage devices [6].

Table 2-1: Basic Storage Device Characteristics

\begin{tabular}{|l|c|c|c|}
\hline \multicolumn{1}{|c|}{ Basic features } & Battery & Flywheel & Supercapacitor \\
\hline Continuous power $(\mathrm{W} / \mathrm{kg})$ & $50-100$ & $200-500$ & $500-2000$ \\
\hline Typical backup time & $5-30 \mathrm{~min}$ & $10-30 \mathrm{sec}$ & $10-30 \mathrm{sec}$ \\
\hline Losses at standby & Very low & Variable & High \\
\hline Environmental impact & Medium-high & Low & Low \\
\hline Maintenance & $1 /$ year & $1 / 5$ years & None \\
\hline Charging efficiency $(\%)$ & $75-95$ & 90 & $85-95$ \\
\hline Current energy price $(\$ / \mathrm{kWh})$ & $150-800$ & $3000-4000$ & $4000-5000$ \\
\hline Service life (year) & 5 & 20 & $>10$ \\
\hline
\end{tabular}

Incorporating all of the previously mentioned distributed generation components into a single microgrid system introduces new issues unique to microgrids. Inherently there is a concern of power imbalance during transition from grid-connected to islanded mode in the case that the microgrid is absorbing or supplying power to the grid before disconnection. In this case a high-speed switch with the proper sensing capabilities can be used to ensure synchronization [9]. In addition, a prevalent roadblock when designing and implementing a microgrid is the issue of system stability. 


\section{2: Complications within Microgrids}

Many factors are capable of contributing to the stability issues in a microgrid. For example, Gaur and Singh concluded in [9] that there is potential for low angular stability due to lower overall system inertia. Standard power grids rely on the inertial support from large synchronous generators where the rotating mass plays a role in maintaining grid frequency during transient periods. As has been covered previously, microgrids incorporate large amount of DG and micro-generation (MG) which are integrated through various types of power electronic converters. During disturbances the converters serve to decouple the DG and MG from the grid, therefore providing no inertial backing, as in the case with large synchronous generators. This reduced system inertia makes the grid more susceptible to voltage and frequency instabilities in the case of transients.

Another potential issue with microgrids is their lower voltage stability due to low amounts of power distribution support [9]. When the power converters for DGs and MGs are operated in the current control mode, the power supplied to the grid is limited to preset values. This results in low power sharing potential during an emergency compared to standard power plants. Traditional power plants are capable of meeting increased demands during a crisis, but MGs are generally switched to autonomous mode during contingencies in the main power grid, thus eliminating potential power sharing. Therefore, due to the current control functioning of DGs and islanding operation of MGs the total power generation within the grid is severely limited.

System instability can additionally result from low frequency power oscillations. As the maximum power point tracking (MPPT) of grid side controllers (GSC) utilized with DGs sets the DG inverter for that operating condition, the MPPT for DGs is susceptible to 
deviations [9]. The deviations for a large number of DGs in a microgrid can reinforce one another and cause oscillations in total power generation. In the event that there is a large number of DGs within the microgrid, these oscillations can cause for alarm as the transient state of the grid can be aggravated.

Currently, microgrids rely quite heavily on accurate design and are created to operate steadily. As it stands, inverters that can be found on the market only offer control at unity power factor. With the development of microgrids, future technology will likely be developed that is more flexible. This will be very useful for many low power AC microgrid where many DC to AC inverters are included. "With a large number of inverters in a microgrid, there are concerns regarding their ability to support such a small power system when it is under large stress. Such stress can be caused by voltage and frequency deviations arising inside or outside the microgrid, or from faulty situations" [9]. Furthermore, there are increasing number of power electronic converters feeding loads, such as dc/dc converters feeding a load like a battery, or dc/ac inverters driven loads which when tightly regulated are assumed to be constant power loads (CPLs). However, CPLs have negative input impedance characteristic which can lower down the system damping and make the system more prone to oscillations [10]. Furthermore, the behavior of a converter dominated load depends on the method of control used. For example, a point-ofload (POL) converter with a resistor connected at its output terminal acts like a CPL if the converter is in voltage control mode to ensure a fixed voltage across the load resistor [11]. Many of the assets found in a microgrid contain such methods of controls in the forms of voltage and frequency regulation. This is evidenced from the layout of a typical microgrid 
as shown in Figure 2-1, with the various generation units simplified as constant dc voltages sources connected to three-phase inverters.

In addition, as touched upon before, the transition from grid-connected to islanded mode introduces complications in a microgrid. Study in [9] demonstrated that the transition to islanded operation mode and the operation of the network in islanded mode require micro generation sources to particulate in active power frequency control, so that the generation can match the load. Due to the systems low inertia and slow response of some micro generation sources, storage devices are required for fast response to increased generation.

\section{3: Modeling of a Microgrid}

In order to design, analyze, and improve a microgrid system, it is necessary to generate an equivalent model of the microgrid containing the various sources of DG and MG. Numerous research on the subject of modeling of a microgrid system have been conducted. For example, storage batteries are modeled as a constant DC source coupled with a static converter to be connected to the local electrical network. Usually its active power is injected into the Microgrid proportionally to the frequency deviation. Microturbine generators, PV, battery and fuel cell generation systems have to be connected through inverters, hence a simple model is hereby adopted for the inverters, in which the switching as well as the internal loss has been ignored [12]. With a completed system model for a microgrid and its generation sources, simulations can be run to analyze how the system performs. Through this method, system stability could be analyzed for various types of islanded-mode grids with the assets running in multiple regulation modes. 
The objective of this thesis is to develop a PSCAD model for a microgrid. The microgrid contains several assets that are capable of running in voltage and/or frequency regulation modes. The model therefore will be used to perform simulations and to study which voltage and frequency regulation mode will yield the most stable operating conditions. Furthermore, since the microgrid may implement several methods in order to isolate the microgrid from the main power grid, it will therefore be useful to determine which method yields the most stable operating, especially when running in islanded mode. 


\section{Chapter 3. Design Requirements}

\section{1: System Capability}

The microgrid of interest in this paper is the [REDACTED] owned by [REDACTED]. A high level representation of the microgrid can be seen in Figure 3-1. The figure contains the relevant assets and only the relevant circuit breakers with regards to islanding.

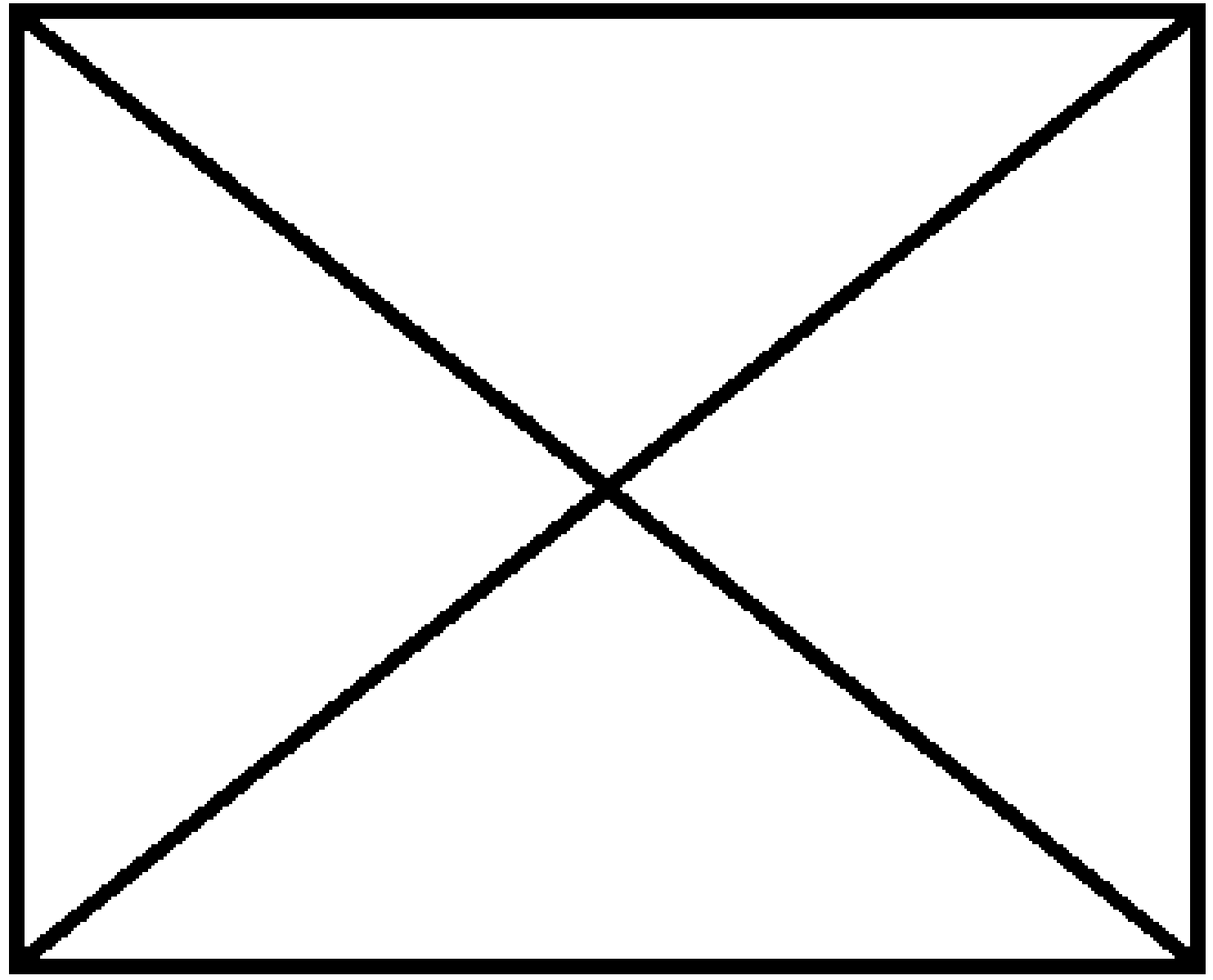

Figure 3-1: High Level Representation of the Microgrid 
As can be seen, the microgrid is fed by a single transmission line into the system. It is worth noting that this single transmission line is highly susceptible to severe weather or other damage which could lead to long outages. For this reason system stability and reliability for islanded operation of the system is particularly important. For this microgrid there are three different methods of islanding that can be utilized as needed for optimal operation in varying circumstances.

The first method of islanding is the most simple of the three, but also leaves the microgrid much more limited than the others. For this case, an island is created by opening the circuit breaker (CB 1 shown in red) upstream of the microgrid. Notice that this method does not allow for the microgrid to power all of the customers in the community. The second island is formed by opening the two low-side transformer bank circuit breakers (CB 2-1 and CB 2-2 shown in blue), thus isolating the distribution bus in the substation from the transmission bus. One of the benefits of this method over island method 1 is the ability to feed all customers as well as the inclusion of the ultracapacitor. Finally, the third method is executed by opening the circuit breaker (CB 3 shown in green) on the single transmission bus from the larger power grid. This island is the most powerful of the three, due to the inclusion of the $26 \mathrm{MW}$ PV facility. As can be seen in Figure 3-1, the PV facility is connected to the system through an express line to the transmission bus. In addition, like island 2, this islanding method allows all customers in the community to be powered. These three islands are summarized in Table 3-1. 
Table 3-1: Summary of the Islands

\begin{tabular}{|c|l|c|}
\hline Island \# & \multicolumn{1}{|c|}{ Notes } & Color of Breakers \\
& Used \\
\hline 1 & $\begin{array}{l}\text { Excludes some of the important } \\
\text { customers in the community, PV } \\
\text { generation, and the ultracapacitor }\end{array}$ & Red \\
\hline 2 & $\begin{array}{l}\text { Feeds all of the microgrid customers } \\
\text { and includes the ultracapacitor but } \\
\text { excludes the PV }\end{array}$ & Green \\
\hline 3 & $\begin{array}{l}\text { Feeds all of the microgrid customers } \\
\text { and incorporates all assets }\end{array}$ & \\
\hline
\end{tabular}

\section{2: Limitations}

Unfortunately the three islands all have stability issues that prevent the incorporation of islanded operation for the community. Island 1 actually operates well in terms of stability, but it is not an ideal choice for islanding due to the exclusion of some of the very critical customers that are fed from the distribution bus. With islands 2 and 3 several attempts were made to operate the microgrid in islanded mode but along with some successes, there were failures. Data collected during the attempts suggest that the voltage and frequency being created from the generation in the grid is unstable. This instability has led to actual loss of generation during the attempts at islanded operation.

\section{3: Requirements and Objective}

In order to successfully simulate the Microgrid an accurate PSCAD model is needed, not only the microgrid itself, but for the assets contained within the grid. Equivalent circuit models that follow the specifications of each asset, along with specific asset capabilities, create the opportunity for reliable simulation of transients in the 
microgrid. With PSCAD simulations, the system can be evaluated for various circumstances in order to run optimally without needing to do costly field testing. PSCAD is useful for revealing how to regulate the assets in order to provide stable voltage and frequency for all three islands. This thesis provides [REDACTED], not only with a PSCAD model of the microgrid to use in the future, but with information on how to optimally control the system without loss of generation. The asset information is summarized in Table 3-2, and along with Figure 3-1, fully represents the system simulated in PSCAD.

Table 3-2: Summary of the Assets

\begin{tabular}{|c|c|c|c|c|}
\hline Asset & $\begin{array}{c}\text { \# of } \\
\text { this } \\
\text { Asset }\end{array}$ & Manufacturer & $\begin{array}{c}\text { Primary } \\
\text { Use }\end{array}$ & Rating \\
\hline $\begin{array}{c}\text { Diesel } \\
\text { Generator }\end{array}$ & 2 & [REDACTED] & Generation & [REDACTED] \\
\hline $\begin{array}{c}\text { Battery System } \\
1\end{array}$ & 1 & {$[$ REDACTED] } & Storage & [REDACTED] \\
\hline $\begin{array}{c}\text { Battery System } \\
2\end{array}$ & 1 & [REDACTED] & Storage & [REDACTED] \\
\hline $\begin{array}{c}\text { Ultracapacitor } \\
\text { System }\end{array}$ & 1 & [REDACTED] & Storage & [REDACTED] \\
\hline $\begin{array}{c}\text { Photovoltaic } \\
\text { Plant }\end{array}$ & 1 & [REDACTED] & Generation & [REDACTED] \\
\hline
\end{tabular}




\section{Chapter 4. PSCAD Design}

\section{1: Diesel Generators}

\subsection{1: Generator Design}

The two diesel generators described previously are modeled in PSCAD using several models that are included in version 4.6 of PSCAD. The full diesel generator, along with a $480 / 12 \mathrm{kv}$ transformer and an equivalent source representing the power grid, are shown in Figure 4-1. The transformer is set as a Y/Y transformer, rated at 2.5MVA, so as to reflect the transformer used in the microgrid.

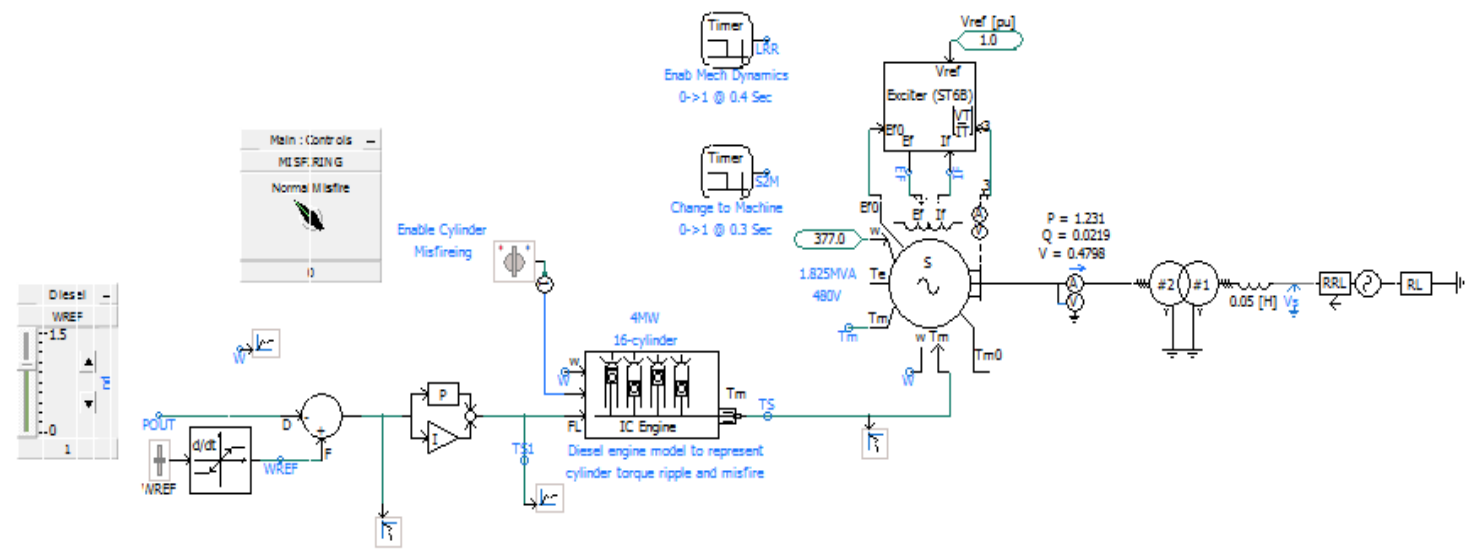

Figure 4-1: 1.825MVA Diesel Generator

The generator shown in Figure 1 is set so that it is rated for $1.825 \mathrm{MVA}$ and outputs approximately $1.22 \mathrm{MW}$. The power setting is an initial power value that is specified for grid-connected operation. The phase-to-ground voltages and the line currents output from the generator are displayed in Figure 4-2. 


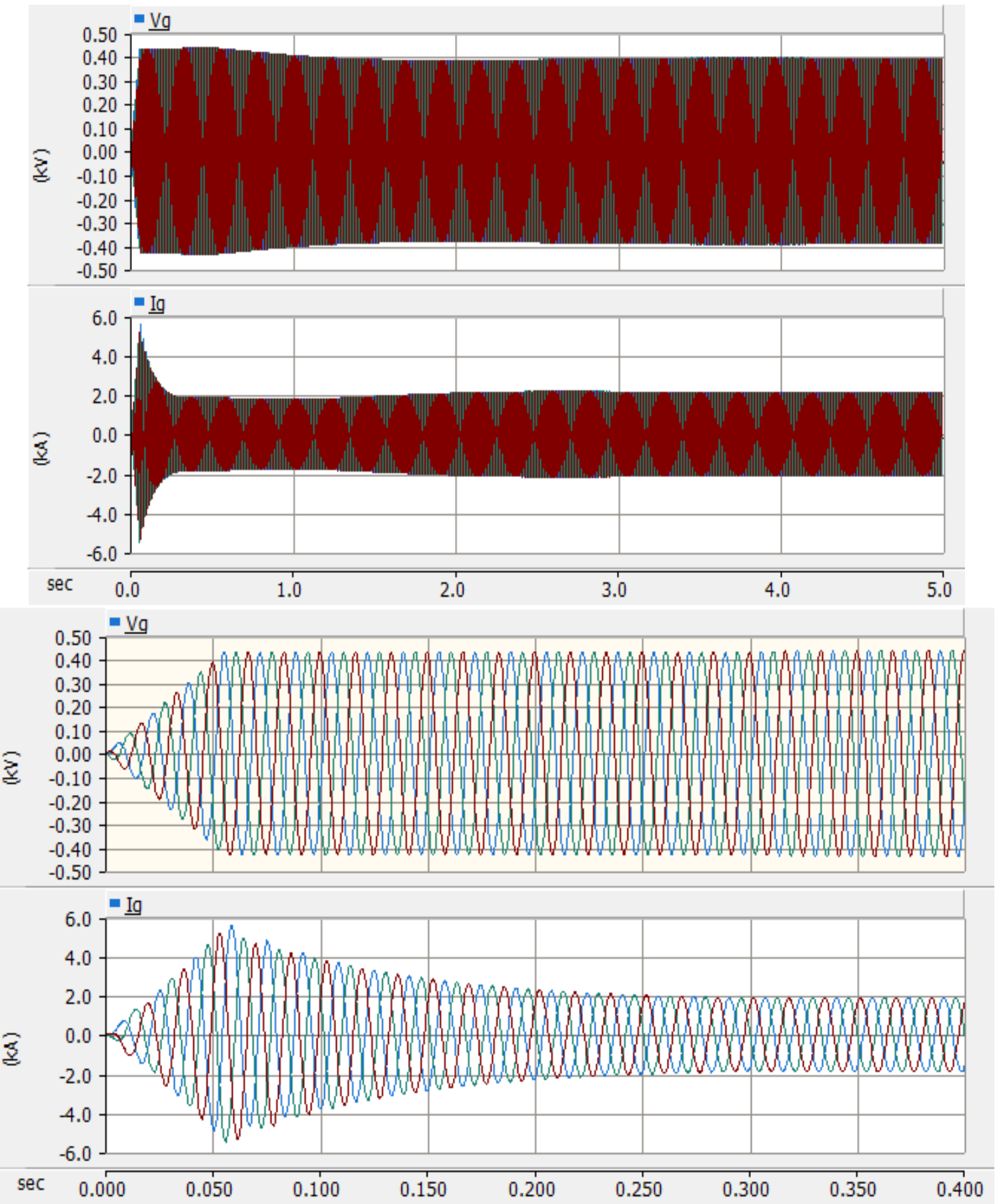

Figure 4-2: Phase-to-Ground Voltages and Line Currents Output from Diesel Generators

The waveforms in Figure 4-2 show that the generator initially has large values of current but quickly levels out at its steady-state value. A calculation could be performed to ensure that the desired power output is achieved but the result is more easily seem in Figure 4-3 
as it is measured in PSCAD. In addition Figure 4-3 displays the RMS line-to-line voltage as a measured value along with the speed of the generator in per-unit.

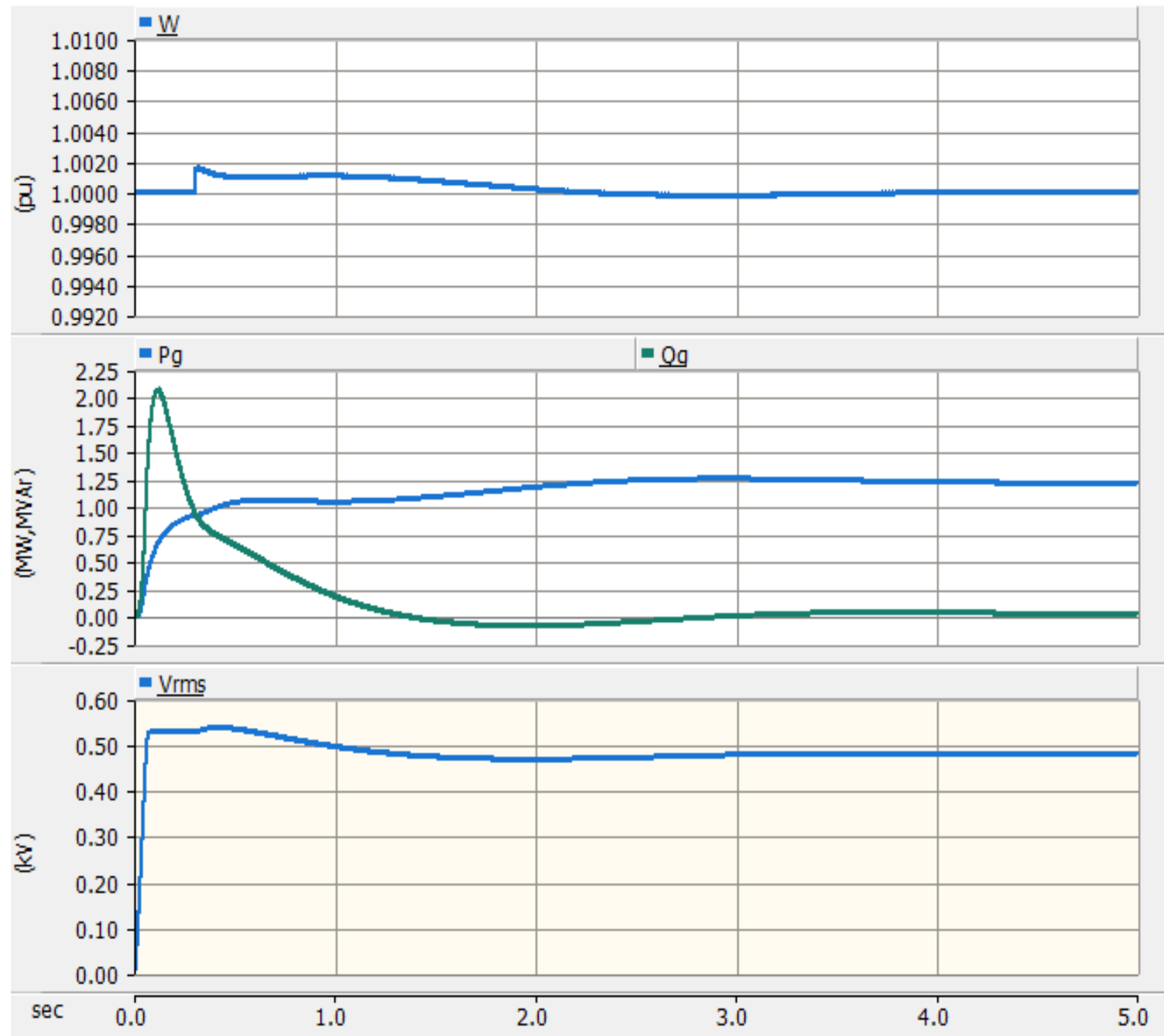

Figure 4-3: Diesel Generator Speed (W), Real Power (Pg), Reactive Power (Qg), and Line-to-Line RMS Voltage

Figure 4-3 shows that the generator maintains its speed, which is $60 \mathrm{~Hz}$, quite well for this simple, and small-scale, simulation. The machine outputs a large amount of reactive power for the first few cycles, which can be observed to reflect the large initial currents shown in Figure 4-2. This large amount of initial reactive power will be discussed further during 
discussion of the synchronous machine settings. Once the machine stabilizes it settles at the desired output values for line-to-line voltage and power output.

\subsection{2: Synchronous Machine Design and Configuration}

The primary component of the diesel generator modelled in PSCAD is the synchronous machine model that PSCAD includes (shown in Figure 4-4).

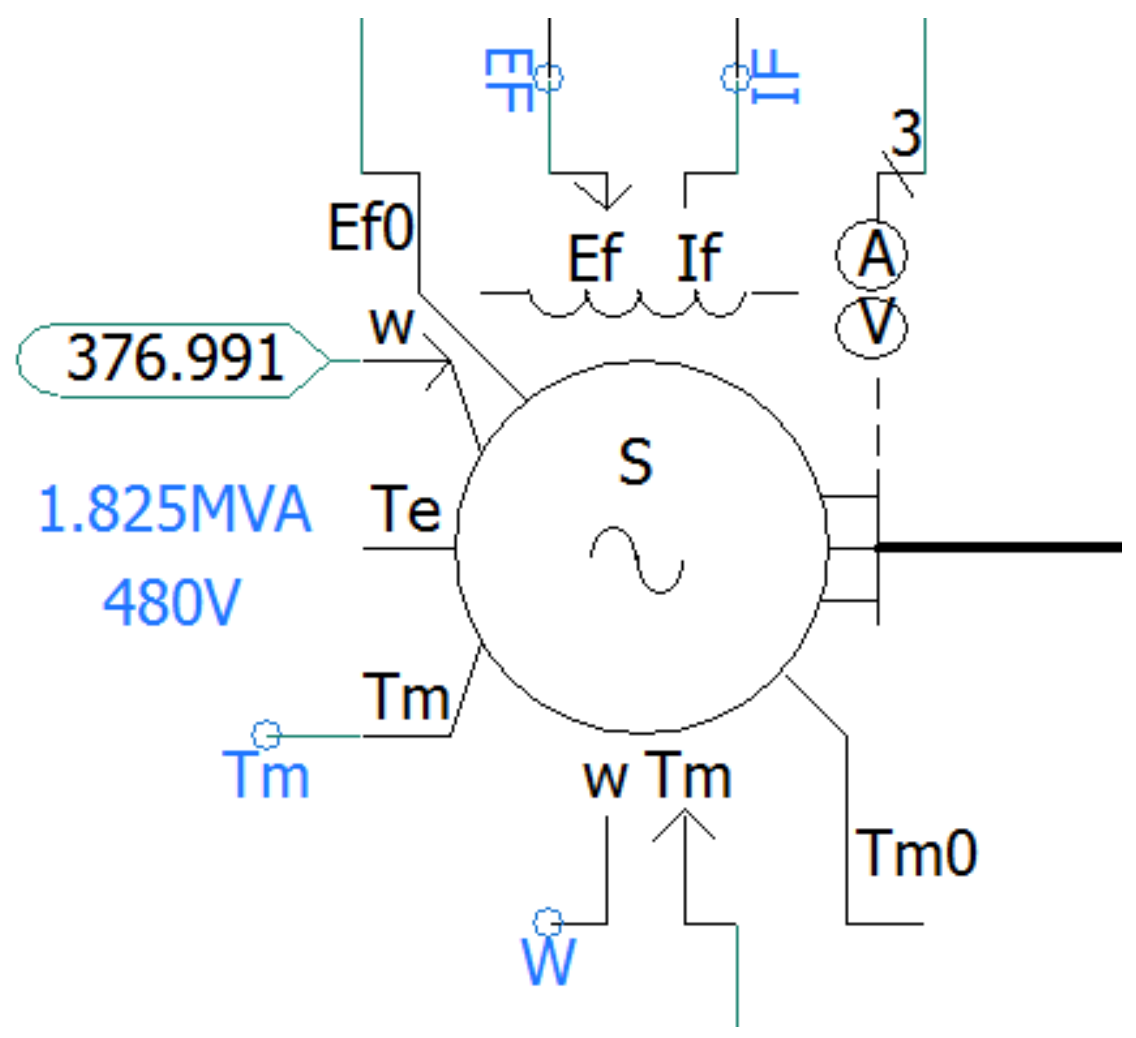

Figure 4-4: Synchronous Machine PSCAD Model

The synchronous machine model must be set to run as a generator, rather than a machine, with the desired parameters so that it produces the necessary output and behaves similarly 
to the actual generators in the microgrid. Figure 4-5 shows the basic configuration settings required for the synchronous machine.

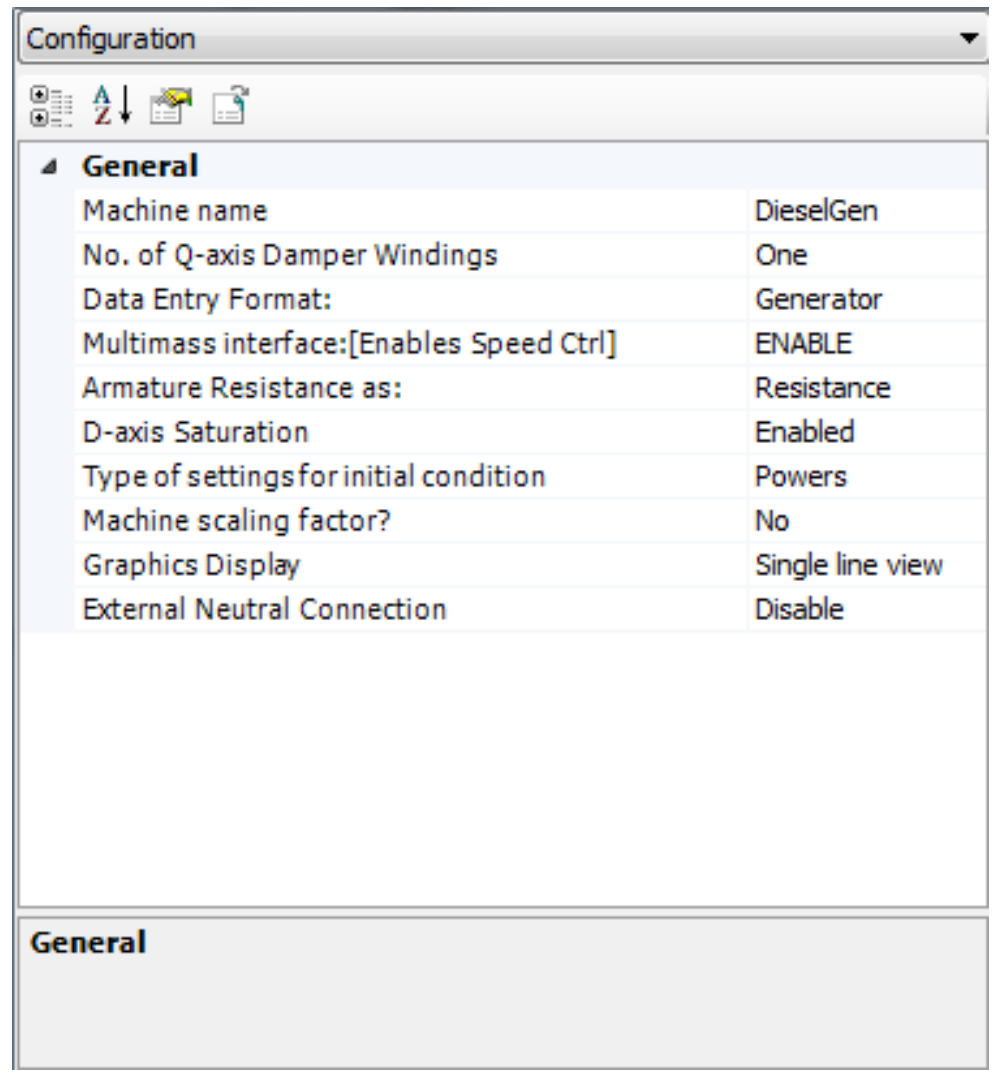

Figure 4-5: Synchronous Machine PSCAD Model Configuration Settings

The "Data Entry Format" setting must be set as generator so that the machine can produce power rather than consume it. In addition, the method of speed control utilized is critical to the way that the synchronous machine performs in simulation. The "multimass interface:[Enables Speed Ctrl]" setting can be used to allow ideal speed control for islanded mode operation. With the speed control enabled the synchronous machine attempts to maintain the rated speed. The machine dynamics are still employed in this mode and the machine speed can vary from the rated value, but any variance is as minimal as possible. 
In order to maintain the desired speed, the generator adjusts active and reactive power being supplied. The speed control set-point can be seen in Figure 4-4 at the "w" input. Observe that the speed is set to 376.991 radians, which is equivalent to $60 \mathrm{~Hz}$. Without the speed control enabled a speed governor must be utilized, this concept will be covered further in section 4.1.4. The other notable setting shown in Figure 4-5 is the "Type of settings for initial condition" setting, which allows the user to specify the power output setting. This setting gives the user some flexibility when initializing the machine, which will be explained in further detail during discussion of the initialization settings. Variable initialization data settings are then shown in Figure 4-6.

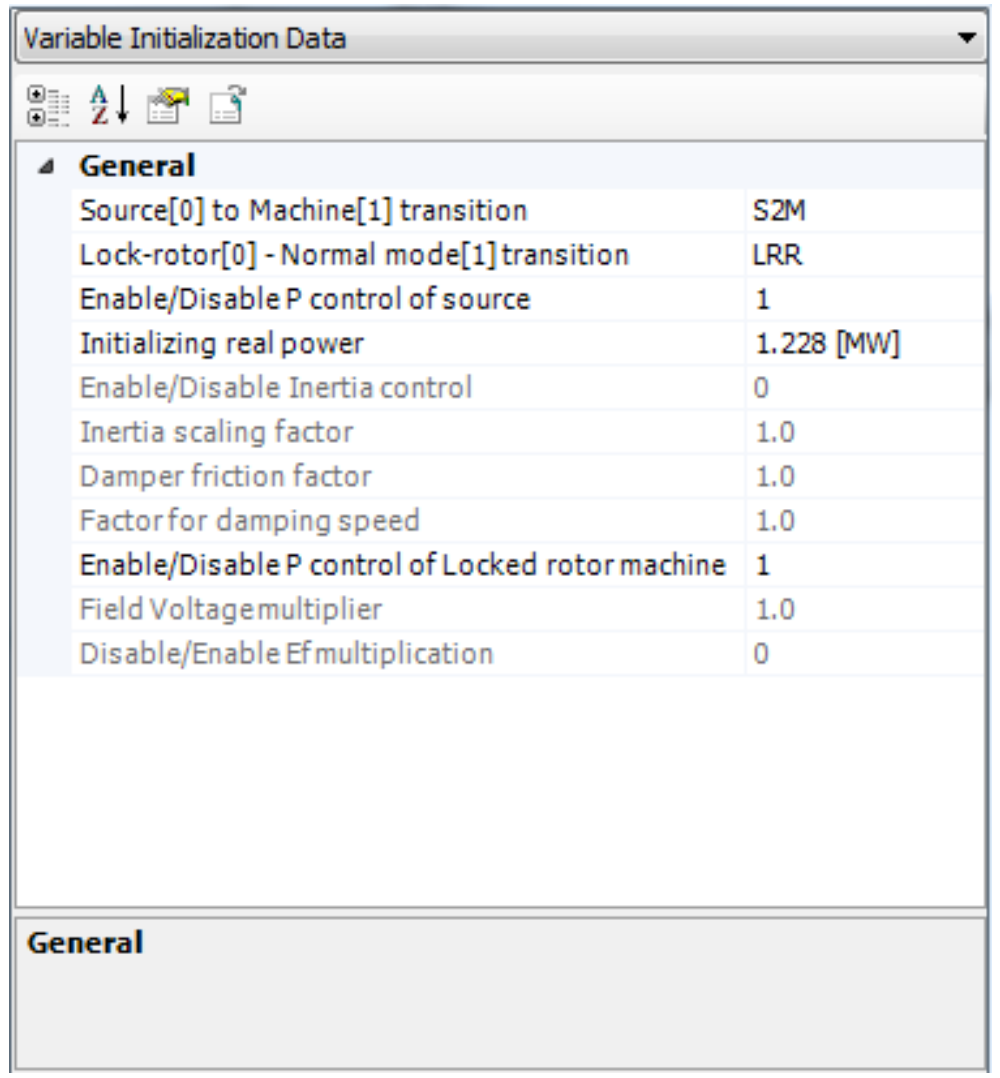

Figure 4-6: Synchronous Machine PSCAD Model Variable Initialization Settings 
Note from Figure 4-6 that some of the settings are displayed in a lighter font, these settings are disabled from user input. The "Source[0] to Machine[1] transition" setting is assigned to a signal, S2M, and is important for the initialization of the machine. The timer shown in Figure 4-4 that is connected to signal S2M transitions the machine at a set time ( 0.3 seconds in this case) from source mode to machine mode. When the machine is in source mode it behaves as a source and simply ramps up to the specified voltage at a specified rate $(0.05 \mathrm{~s})$. This is the reason for the large initial current and reactive power observed in Figure 4-3. As a source the voltage to be supplied is specified, while no other output parameters are regulated. Once the transition from source to machine is made, the machine is switched to constant speed (or locked rotor) mode. In the constant speed mode the machine equations contained within the model hold, but the mechanical dynamics are not in place during this period. At the moment locked rotor mode is entered the exciter is enabled. The rotor maintains the base angular frequency as specified. This mode of operation is only maintained briefly to help the machine to reach the desired steady state, and at the desired time of $0.4 \mathrm{~s}$ the LRR signal "unlocks" the machine. At this point the governor system, which is an internal combustion module representing a diesel engine in this case, is conditioned to give input to the machine (if speed control is disabled). At this point the machine is running freely as a generator. Additionally the "Initializing real power", the initial power set-point, is set to the desired value of $1.228 \mathrm{MW}$. It is worth noting that the machine does not need to be initialized as a source when the "Type of settings for initial condition" setting is set to "Powers", that is simply the typical method of initialization as stated in the PSCAD help menu for non-advanced PSCAD users. Instead the source to machine transition can be made to happen at 0 s and the power output and voltage at the 
machine terminals can be seen in Figure 4-7. This method of initialization should only be used with proper understanding of the system load flow.

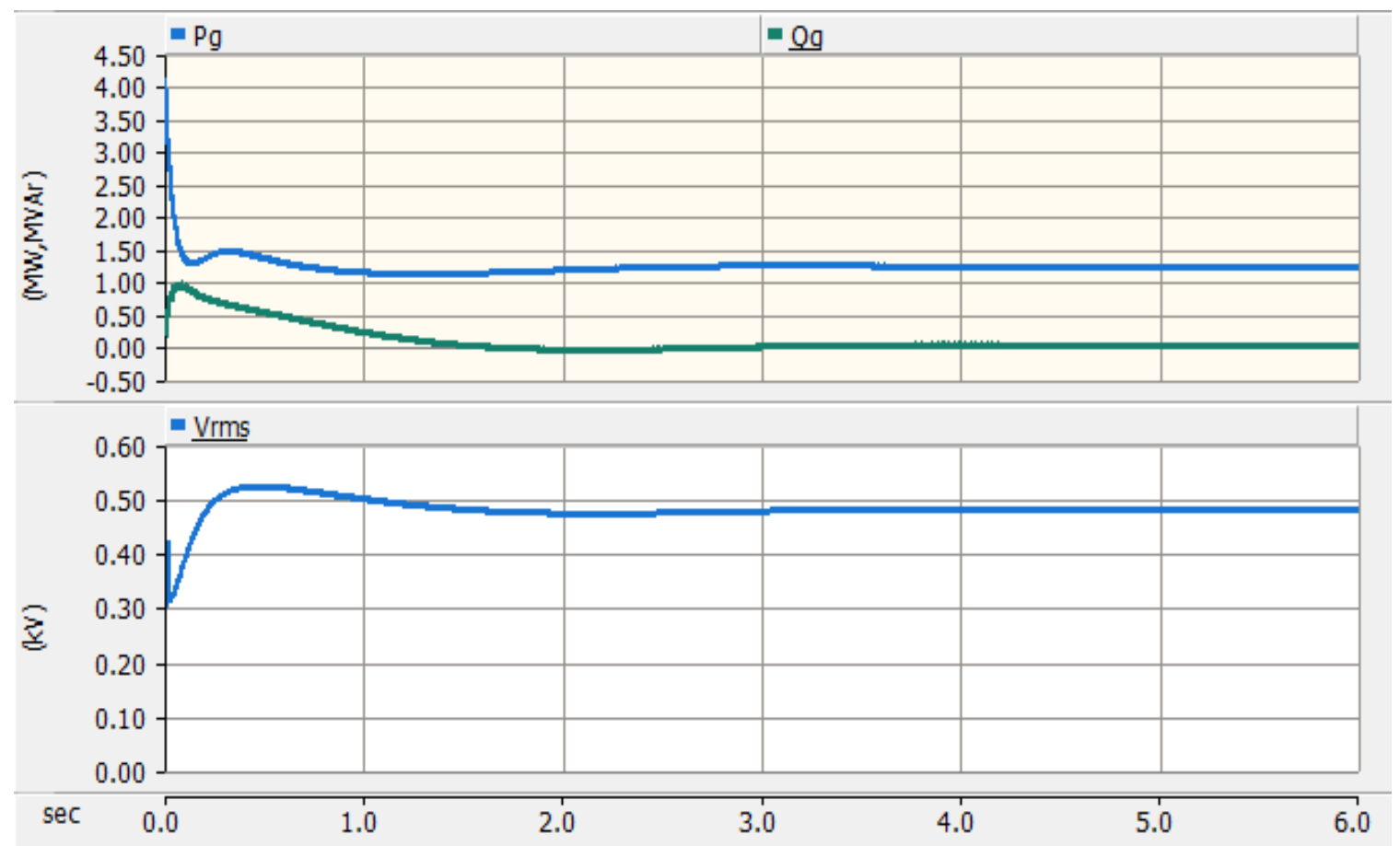

Figure 4-7: Diesel Generator Real Power (Pg), Reactive Power (Qg), and Line-to-Line RMS Voltage for Advanced Initialization

In addition the basic data settings can be seen in Figure 4-8. In these settings the machine rating is controlled through the RMS line-to-neutral voltage and the rated RMS line current. Notice that the voltage, $\mathrm{V}_{\mathrm{LN}}$, and current, $\mathrm{I}_{\mathrm{L}}$, are set according to equation 4-1 for three phase apparent power, $\mathrm{S}$, so as to allow the machine to be rated for $1.825 \mathrm{MVA}$.

$$
S=3 V_{L N} I_{L}
$$


The basic settings tab is also where the frequency is specified to be $60 \mathrm{~Hz}$ and the inertia constant is set as 3s. The other values shown in Figure 4-8 are left as default values.

\begin{tabular}{|ll|}
\hline Basic Data \\
\hline $\begin{array}{l}\text { General } \\
\text { Rated RMS Line-to-Neutral Voltage }\end{array}$ \\
$\quad$ Rated RMS Line Current & \\
Base Angular Frequency & $0.2771279546[\mathrm{kV}]$ \\
Inertia Constant & $2.1951338364[\mathrm{kA}]$ \\
Mechanical Friction and Windage & $60[\mathrm{~Hz}]$ \\
Neutral Series Resistance & $3[\mathrm{~s}]$ \\
Neutral Series Reactance & $0.0[\mathrm{pu}]$ \\
Iron Loss Resistance & $1.0 \mathrm{E} 4[\mathrm{pu}]$ \\
Number of coherent machines & $0.0[\mathrm{pu}]$ \\
& $300.0[\mathrm{pu}]$ \\
& 1.0 \\
\hline
\end{tabular}

Figure 4-8: Synchronous Machine PSCAD Model Basic Data Settings

Finally, the generator data for the synchronous machine was set according to the generator data in the Generator Data Format settings tab shown in Figure 4-9. 


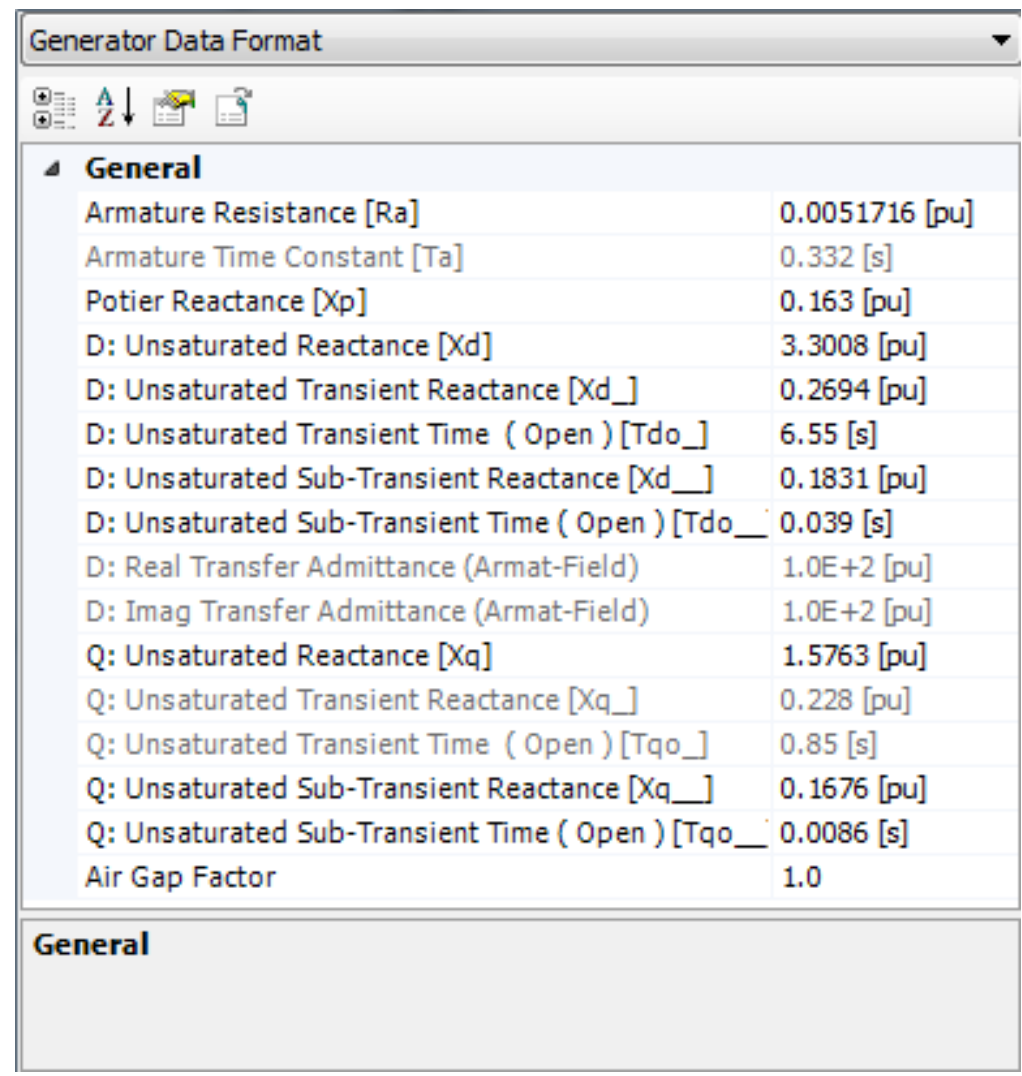

Figure 4-9: Synchronous Machine PSCAD Model Generator Data Format Settings

\subsection{3: Exciter Configuration}

The exciter used for the diesel generator model is a standard IEEE exciter ST6B model [13] and can be seen in Figure 4-10. The EF0 parameter seen in the figure defines the output field voltage to the machine during initialization as defined by the synchronous machine. The $[\mathrm{VT} / \mathrm{IT}]$ input parameter is a 3 -element array that receives data from the synchronous machine. The VT included in the input is the terminal voltage and IT, which is a complex value, is the synchronous machine terminal current. Vref is a user defined value that can be set to a number of values, potentially by using a slider, although in this case it is simply set as the ideal value of 1.0. The final input parameter, If, defines the field 
current which is generated from the synchronous machine model. The Ef output is the field voltage as computed by the exciter and is applied directly to the synchronous machine.

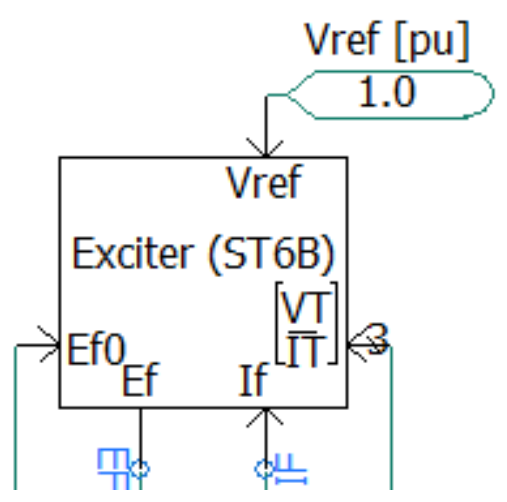

Figure 4-10: Exciter (ST6B) for the PSCAD Diesel Generator Model 


\subsection{4: IC Diesel Engine Model Design}

The torque applied to the synchronous machine is decided by the internal combustion diesel engine model that can be seen in Figure 4-11.

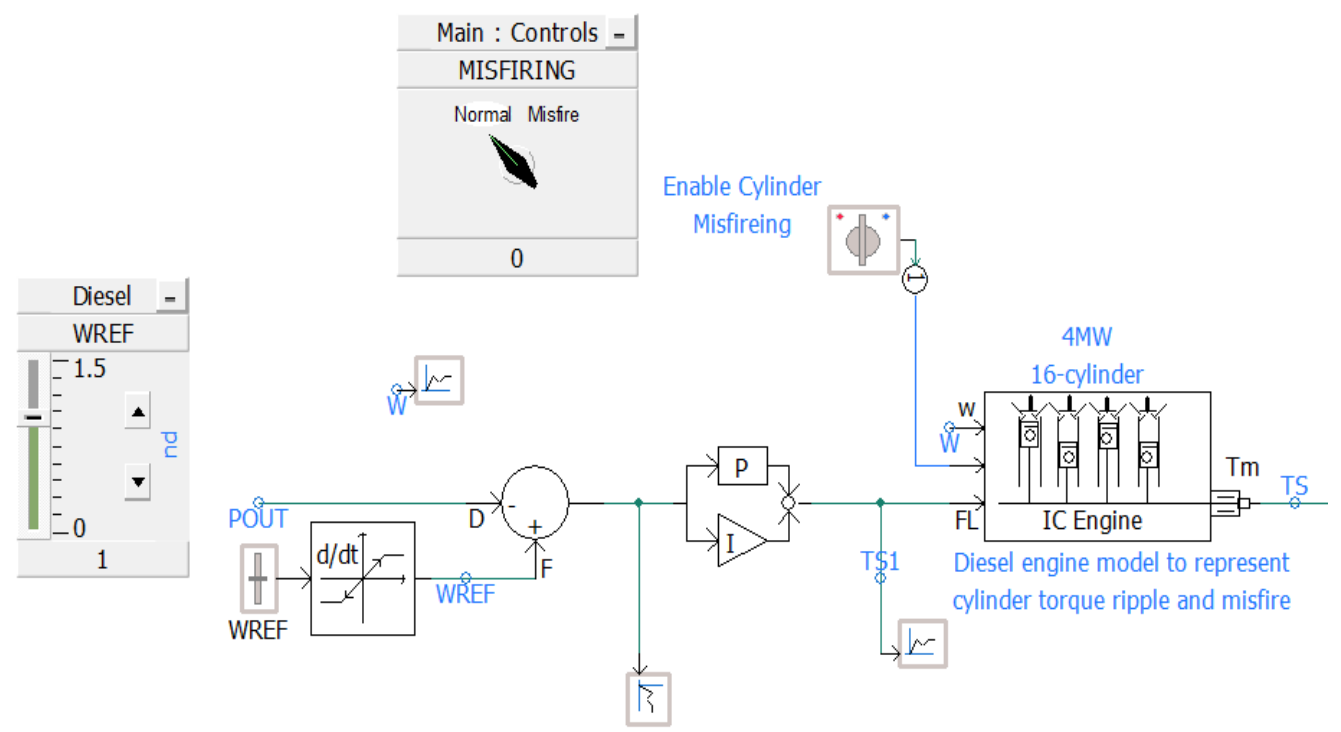

Figure 4-11: Diesel Internal Combustion Engine Model

The input shaft mechanical speed, $w$, is dictated by the speed of the synchronous machine so that the two machines are ensured to run at the same speed. The engine fuel intake, FL, is determined by a comparison of output power of the synchronous machine in per unit and a per-unitized reference speed. The fuel intake to the combustion engine can be controlled in several ways. Figure 4-11 shows the reference speed being compared to the output power of the synchronous machine through a summing/difference junction, which is then put through a simple PI controller before being input to the engine as the fuel intake. Note that a rate limiter is placed on the reference speed to account for sudden changes made by the 
user on the slider control. This method of control for the generator allows the user to specify the desired output power. Instead, in islanded mode operation, the fuel intake can be controlled by modulating the speed of the machine, rather than the power. With proper control, this method mimics the function achieved by enabling the speed control. The final input to the engine is the control for engine misfiring, MF, which is not particularly of interest for this study, but is in place regardless. The output of the engine is the mechanical torque, in per-unit, that is directly input to the synchronous machine and is proportionally scaled according to the fuel intake. The engine is configured according to the settings shown in Figure 4-12. The engine is rated at 4MW to coincide with settings received by [REDACTED].

\begin{tabular}{|ll|}
\hline Configuration & \\
\hline $\begin{array}{l}\text { General } \\
\text { Engine Rating } \\
\text { Machine Rating } \\
\text { Engine Rated Speed } \\
\text { Gear Box Efficiency } \\
\text { Gear Ratio }\end{array}$ & $4[\mathrm{MW}]$ \\
& $40[\mathrm{MVA}]$ \\
& $0.76[\mathrm{pu}]$ \\
& 1 \\
\hline
\end{tabular}

Figure 4-12: Diesel Internal Combustion Engine Model Configuration Settings 


\section{2: Photovoltaic (PV) Array Design}

\subsection{1: Grid-Tied Photovoltaic Array}

The photovoltaic array created for the microgrid is derived from similar microgrid application examples generated by Manitoba HVDC Research Centre [14] and then redesigned to perform as needed for the microgrid. The complete PV array block diagram shown in Figure 4-13 is created using the PV array model contained within PSCAD 4.6 and connected to the main grid through a boost DC/DC converter, a Voltage Sourced Converter (VSC), and a $34.5 \mathrm{kV} / 34.5 \mathrm{kV} / 69 \mathrm{kV}$ three winding transformer. The transformer is set so that it reflects the transformer used in the microgrid.

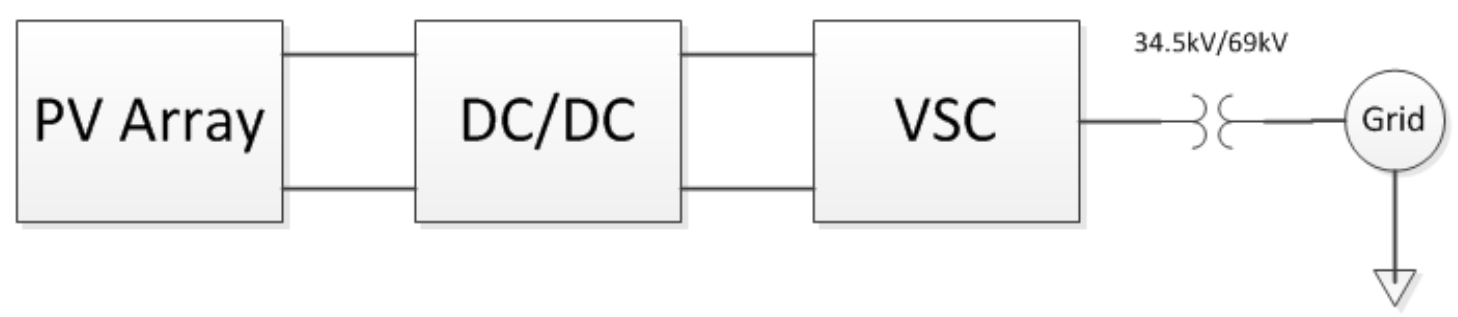

Figure 4-13: PV Array with DC/DC Converter and VSC

The PV array is designed so that it can output up to $26 \mathrm{MW}$ of power, depending on temperature and solar irradiance, to the grid at 34.5kV RMS line-to-line. Figure 4-14 shows that the PV array, connected through the power electronics, can output the necessary $26 \mathrm{MW}$ and nearly no reactive power at approximately $34.5 \mathrm{kV}$ line-to-line as needed for the PSCAD model. The ripple shown on all three graphs is a result of the messy output of the Boost converter, which will be seen in discussion of the Boost converter. 

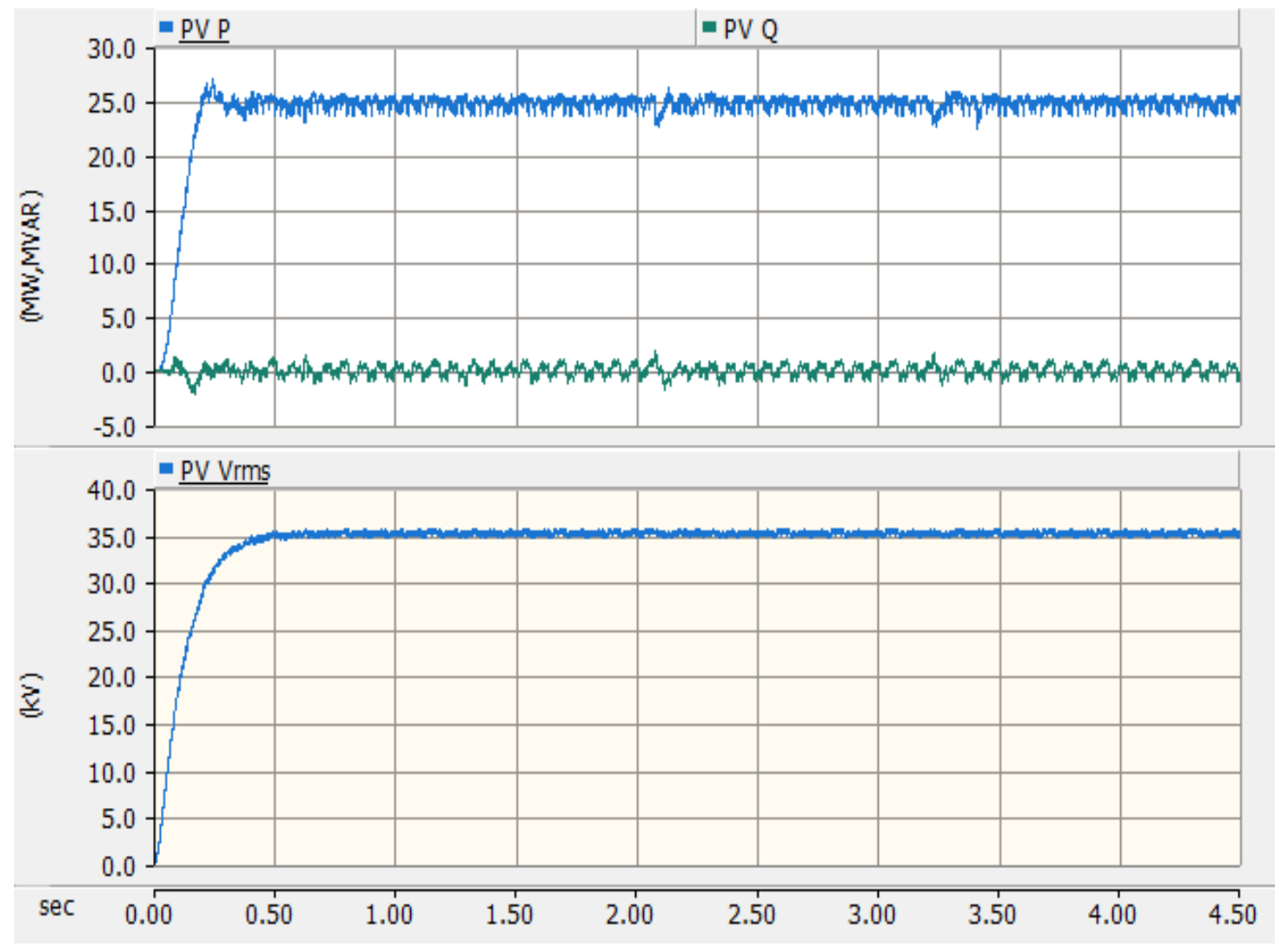

Figure 4-14: PV Array Power Output

\subsection{2: PV Array}

The PV array model included with PSCAD is shown in Figure 4-15 and includes a high and a low output for DC voltage across them, along with inputs for temperature of the cells and the irradiation provided. The temperature is input as degrees Celsius and the Irradiation is Watts per square meter. 

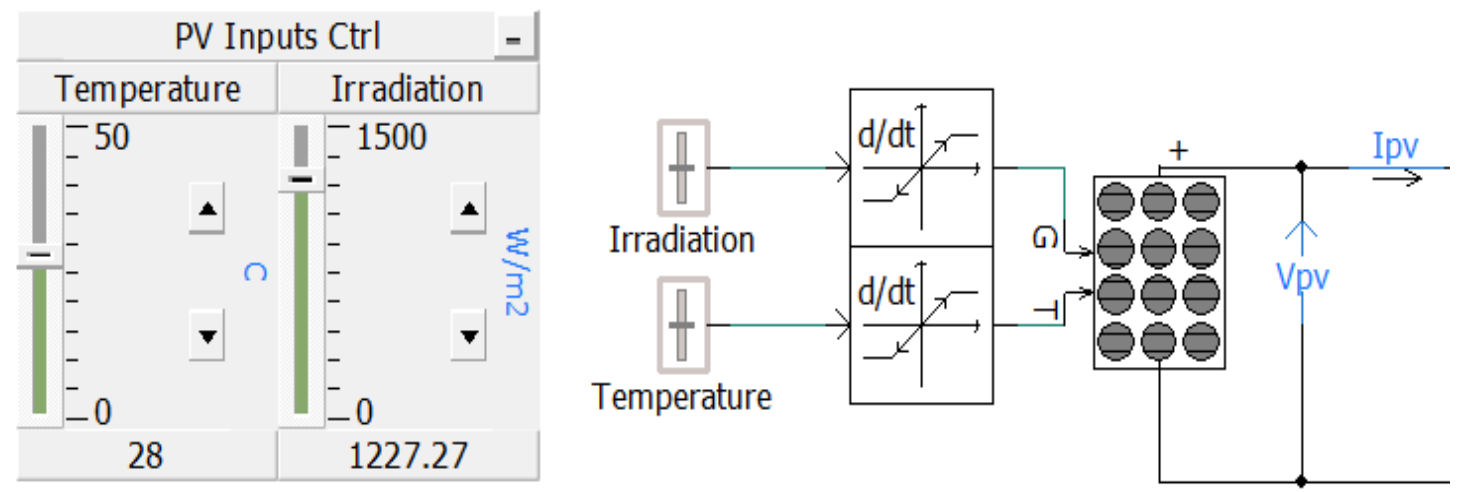

Figure 4-15: PV Array with Variable Inputs

The array is capable of outputting the desired power through the dimensions of the PV modules as well as the entire array as shown in Figure 4-16. The number of cells and modules connected in series was determined using a cell open circuit voltage of $0.7 \mathrm{~V}$. Using this the voltage of the array was set for a needed $30 \mathrm{kV}$ by designing the array as shown in Figure 4-16. Similarly the power output was set using the short-circuit current per cell of $2.5 \mathrm{~A}$ as set by the PV array model. 


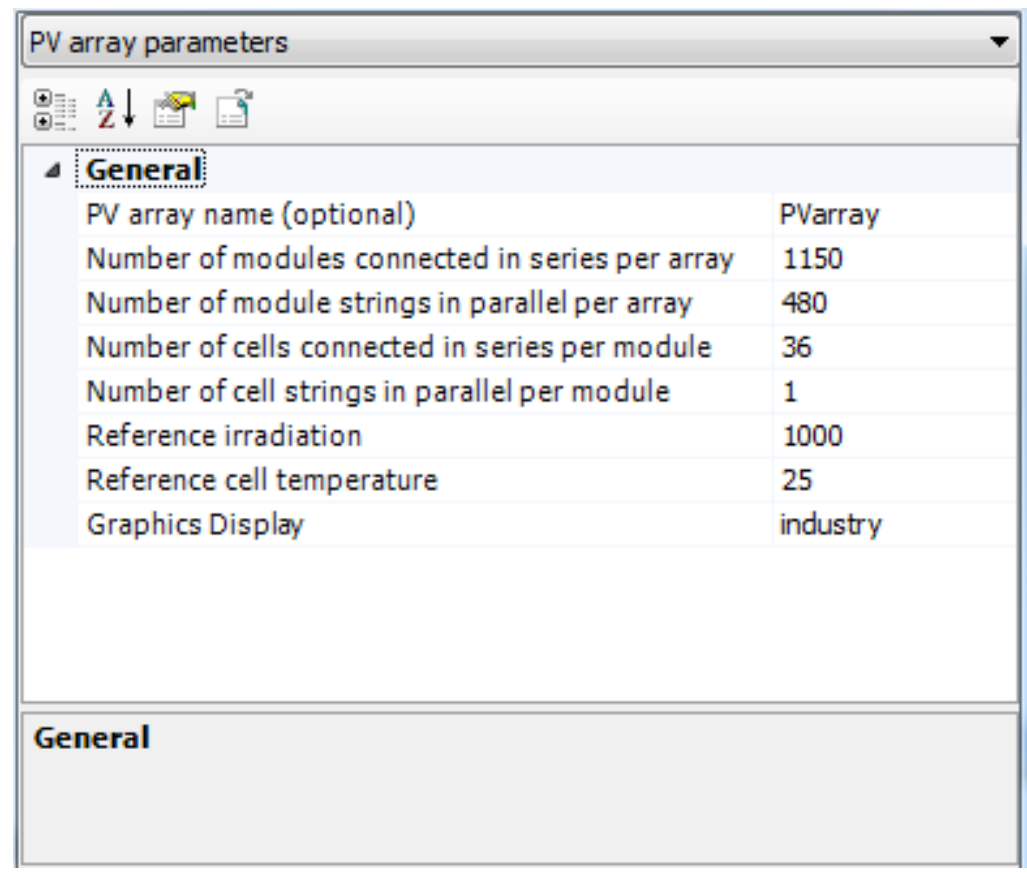

Figure 4-16: PV Array Parameters

The power output by the PV array is designed so that up to $26 \mathrm{MW}$ could be delivered to the grid. With this requirement in mind the PV array outputs significantly more power than is needed in order to compensate for losses in the DC/DC converter. The PV array power output can be observed in Figure 4-17. After less than 0.1s the PV array reaches a steady power output level, assuming there are no sudden changes in irradiation. 


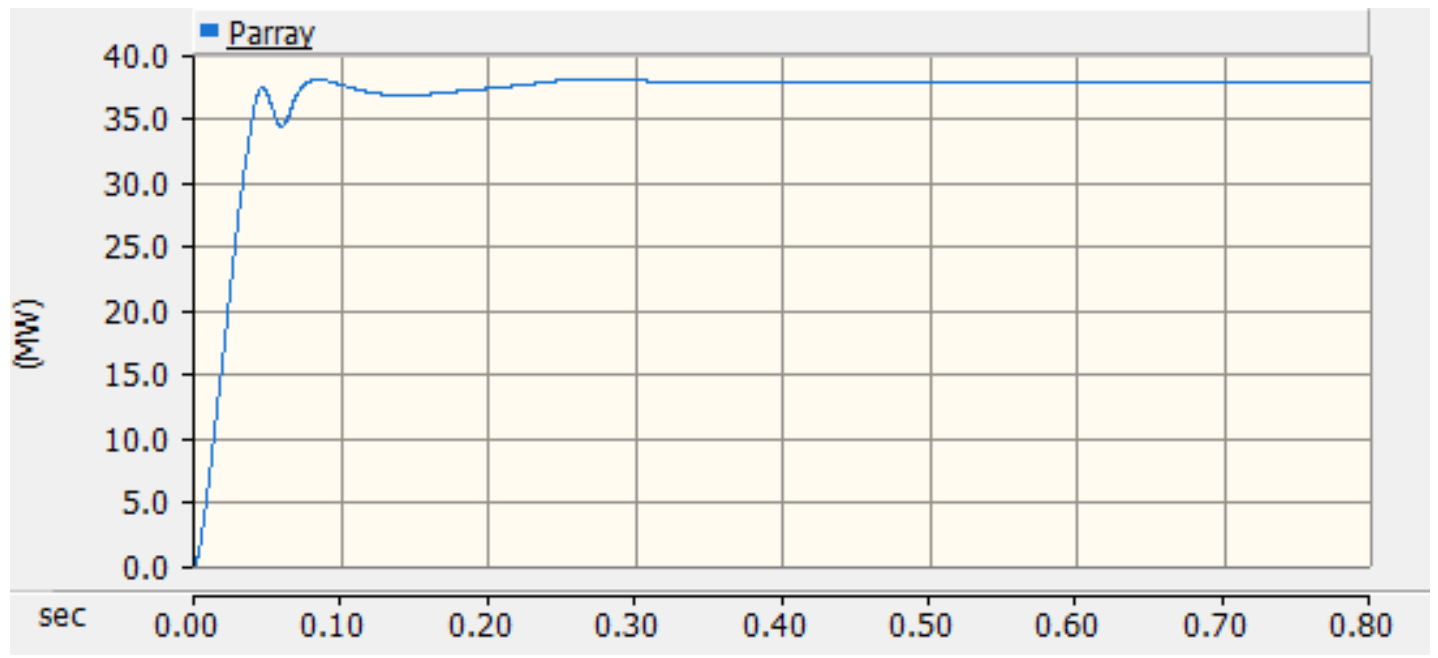

Figure 0-1 4-17: PV Array Power Output at Terminals

Figure 4-17: PV Array Power Output at Terminals

In addition the Boost converter is partially controlled through the use of MPPT tracking as shown in Figure 4-18. The MPPT model is set using the open circuit voltage and short circuit current of the PV array. The voltage and current are input and sampling so that a reference power value can be determined and sent to the Boost converter to adjust the duty cycle accordingly. The deblock signal (DBlkPV) is simply used to enable the DC/DC converter and a similar deblock signal is used for each power electronic component in the entire microgrid model.

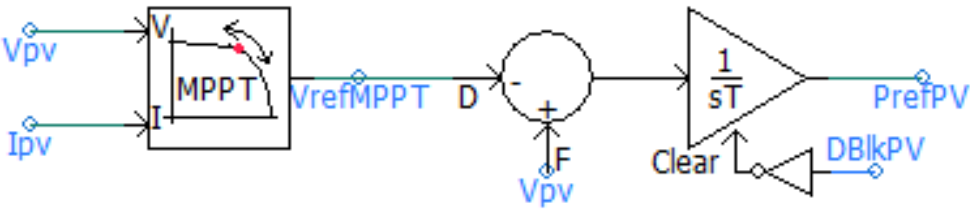

Figure 4-18: PV Array MPPT 


\subsection{3: DC/DC Boost Converter}

The DC/DC Boost converter in Figure 4-19 works as expected, boosting the voltage and lowering the output current to a level that maintains the input power as efficiently as possible.

\section{Boost converter}

(DC-DC)

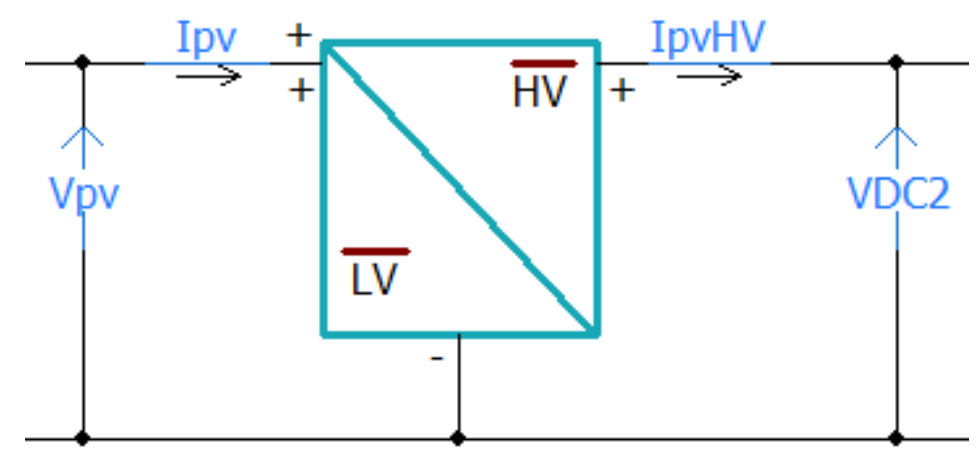

Figure 0-2 4-19: DC/DC Boost Converter for PV Array

Figure 4-19: DC/DC Boost Converter for PV Array

The Boost converter output power shown in Figure 4-20 reflects the input power, of course with noisy output as is expected of a Boost converter [15] and with significant power losses. If the DC/DC converter was designed for a different purpose the efficiency might serve as a problem, but as long as the grid sees the desired power level from the PV Array it is not a critical issue for this study. 


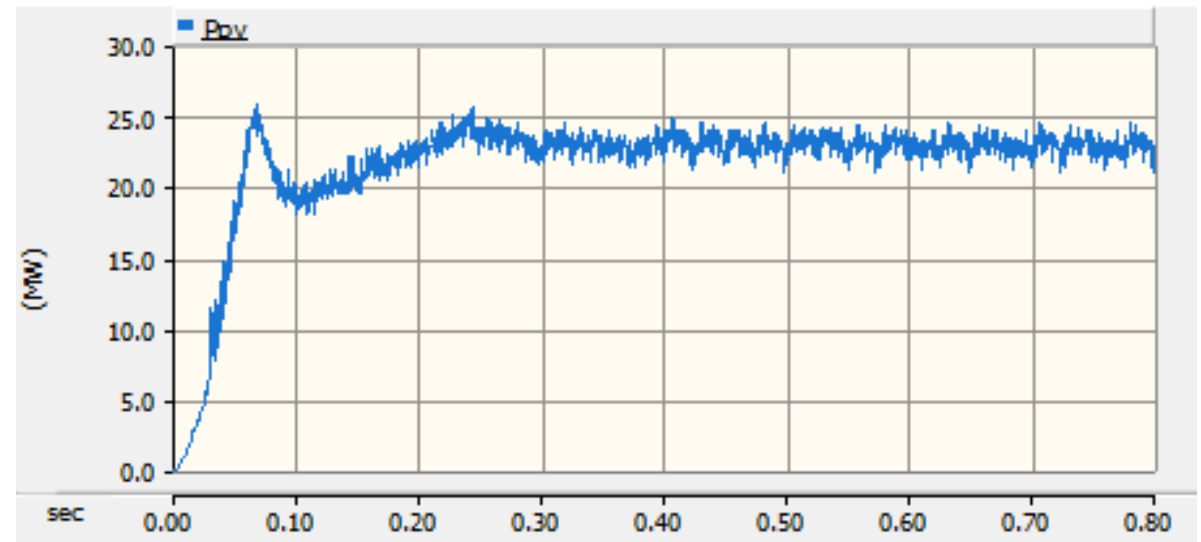

Figure 4-20: DC/DC Boost Converter Power Output

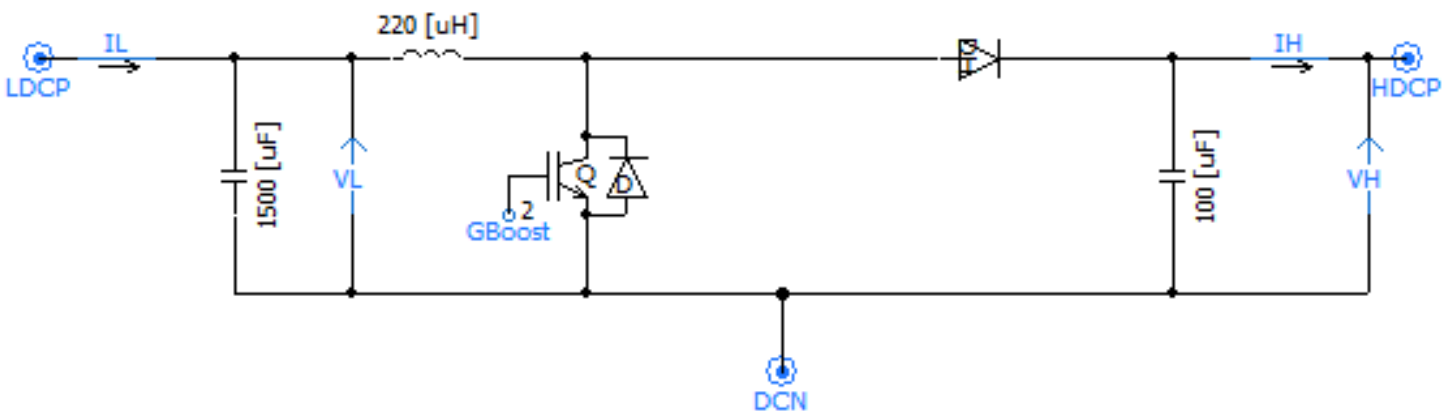

Figure 4-21: DC/DC Boost Converter

When the internal components of the DC/DC converter module are examined the converter shown in Figure 4-21 can be seen. The output of the converter is the high voltage side which connects at the electrical connection node, HDCP. It follows that the input is the low voltage side with the input electrical connection, LDCP. The values used for the components were designed using the following equations from [15]. Table 4-1 is meant as a reference for the Boost converter equations. 


$$
\begin{gathered}
L=\frac{D(1-D)^{2} V_{o}}{2 f I_{\text {omin }}} \\
C_{o}=\frac{D}{\frac{\Delta V_{o}}{V_{0}} f R_{\text {omin }}} \\
C_{\text {in }}=\frac{D^{2}}{\frac{\Delta V_{\text {in }}}{V_{\text {in }}} f^{2} L}
\end{gathered}
$$

Table 4-1: Variables Used in Boost Converter Calculations

\begin{tabular}{|c|c|}
\hline Variable & Variable Description \\
\hline $\mathrm{D}$ & Duty Cycle \\
\hline$\Delta \mathrm{V}_{\mathrm{o}}$ & Output Voltage Ripple \\
\hline $\mathrm{V}_{\mathrm{o}}$ & Average Output Voltage \\
\hline $\mathrm{I}_{\text {omin }}$ & Minimum Average Output Current \\
\hline $\mathrm{f}$ & Switching Frequency \\
\hline $\mathrm{R}_{\text {omin }}$ & Minimum Output Resistance \\
\hline$\Delta \mathrm{V}_{\text {in }}$ & Input Voltage Ripple \\
\hline $\mathrm{V}_{\text {in }}$ & Average Input Voltage \\
\hline $\mathrm{L}_{\mathrm{L}}$ & Critical Inductance \\
\hline $\mathrm{C}_{\text {out }}$ & Critical Output Capacitance \\
\hline $\mathrm{C}_{\text {in }}$ & Critical Input Capacitance \\
\hline
\end{tabular}

The converter controls are shown in Figure 4-22 and it can be observed that the controls are rather simple. 


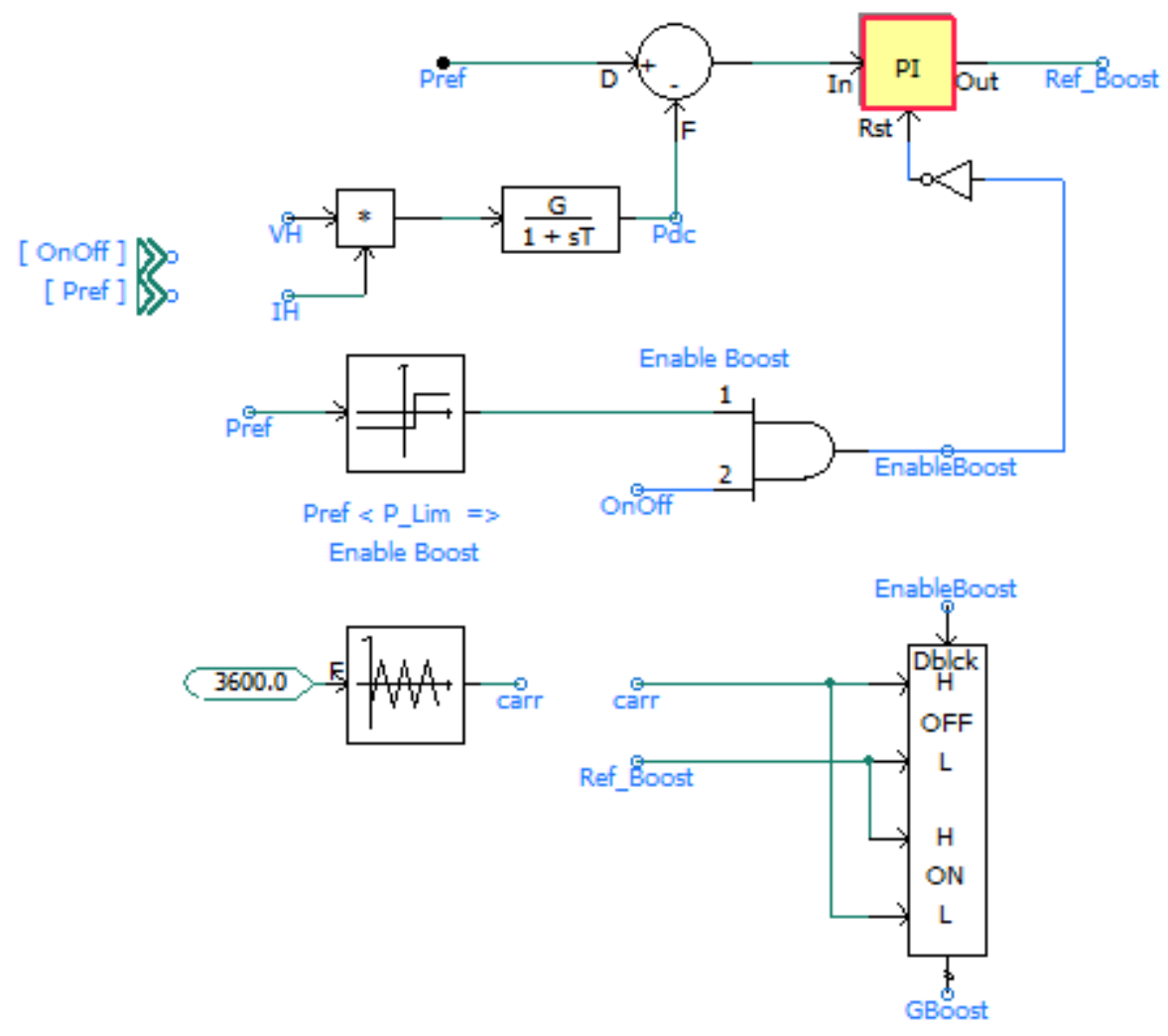

Figure 4-22: DC/DC Boost Converter Controls

The imported signals, OnOff and Pref, shown in the figure are valued by the deblock signal for the converter and the reference power output from the MPPT for the solar array. The duty cycle is controlled by comparing the output power of the converter to Pref. After being sent through a summing/difference junction the difference of Pref to the converter output power is sent through a PI controller with freeze capability. This freeze capability allows for the converter to be disabled if the converter deblock signal is low or if the reference power is greater than a maximum power value set by the user. The output of the PI controller provides the duty cycle, Ref_Boost. The duty cycle, along with a $3600 \mathrm{~Hz}$ carrier signal are then used to generate the firing pulse for the transistor in the Boost converter. 


\subsection{4: VSC (Voltage Source Converter)}

The VSC module (Figure 4-23) connects to the power grid through a three winding transformer with the AC output shown in Figure 4-14. The VSC used is created to match VSC modules found in many PSCAD examples [14] with slight variation in the control and filtering.

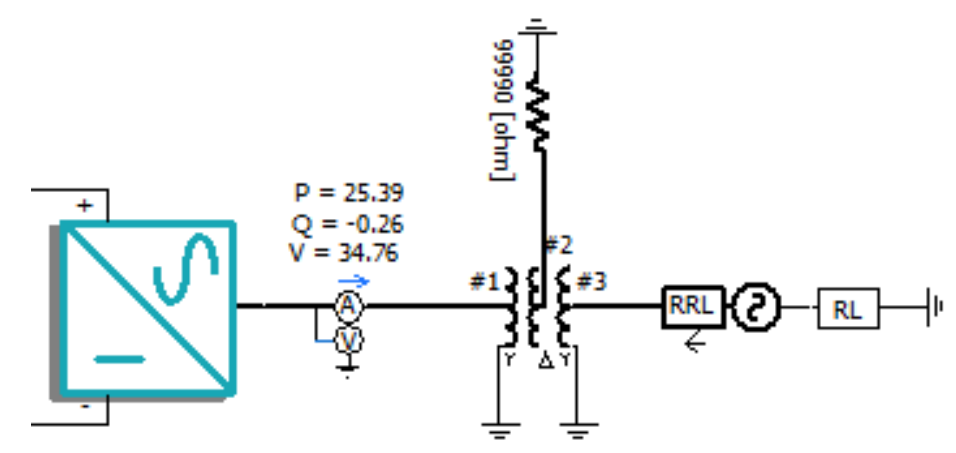

Figure 4-23: VSC Connected to Equivalent Power Grid

The converter is realized using six IGBTs as is shown in Figure 4-24 along with simple filtering on both the $\mathrm{DC}$ and $\mathrm{AC}$ sides of the converter. The high rail connects through the DC_P electrical connection and the DC_M connects to the low rail on the DC side. The uvw electrical connection is the AC output of the converter. The firing pulses of the IGBTs are determined within the Converter controls module shown. The control module takes in values measured from both the $\mathrm{AC}$ and $\mathrm{DC}$ sides of the converter as inputs. 


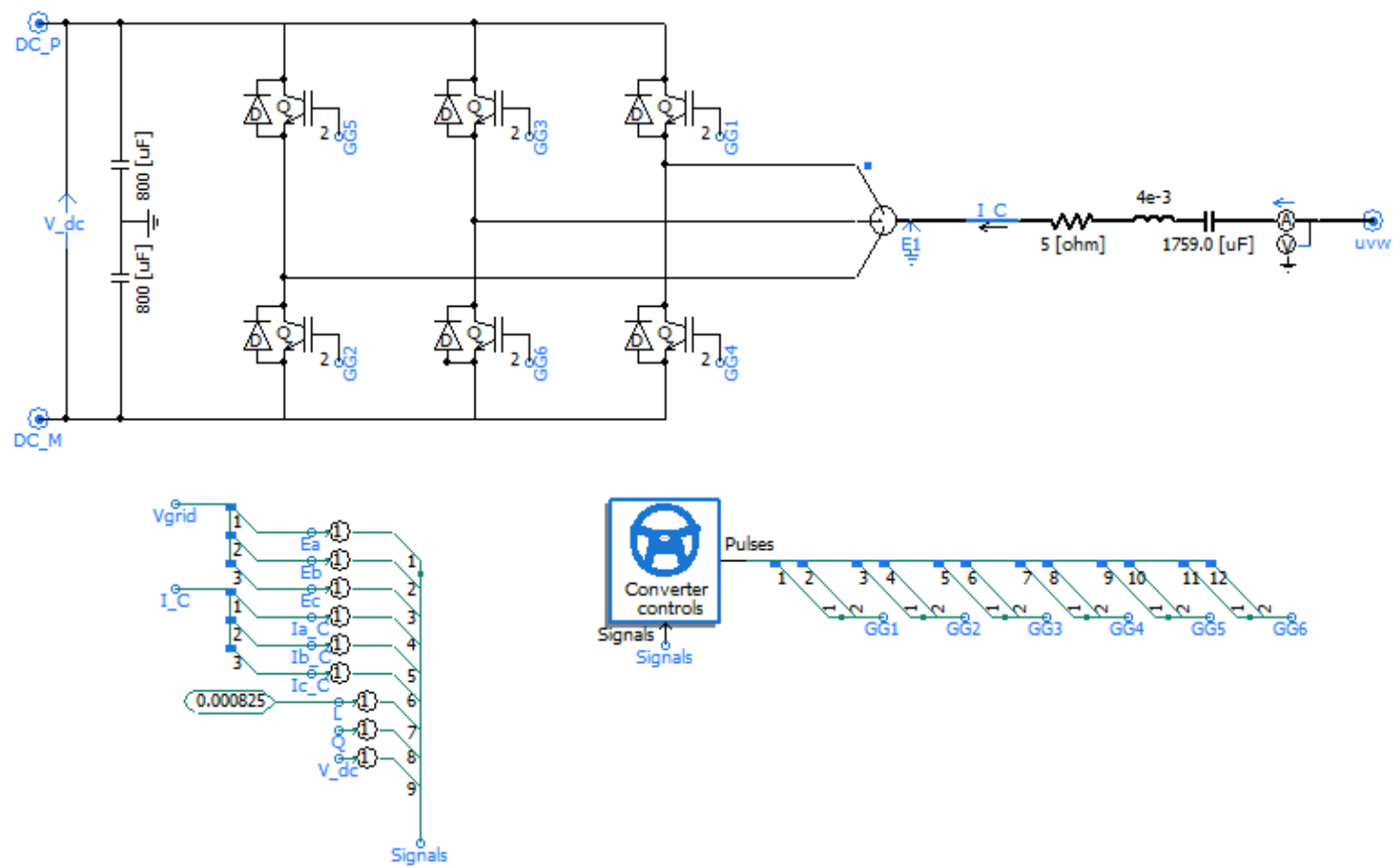

Figure 4-24: Voltage Sourced Converter

Within the rectifier controls (Figure 4-25) module a reference angle is calculated using a PLL model, built-in to PSCAD 4.6, with the phase voltages from the AC side of the VSC as inputs. Using this reference angle $\mathrm{ABC}$ to $\mathrm{DQ} 0$ models are used to acquire d-axis and q-axis voltage and currents.

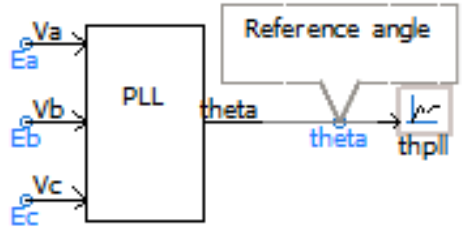

$$
\text { (iq }
$$

Figure 4-25: D-Axis and Q-Axis Voltage and Currents 
Using the $\mathrm{d}$ and q-axis voltage and current waveforms, along with user input parameters for the Edc_ref and Qref, the DC voltage, reactive power, and d and q-axis currents are regulated. The Edc_ref and Qref are input to the parameter field of the VSC and imported to the controls module. First the DC voltage and the reactive power, Q are regulated using familiar methods. The same summing/difference junction along with PI controllers are utilized. As was done with the DC/DC converter, a deblock signal is used to turn on and off the converter. The outputs provide the reference signals for the regulation of d-axis and q-axis currents, idref and iqref. The final waveforms for d-axis and q-axis voltage, vd1 and vq1, are acquired using a similar method. This process as implemented in PSCAD is shown in Figure 4-26.
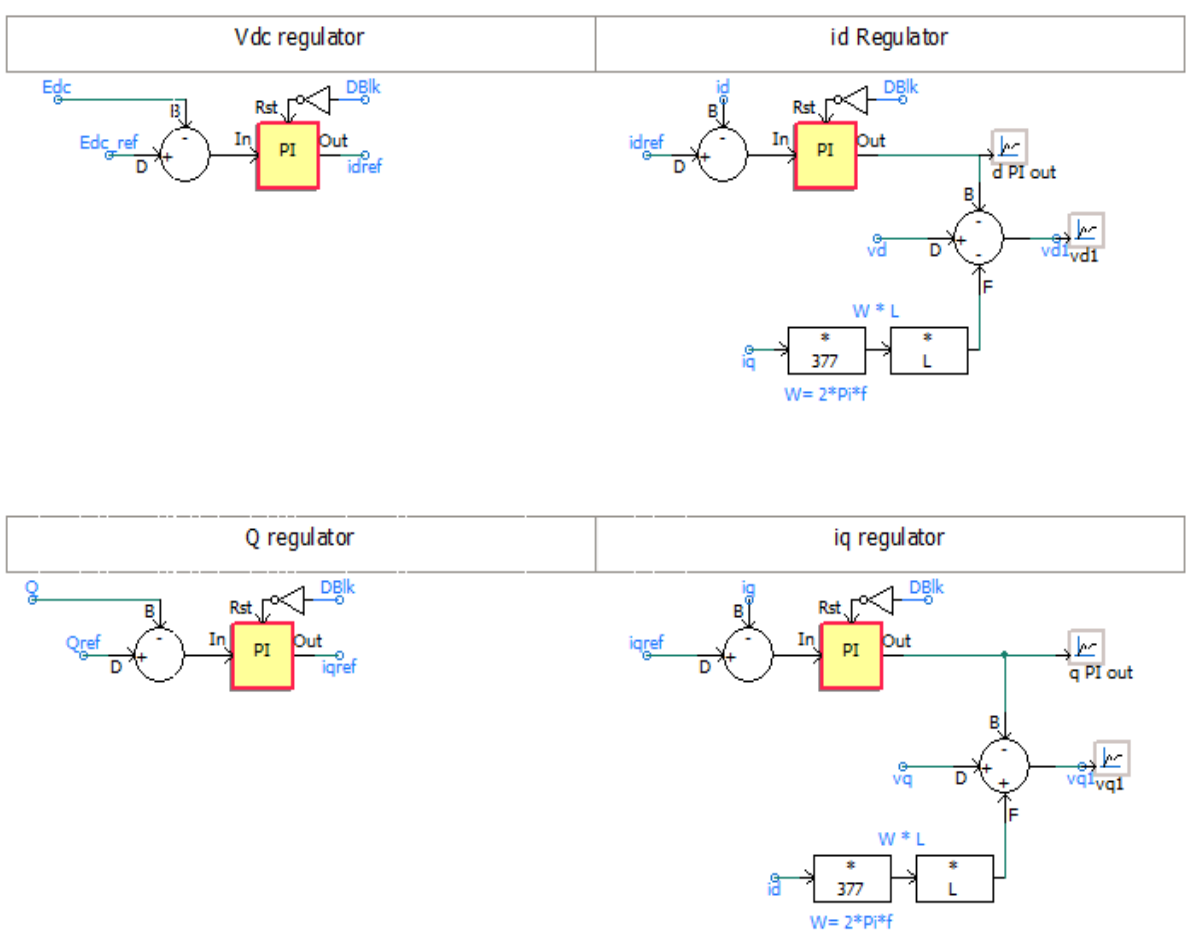

Figure 4-26: Regulation of DC Voltage, Reactive Power, and D/Q-Axis Parameters 
The resulting waveforms are then sent through the reverse process and transformed through a DQ0 to ABC model to acquire reference waveforms, Ref_a, Ref_b, and Ref_c as shown in Figure 4-27. Before the reference waveforms are acquired, however the d/q-axis voltage waveforms are transformed into polar coordinated where the magnitude is scaled according to the dc voltage and the resulting magnitude and phase are transformed back into rectangular form.

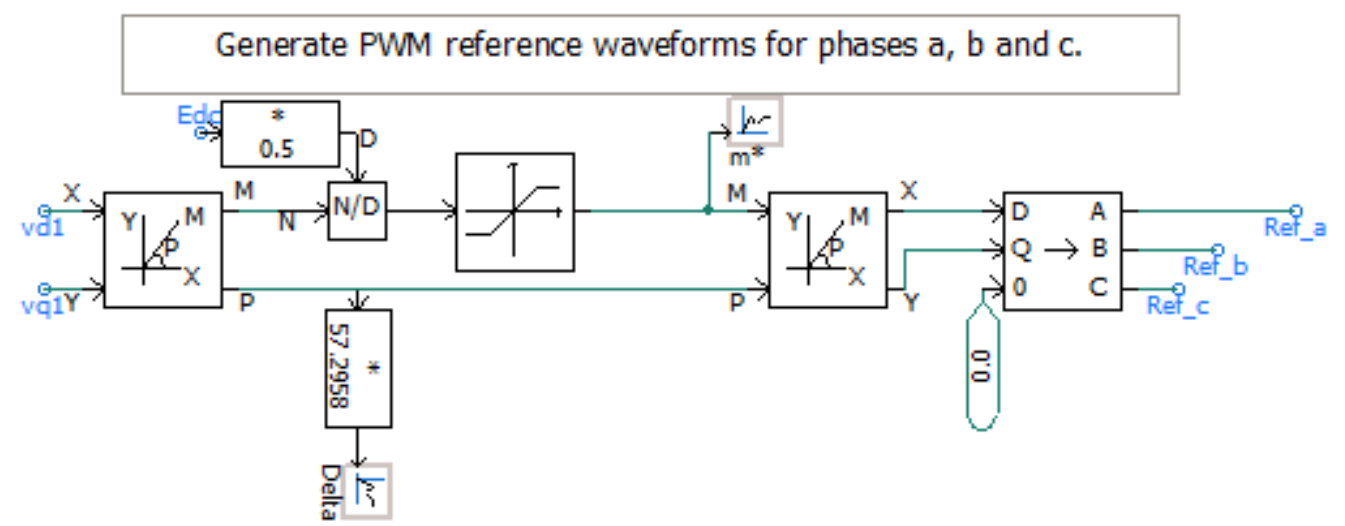

Figure 4-27: Generation of Reference A, B, and C Waveforms

With the reference waveforms, switching pulses are acquired for the VSC IGBTs using a carrier frequency of $2700 \mathrm{~Hz}$, as can be seen in Figure 4-28. 


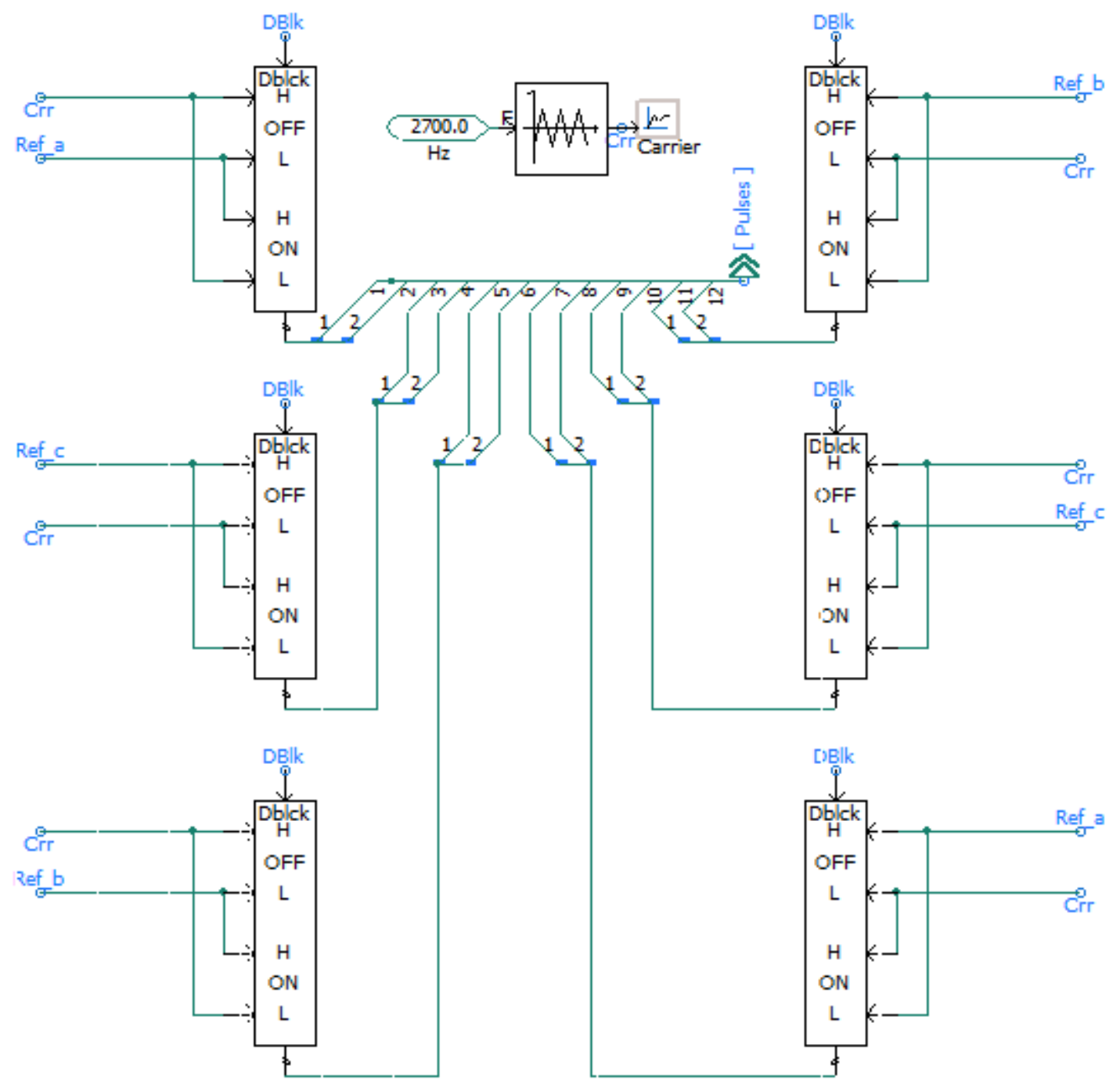

Figure 4-28: VSC IGBT Firing Pulse Generation

\section{3: Battery System Design}

\subsection{1: Grid-Tied Battery System}

Both of the battery assets in the microgrid have the same design process and contain mostly the same components, just with some slight variances in values. The battery design is taken from a similar three phase grid-tie battery example created by Manitoba HVDC Research Centre [14] and was redesigned to match the needs of this study. The entire 
battery system block diagram is shown in Figure 4-29 and connects to an equivalent power grid through a transformer. The transformer details are displayed in Table 4-4.

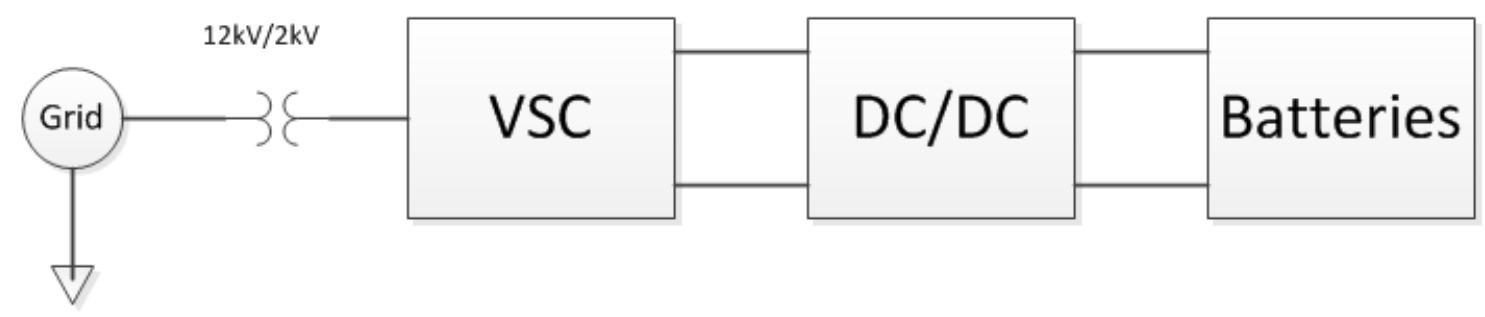

Figure 4-29: Grid-Tied Battery System

The battery/inverter model is capable of both charging and discharging at the required power level for both battery system 1 and battery system 2. Figures 4-30 and 4-31 show the real and reactive power for the battery systems. The batteries are initialized in discharge mode and then switched to charge mode at approximately $0.75 \mathrm{~s}$. The reactive power is set to be zero for the graphs shown, but can be specified for a different set-point within the battery system capability.

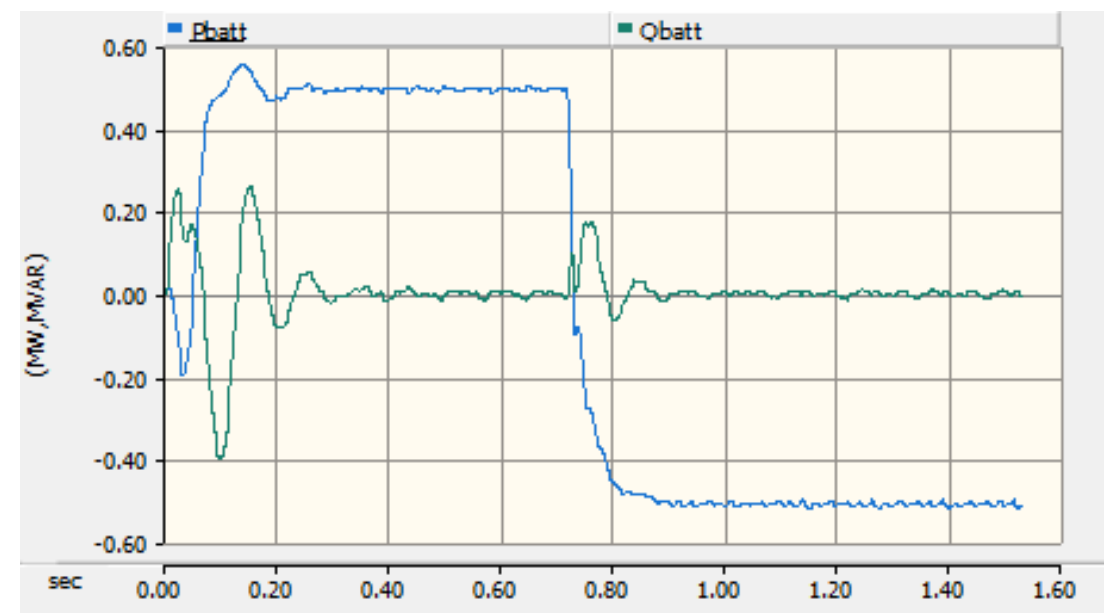

Figure 4-30: Battery System 1 Real and Reactive Power Curves 


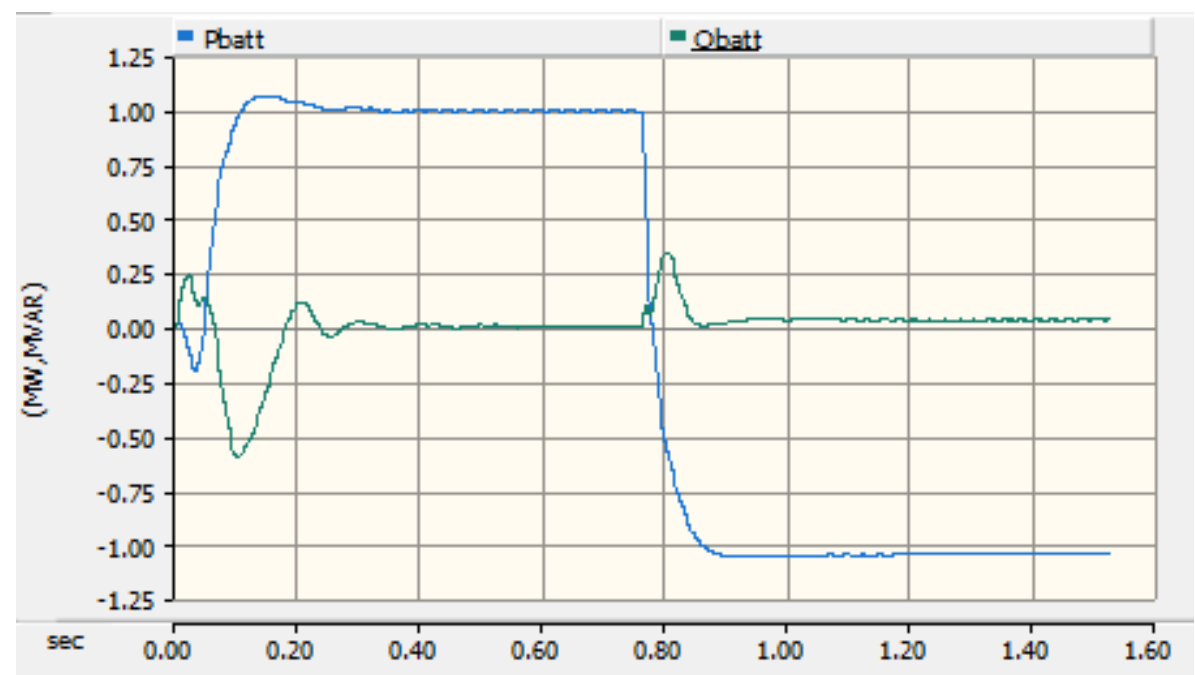

Figure 4-31: Battery System 2 Real and Reactive Power Curves

For the PSCAD model of both battery systems the voltage is set at a higher value than the actual battery systems in the microgrid. This voltage level difference is reflected in Table 4-4. The reason for this inconsistency is covered in more detail in the following section

Table 4-2: Battery Transformer Data

\begin{tabular}{|c|c|c|c|}
\hline & Battery Asset & Winding Type & $\begin{array}{c}\text { Transformer } \\
\text { Ratio }\end{array}$ \\
\hline \multirow{2}{*}{ Microgrid Actual } & Battery System 1 & $\Delta / \mathrm{Y}$ & $12 \mathrm{kV} / 208$ \\
\cline { 2 - 4 } & Battery System 2 & $\mathrm{Y} / \Delta$ & $12 \mathrm{kV} / 374$ \\
\hline \multirow{2}{*}{$\begin{array}{c}\text { PSCAD Model of } \\
\text { Microgrid }\end{array}$} & Battery System 1 & $\Delta / \mathrm{Y}$ & $12 \mathrm{kV} / 2 \mathrm{kV}$ \\
\cline { 2 - 4 } & Battery System 2 & $\mathrm{Y} / \Delta$ & $12 \mathrm{kV} / 2 \mathrm{kV}$ \\
\hline
\end{tabular}




\subsection{2: Battery Equivalent Module}

The battery module is created using built-in battery models that are new to PSCAD 4.6 and is shown in Figure 4-32.

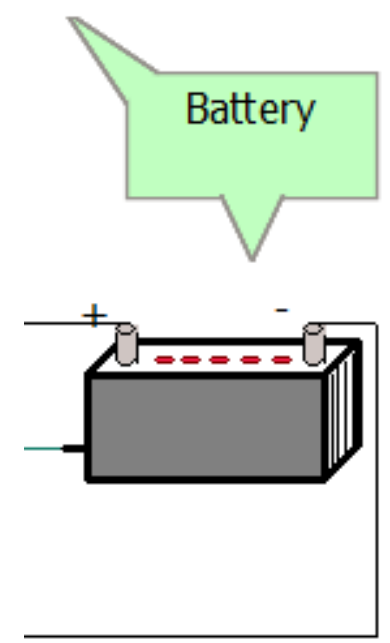

Figure 4-32: Battery Module for PSCAD Battery Systems

The battery module is created using 10 of the individual battery models, and the battery system models are designed for $2 \mathrm{kV}$ rather than the actual values seen in the microgrid. The battery model included within PSCAD struggles to output the power needed in the system at the low voltage levels seen in the actual microgrid. This problem is mitigated by placing more of these battery models in parallel to increase power output while maintaining the voltage. In addition the power quality and control of reactive power are difficult to achieve when using low voltage battery models so the battery systems are designed for $2 \mathrm{kV}$. For this study the power output from the battery systems is critical whereas the voltage level of the battery models is not. 


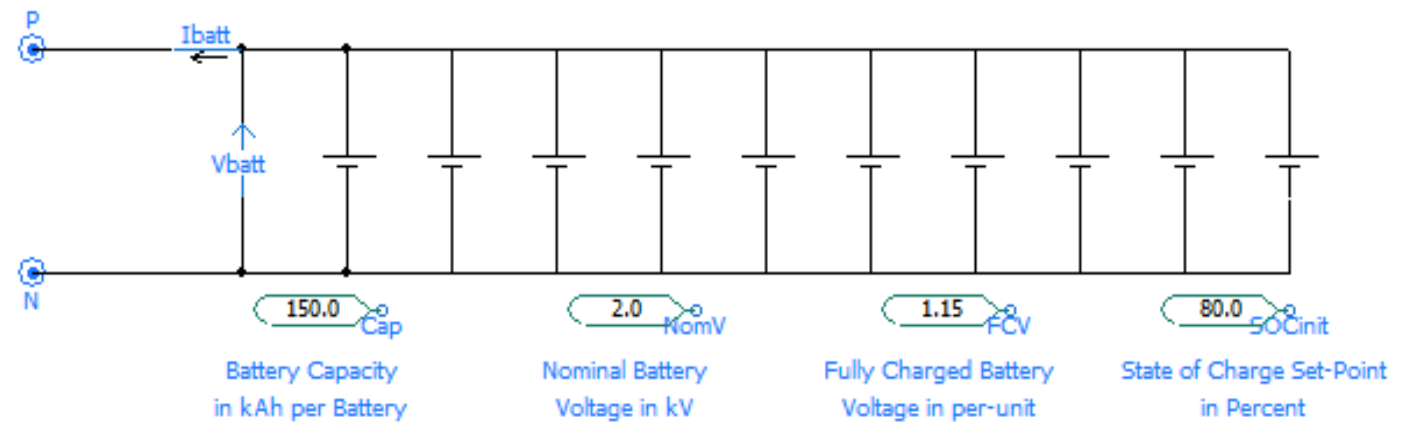

Figure 4-33: Battery Equivalent Used for the Battery Systems

The battery components use shepherd model data entry and are configured according to the parameters shown in Table 4-5.

Table 4-3: Battery Configuration Data

\begin{tabular}{|c|c|c|}
\hline Parameter & Battery System 1 & Battery System 2 \\
\hline Nominal Voltage & $2 \mathrm{kV}$ & $2 \mathrm{kV}$ \\
\hline Rated Capacity & $1.5 \mathrm{MWh}$ & $3 \mathrm{MWh}$ \\
\hline $\begin{array}{c}\text { Fully Charged } \\
\text { Battery Voltage }\end{array}$ & 1.15 per-unit & 1.15 per-unit \\
\hline
\end{tabular}

The charging and discharging capability of the battery system can be observed in Figure 434. The figure shows the battery system discharging and charging with quick transitions determined manually by the user. The initial state of charge for this simulation is set to be $80 \%$. The figure makes it clear that the battery discharges at a slightly faster rate than it charges, which is a result of power losses in the Buck/Boost DC/DC converter and the VSC. 


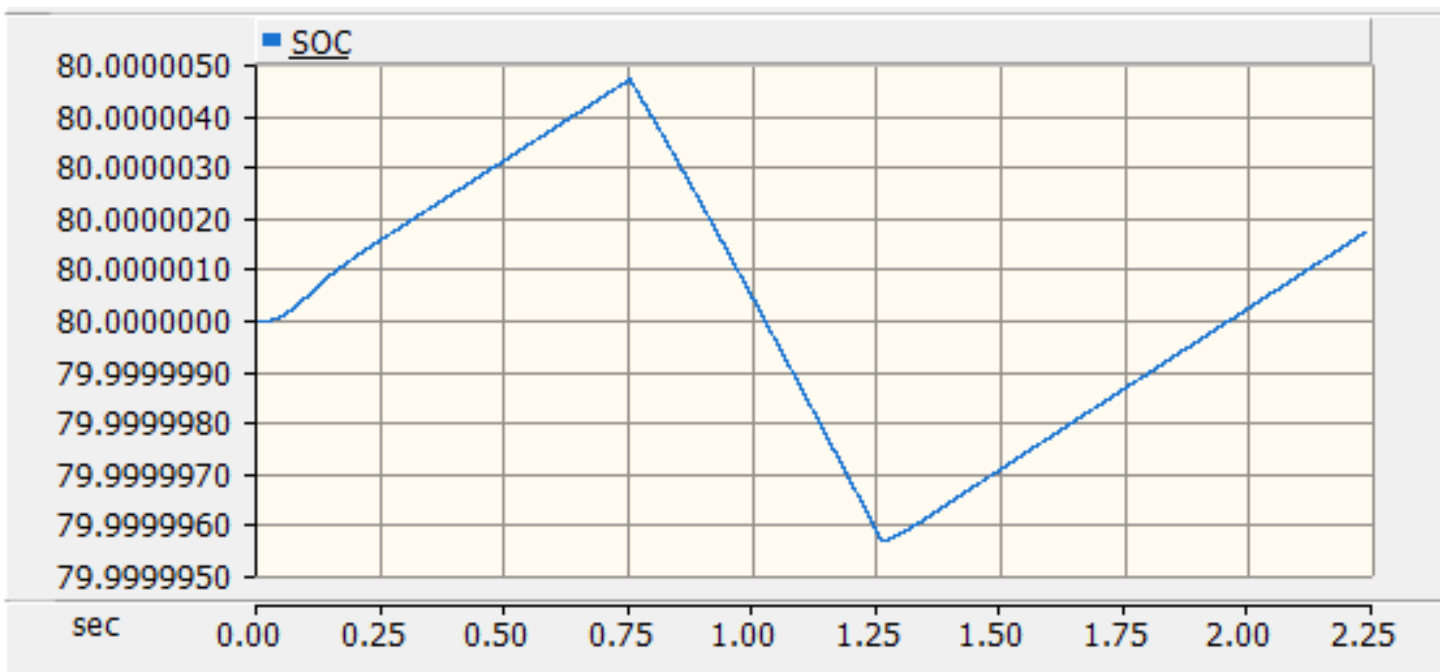

Figure 4-34: State of Charge of Battery System for Discharge and Charging

\subsection{3: Buck/Boost DC/DC Converter}

The Buck/Boost DC/DC converter shown in Figure 4-35 was designed for bidirectional compatibility with current flowing from low-voltage side (LDCP) to highvoltage side (HDCP) when discharging and vice versa for charging.

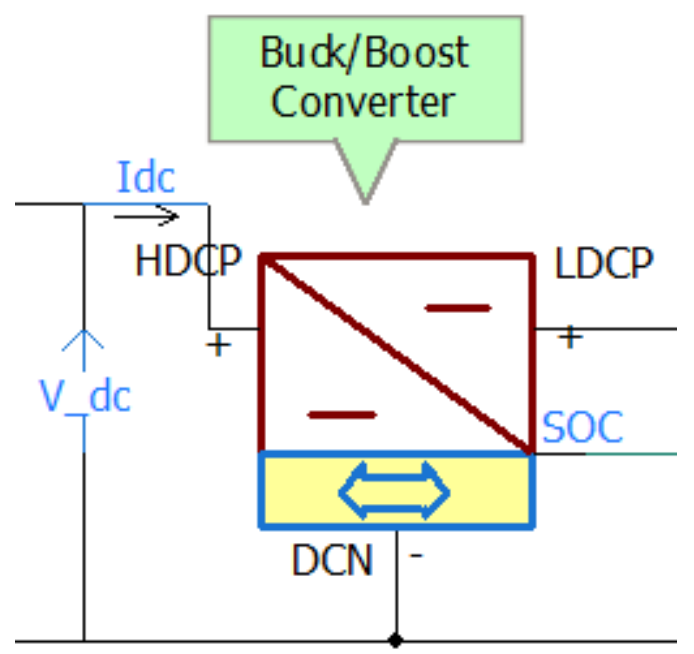

Figure 4-35: Buck/Boost Converter Module for Battery Systems 
Within the Buck/Boost module it can be observed (Figure 4-36) that the Buck/Boost converter is actually made using separate Buck and Boost converters. The converters are switched between using breakers that open and close depending on whether charge or discharge mode is selected. When discharge mode is selected the boost converter is enabled, and charge mode enables the buck converter. The DC/DC converter was designed this way rather than an actual Buck/Boost converter to improve the bidirectional functionality of the converter. The controls that enable the converter and determine the mode of operation are shown in Figure 4-37. Included in the controls is the SOC (state of charge) imported from the battery that disables the converter if the battery is either fully charged or depleted.

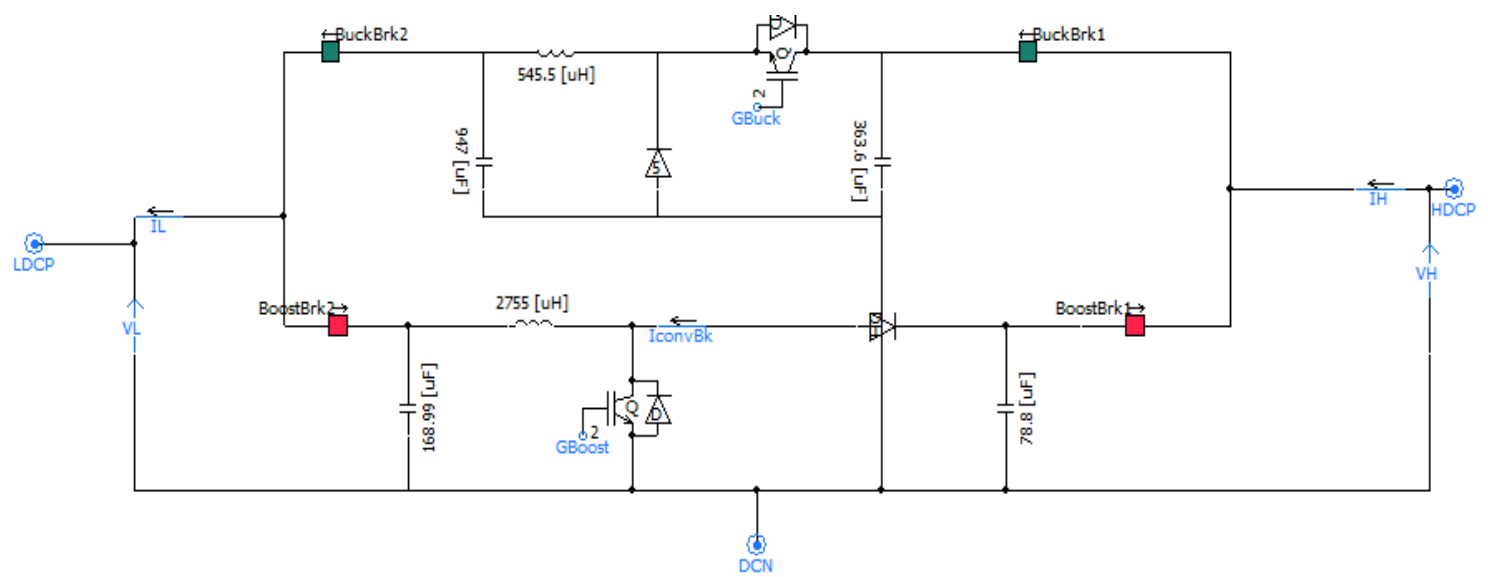

Figure 4-36: Buck/Boost Converter for Battery Systems 


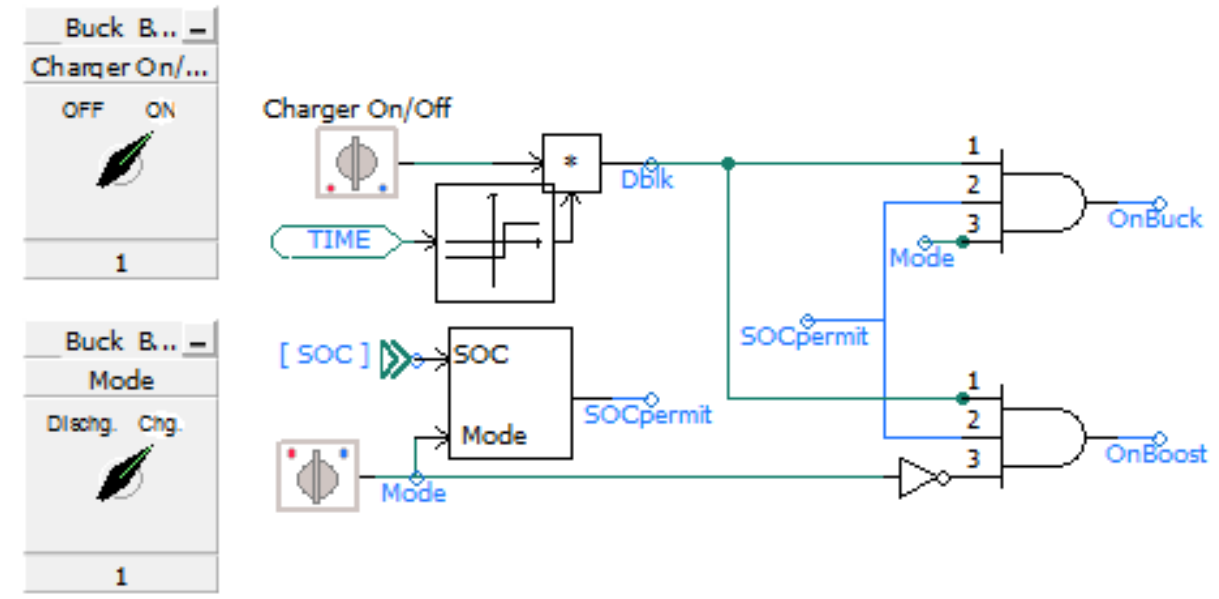

Figure 4-37: Buck/Boost Converter On/Off and Mode Controls

The Boost converter portion was designed using the same method as described in section 4.2.3 and can be reviewed with equations 4-2 through 4-4 along with Table 4-1. A similar design process was employed for the Buck converter. The equations used for the Buck converter design are 4-5, 4-6, and 4-7 and Table 4-6 can be used as a reference for all variables [15].

$$
\begin{gathered}
L=\frac{(1-D) V_{o}}{2 f I_{\text {omin }}} \\
C_{o}=\frac{(1-D)}{\frac{\Delta V_{o}}{V_{0}} 8 L f^{2}} \\
C_{\text {in }}=\frac{D I_{\text {omax }}(1-D)}{\Delta V_{\text {in }} f}
\end{gathered}
$$


Table 4-4: Variables Used in Buck Converter Calculations

\begin{tabular}{|c|c|}
\hline Variable & Variable Description \\
\hline $\mathrm{D}$ & Duty Cycle \\
\hline$\Delta \mathrm{V}_{\mathrm{o}}$ & Output Voltage Ripple \\
\hline $\mathrm{V}_{\mathrm{o}}$ & Average Output Voltage \\
\hline $\mathrm{I}_{\text {omin }}$ & Minimum Average Output Current \\
\hline $\mathrm{I}_{\mathrm{omax}}$ & Maximum Average Output Current \\
\hline $\mathrm{f}$ & Switching Frequency \\
\hline$\Delta \mathrm{V}_{\text {in }}$ & Input Voltage Ripple \\
\hline $\mathrm{L}_{\mathrm{L}}$ & Critical Inductance \\
\hline $\mathrm{C}_{\mathrm{out}}$ & Critical Output Capacitance \\
\hline $\mathrm{C}_{\text {in }}$ & Critical Input Capacitance \\
\hline
\end{tabular}

The remaining controls for both the Buck and the Boost converters are shown in Figure 438 and Figure 4-39. Both sets of controls use common strategies that have been seen in the power electronics discussed in sections 4.2.3 and 4.2.4. The controls use summing/difference junctions to compare the actual power in or out of the battery system to set reference values. The difference output from the junctions is sent through a PI controller with freeze capability to determine the duty cycle for the transistor firing pulses. Both the Buck and the Boost converter have a set of controls to decide the duty cycle based off of a desired power level to either charge or discharge at. 

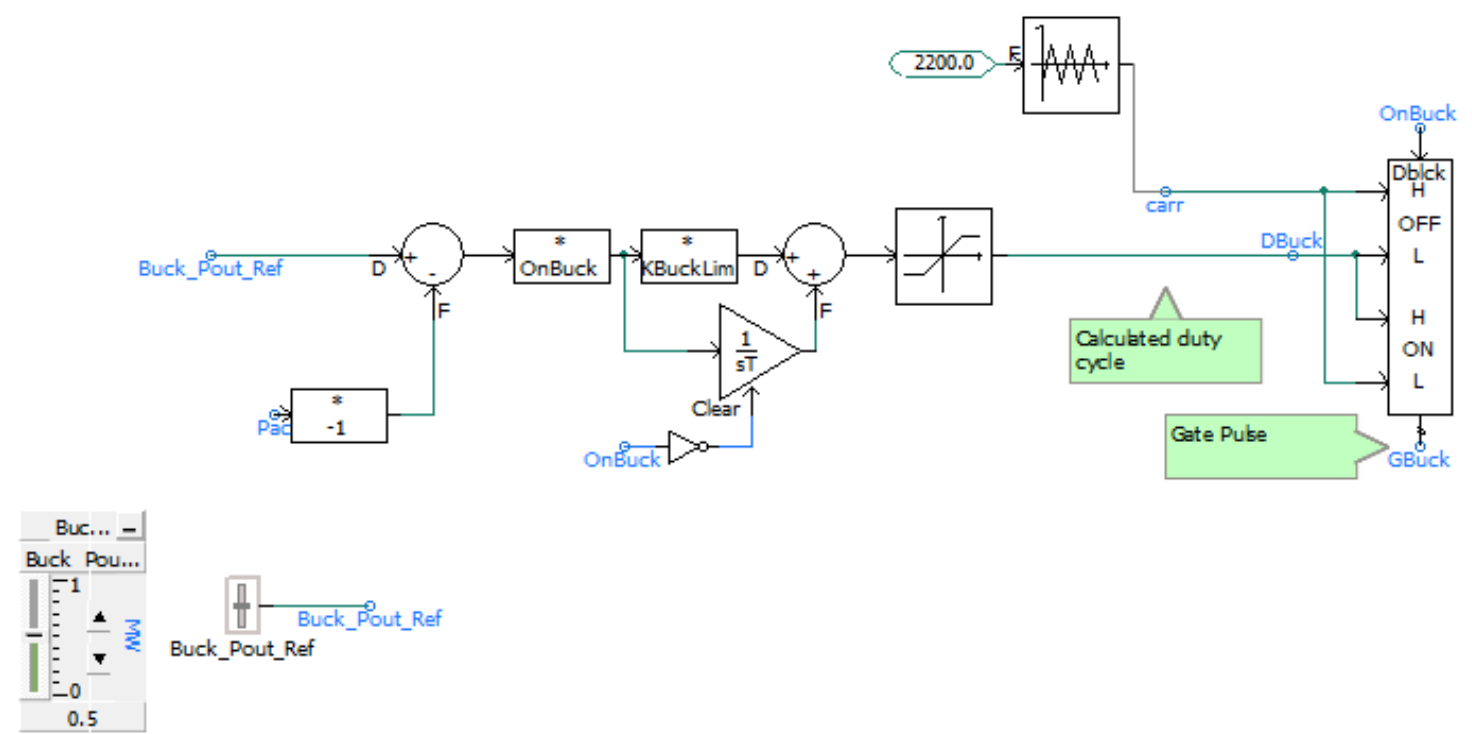

Figure 4-38: Buck Converter Controls for Battery Systems

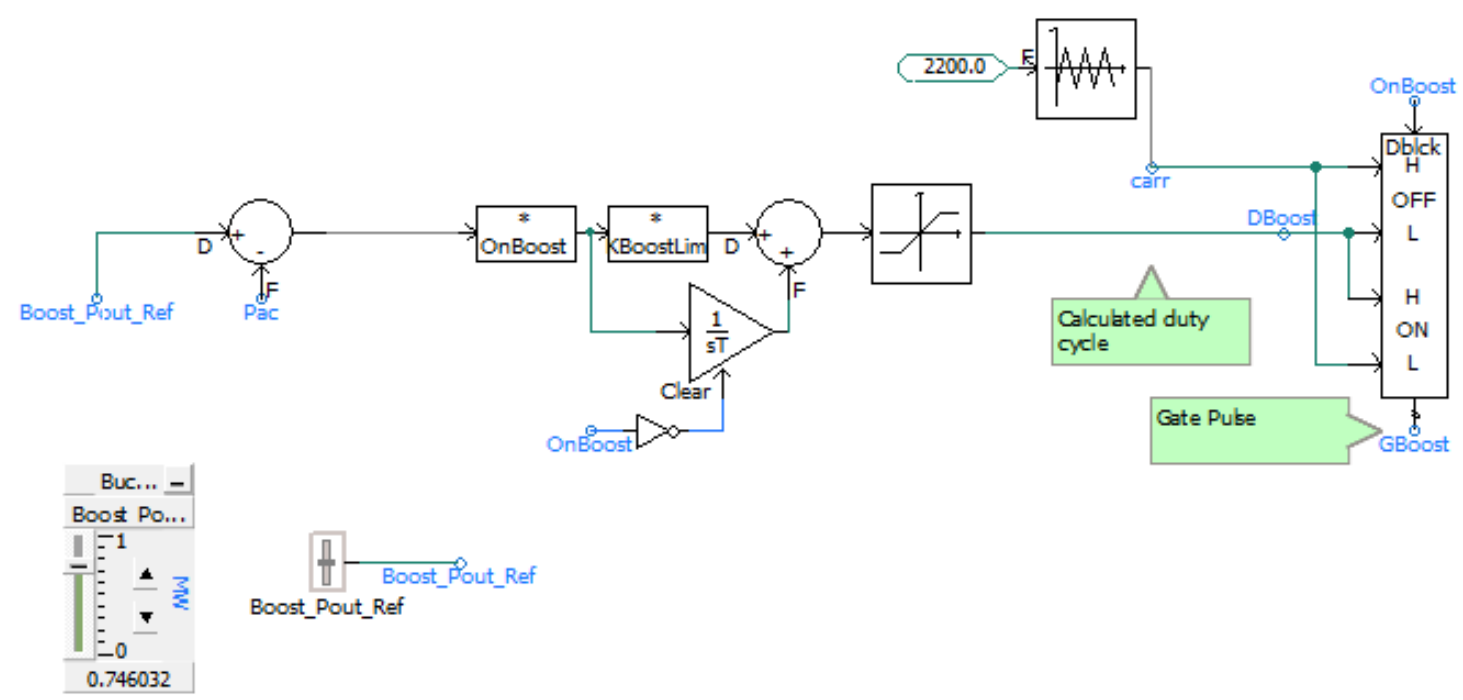

Figure 4-39: Boost Converter Controls for Battery System 


\subsection{4: Battery VSC}

The battery systems use the same VSC module that was explained in section 4.2.4. The only notable difference in the battery system VSC design is the need for more significant AC filtering. The AC LCL filter used for the battery systems is shown in Figure 4-40. The filter was designed using the strategy explained in [16]. The filter design reference states essentially that the larger the total inductance used for the filter, the better the filtering capability. With smaller inductance the system response time is improved. Ultimately enough inductance needs to be used to provide an acceptable output. In addition, a general rule of thumb is that the grid-connected inductor be selected so that it is one fifth the size of the VSC-connected inductor. Furthermore the capacitor must be selected to be large enough to provide the needed filtering, while not being so large as to allow a large amount of reactive power current flow.

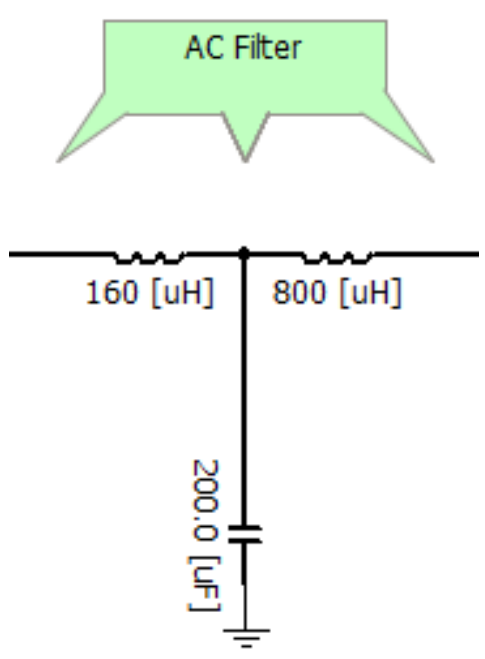

Figure 4-40: LCL Filter for Battery Systems 


\section{4: Ultracapacitor Design}

\subsection{1: Grid-Tied Ultracapacitor}

Additional energy storage within the system includes an ultracapacitor, or Super Capacitor Energy Storage (SCES), connected to the grid, like the batteries, through a Buck/Boost converter and a Voltage Sourced Converter (VSC) and is tied to the grid through a Delta/Wye $480 / 12 \mathrm{kV}$ transformer. The full ultracapacitor block diagram is shown in Figure 4-41.

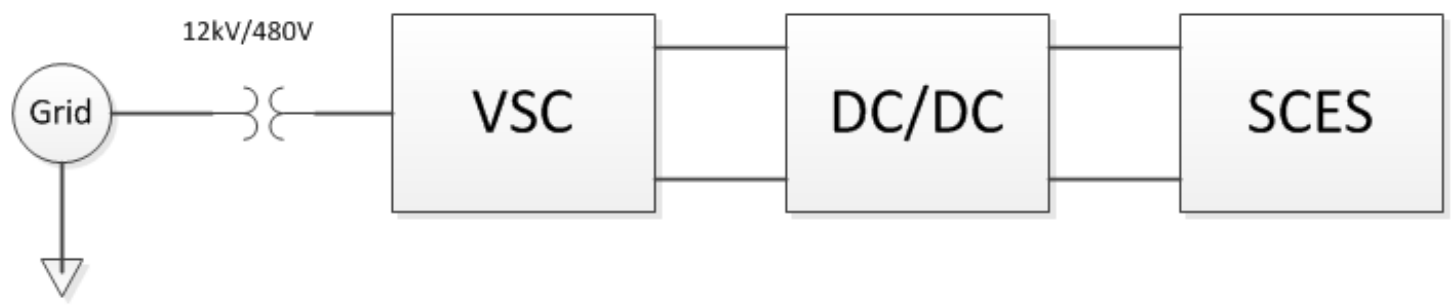

Figure 4-41: Grid-Tied Ultracapacitor

A typical ultracapacitor is capable of charge and discharge cycles and can output a steady power level. The Ultracapacitor model created in this thesis is only capable of discharging, which will be covered more in depth in the next section. The power output when discharging, set for the maximum output level of the module can be seen in Figure 4-42. The reactive power output was set to be zero for this instance. 


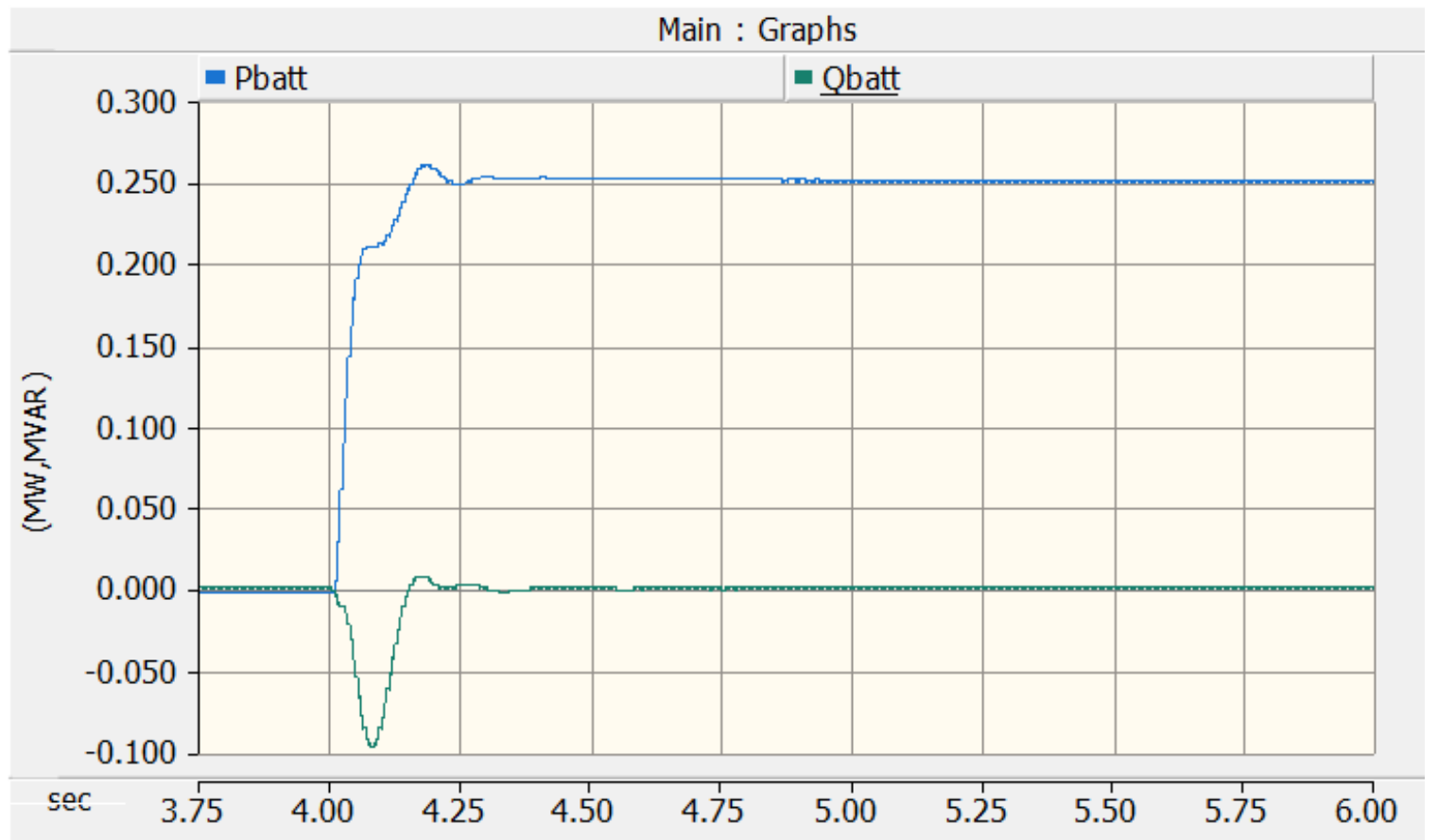

Figure 4-42: Ultracapacitor Module Power Output

\subsection{2: Ultracapacitor Model}

The ultracapacitor, or Super Capacitor Energy Storage (SCES), module is designed to perform a similar function to the battery energy storage. The ultracapacitor is shown in Figure 4-43. The DC/DC converter and VSC used follow the same design process as covered in sections 4.3.3 and 4.3.4 and will not be covered again in detail within this chapter. 


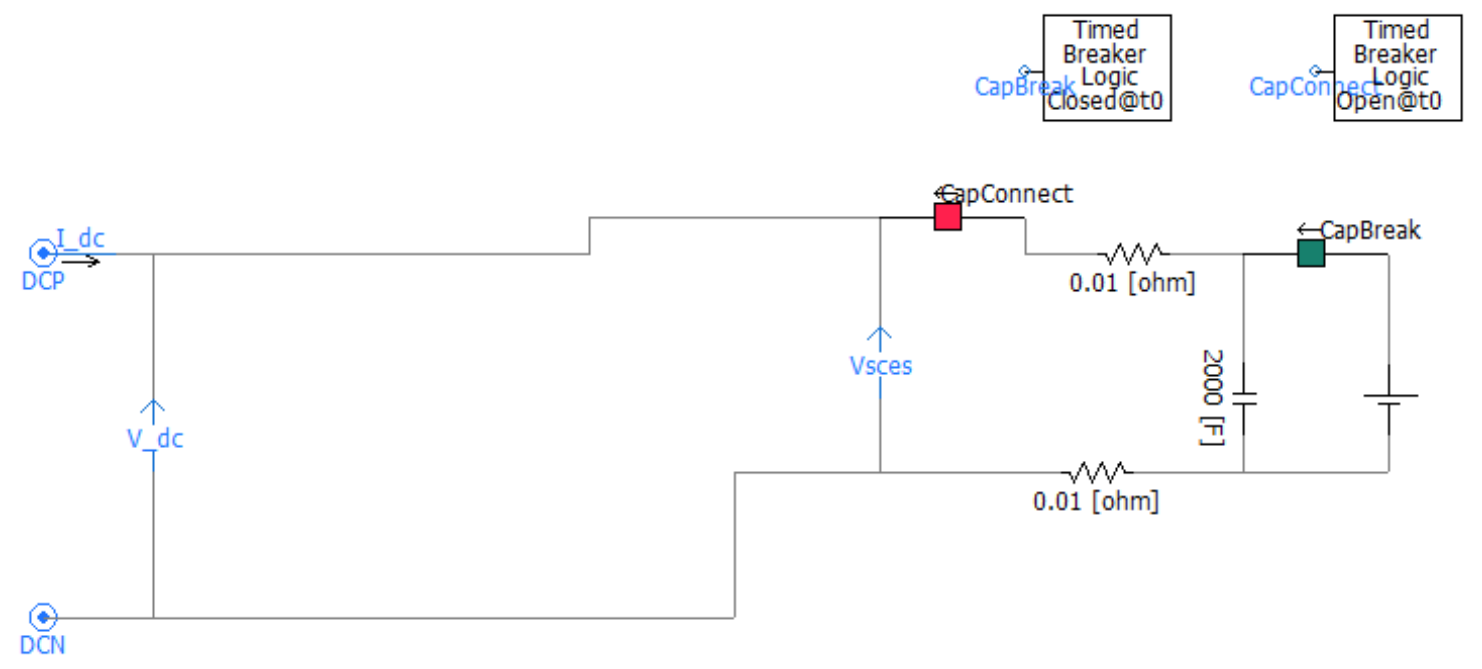

Figure 4-43: Ultracapacitor Model

As was stated before, in an actual microgrid, an ultracapacitor system would be capable of both charge and discharge cycles. For the purpose of this study it was realized that including the typical charge cycle using grid power was going to be impossible. In order to utilize a large enough capacitor, and store enough energy onto the capacitor, to provide steady power output, charging from the grid could not be realized. Furthermore, this causes the concern of using the ultracapacitor even for discharging power, considering that there is no way in PSCAD to initialize a capacitor to a certain charge level. In order to get around this issue, an unrealistically large battery model was connected to the capacitor in parallel, while both are disconnected from the system in order to quickly charge the capacitor. The capacitor is allowed to charge for 4 seconds before being disconnected to the battery, and reconnected to the rest of the system. A capacitor value of $2000 \mathrm{~F}$ was chosen so that it could both be charged in a reasonable amount of time, and output a steady amount of power. The power, energy, and voltage of the ultracapacitor over time can be observed in Figure 4-44. The energy contained within the capacitor at any given point of time after 
being charged was calculated using equation 4-8 where E represents energy in Mega Joules.

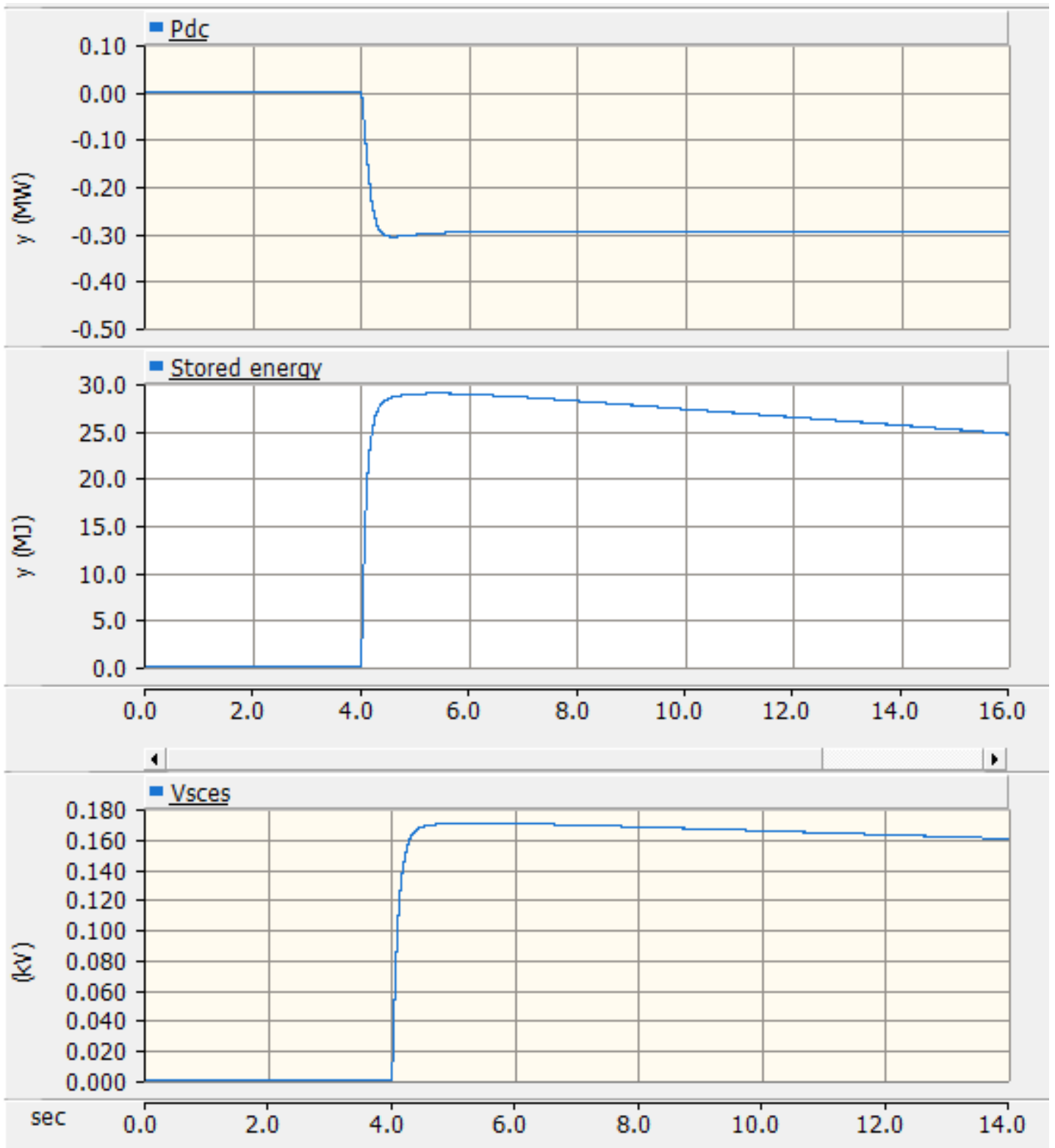

Figure 4-44: Ultracapacitor Power, Energy, and Voltage

$$
E=0.5 C V^{2}
$$




\section{5: Capacitor Bank Design}

Additionally a capacitor bank was included to the full design to allow for MVAR correction in accordance with the microgrid. The capacitor bank is shown in Figure 4-45 including four 1.5MVAR capacitor steps. The capacitor values were selected according to equations 4-9 and 4-10.

$$
\begin{aligned}
& X_{C}=\frac{\left(\frac{12 k V}{\sqrt{3}}\right)^{2}}{1.5 M V A R}=32 \Omega \\
& C=\frac{1}{2 \pi(60 H z) X_{C}}=82.9 \mu F
\end{aligned}
$$




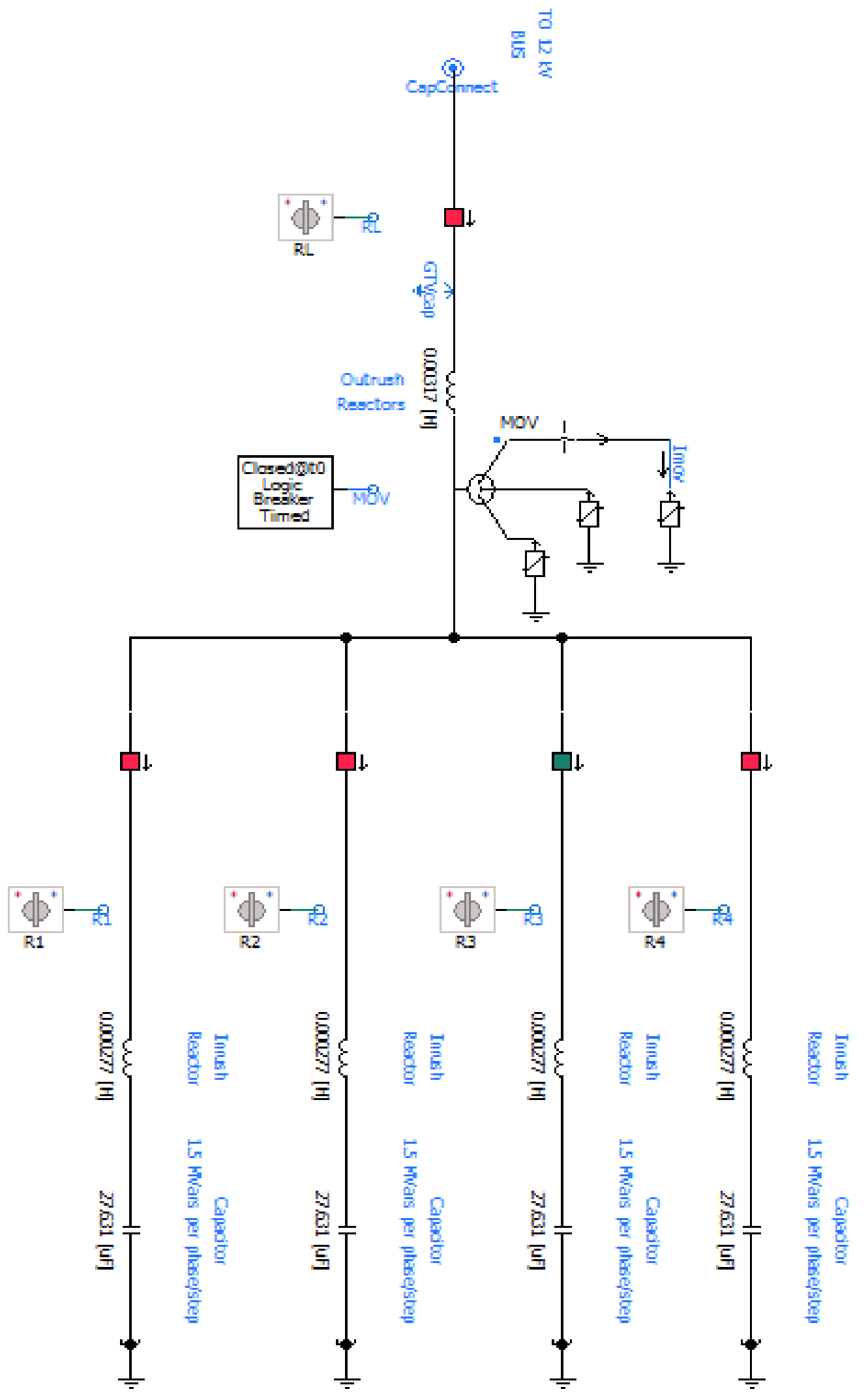

Figure 4-45: Capacitor Bank 


\section{6: Control Mode Methods}

It is worth also holding a separate discussion for the methods of control used for the assets contained within the microgrid. Controlling the assets in order to improve microgrid stability is integral to this study and deserves some focus. Recall that the designed control for the energy storage assets shown includes active and reactive power control. Figures 4-46 and 4-47 serve as a reminder to the method of control employed in the design thus far.

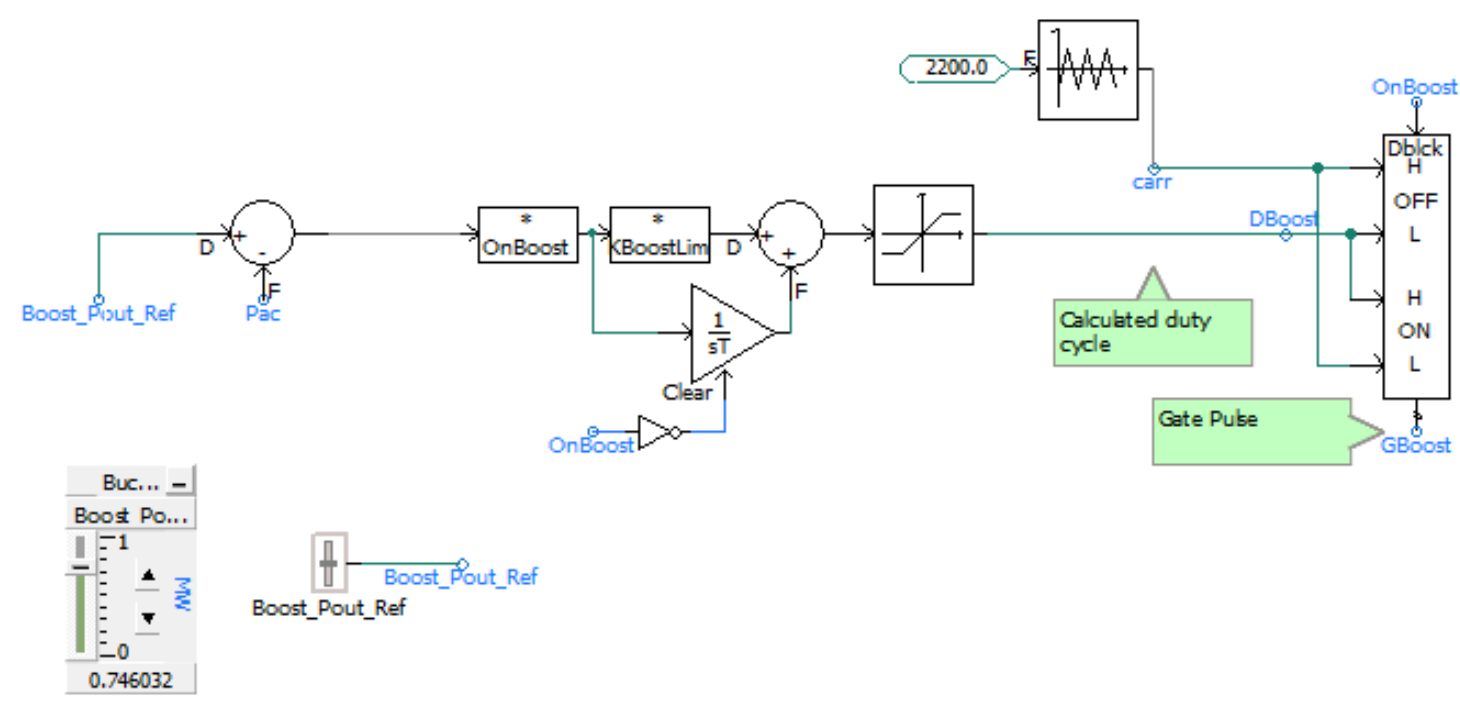

Figure 4-46: Active Power Control of Energy Storage 


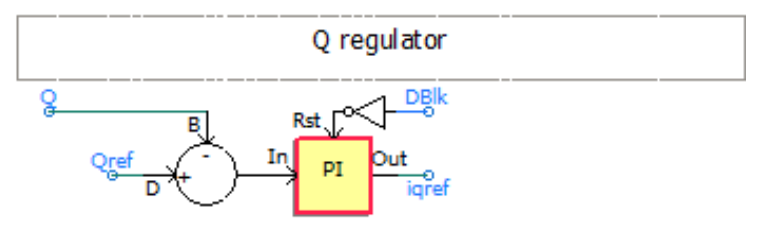

Figure 4-47: Reactive Power Control of Energy Storage

The real power that is discharged from the energy storage systems is controlled at the DC/DC converter by using control of the duty cycle to achieve the desired power level. The reactive power that is consumed or discharged by the energy storage is controlled at the VSC. This method of control for active and reactive power is a typical capability of energy storage systems at the inverter level, as is the case with the energy storage contained within the microgrid. The [REDACTED] inverter manual serves as an example to inverter capabilities for energy storage within the microgrid [17]. The method of PQ control for the assets within the microgrid is useful for grid-connected operation, where the power of the energy storage systems has no regard for system conditions, such as unbalance. Another control mode is implemented in PSCAD in order to properly investigate the effectiveness of different control modes in islanded mode operation. The most effective control mode within the capability of the inverters for system stability contained in the microgrid is known as Virtual Generator Mode, or voltage and frequency regulation mode (VF mode). In this mode of operation the energy storage devices mimic the behavior of regular rotary generators. This mode provides voltage stability by injecting reactive power for system voltage droop, or absorbing reactive power when system voltage rises. Similarly, active power must be injected into the system when system frequency droops, or it must be absorbed when frequency rises. If not already, it should become clear why Virtual 
Generator Mode would be more desirable for islanded operation of the microgrid. In order to implement this control mode into the PSCAD model, a seemingly slight modification is made to the active and reactive power control as is shown in Figures 4-48 and 4-49.

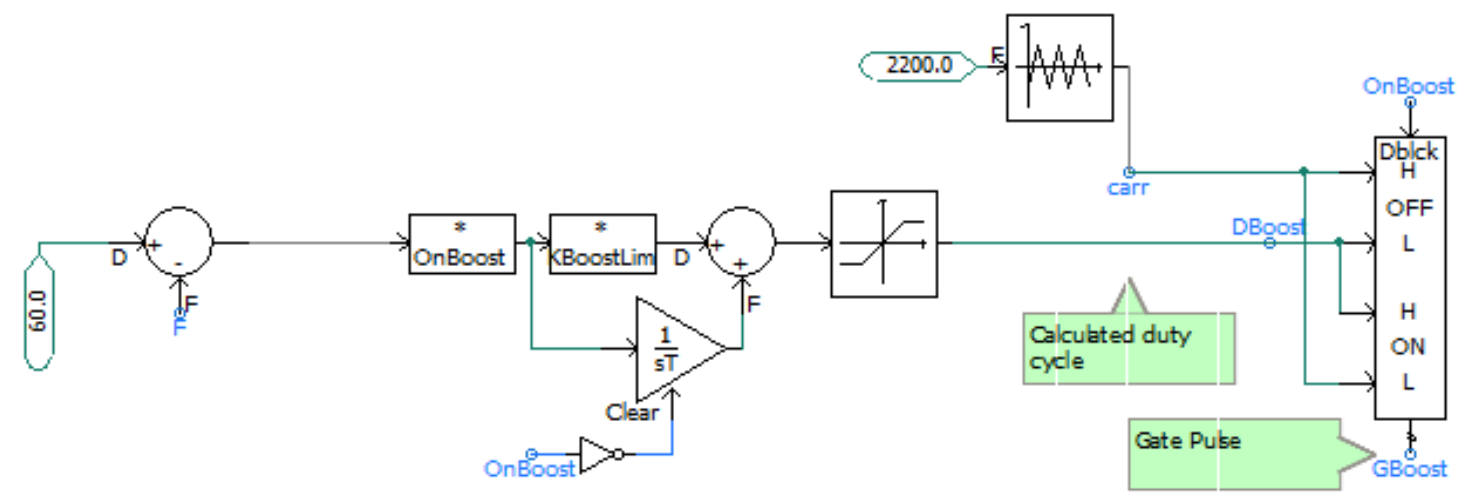

Figure 4-48: Frequency Regulation of Active Power Control of Energy Storage

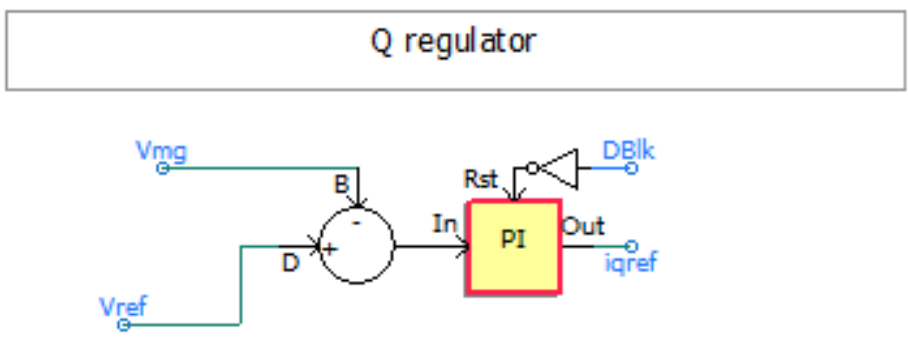

Figure 4-49: System Voltage Regulation of Reactive Power Control of Energy Storage

The figures show that the power control of the energy storage devices is regulated according to the system voltage and frequency levels, as required for Virtual Generator Mode. It is worth noting that the PI controllers must be tuned differently for both the PQ and VF methods of control and is critical for optimal operation in each control mode. In addition, note that no control method is employed in the PV array power electronics, 
considering that would be unrealistic. The PV array simply outputs the power that it is capable of according to temperature and irradiation levels.

\section{7: Full Microgrid}

All of the designed modules were compiled together to form the complete microgrid. The microgrid is shown in full in Figure 4-50. The entire microgrid is a very large PSCAD model, so it is worthy of note that simulations take a significant amount of time to run. 


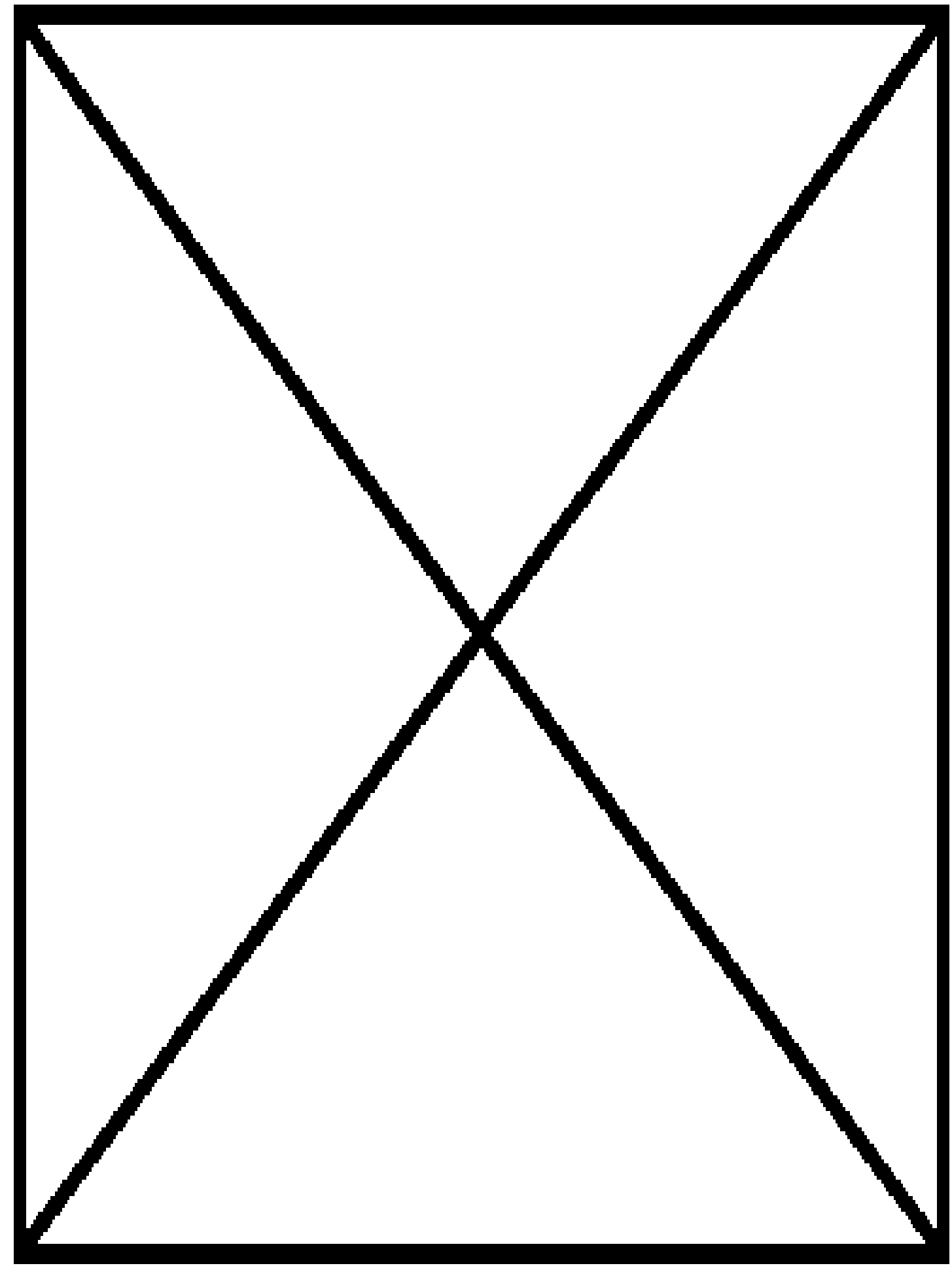

Figure 4-50: Microgrid 
As is expected the Microgrid is stable after start-up when connected to the primary power grid. The system frequency, voltage, and phase are displayed in Figure 4-50. The measurements are all made at the main system bus.

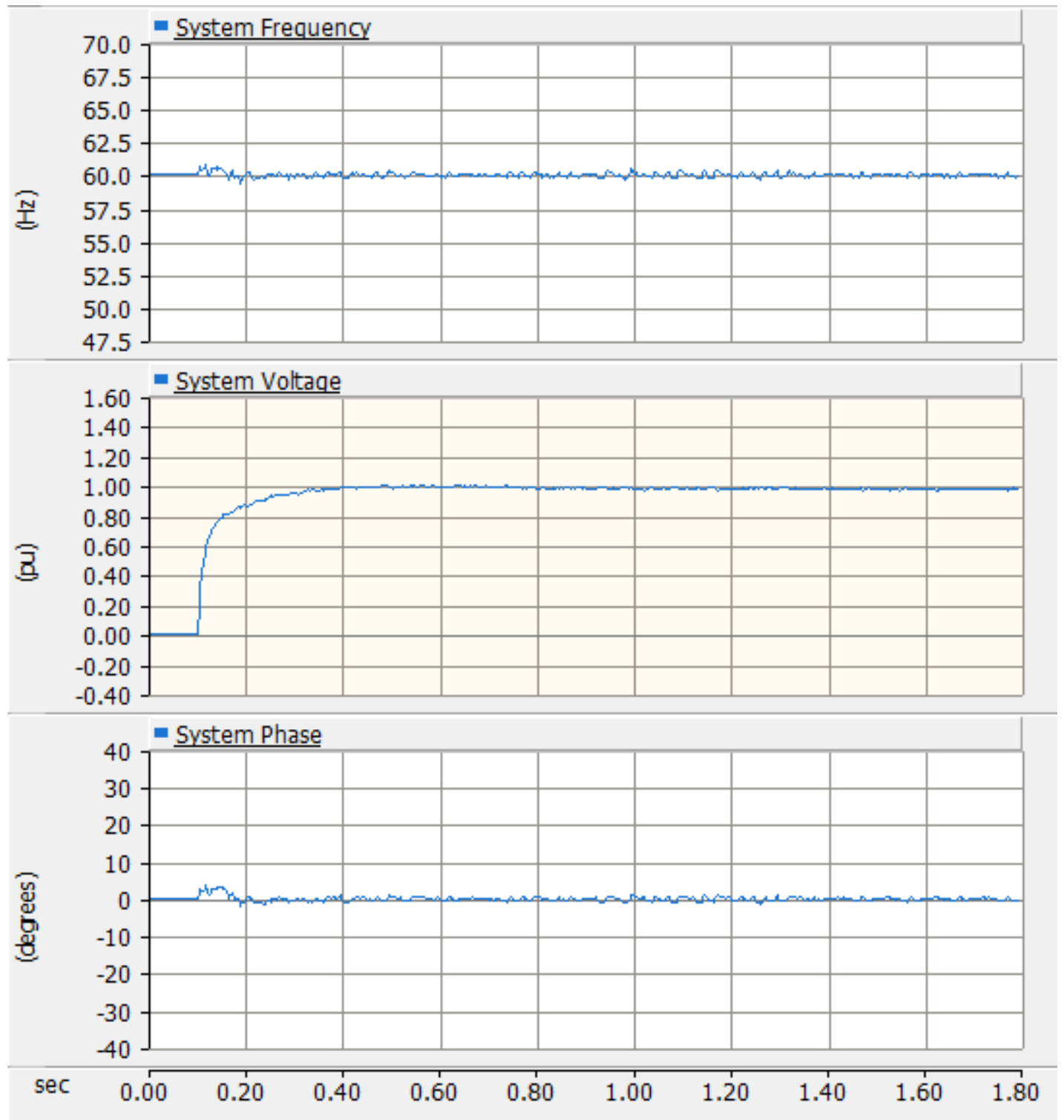

Figure 4-51: System Frequency, Voltage, and Phase 


\section{Chapter 5. PSCAD Simulations and Testing}

\section{1: Testing Procedure}

As was stated in previous chapters, the primary goal of this study is to determine the effective control methods of assets that can be used to improve microgrid stability. In order to observe this, simulations were run for the microgrid for any given set of system conditions with the energy storage devices running in both PQ and Virtual Generator control modes. The system conditions are designed such that an imbalance exists in active and/or reactive power between the power generated by the distributed generation and the static loads contained within the grid when islanding occurs. The designed testing procedure to display the difference is summarized in Table 5-1. The results for each test are effectively displayed using frequency, voltage, and phase measurements taken from the microgrid at the main bus. Note that the phase measurement was originally designed for use with power system controls that used DC link power to dampen electromechanical oscillations and is not representative of phase angle with regards to system stability [14].

Table 5-1: Testing Procedure for the Microgrid

\begin{tabular}{|c|c|}
\hline Test Number & System Condition at time of Islanding \\
\hline 1 & Load demands more $\mathrm{P}$ than is generated \\
\hline 2 & Load demands more Q than is generated \\
\hline 3 & Load demands less Q than is generated \\
\hline 4 & Load demands more P and Q than is generated \\
\hline
\end{tabular}


The tests run for this microgrid use static loads, and ultimately does not differentiate between the three different Islanding methods. The relevant differences in islanding technique with respect to the tests shown in this chapter is in the assets included within the island. In order to include all of the assets, testing was completed by creating an Island at the breaker tying to the main power grid. Before observing the test results it is important to know that disconnect from the main power grid occurs at $0.25 \mathrm{~s}$ on all of the graphs. In actuality the islanding occurs 4 seconds into simulation, thus allowing for the ultracapacitor to charge sufficiently. For practical reasons the "snapshot" technique was utilized to speed up the testing process, considering that the microgrid model is quite large and takes a significant amount of time to simulate. This snapshot technique allows for the system to initialize from a set time into the simulation. When the system initializes from a snapshot the displayed time is reset to zero. In addition, for all of the simulations shown in this chapter the PI controllers for the virtual generator control mode were not altered and the results shown demonstrate the best case tuning for all scenarios. The following test cases should demonstrate that, although reactive power control is used to create voltage balance and active power control is used to control frequency balance, both voltage and frequency are inevitably disturbed somewhat no matter what kind of imbalance exits during islanding. In addition the control for both $\mathrm{P}$ and $\mathrm{Q}$ each had to be adjusted in with the other in mind, considering that they inevitably affect each other. In addition, the following tests show a natural instability, or noisy system voltage and frequency levels, as a result of harmonics caused by the power electronics. If more effective filtering were to be achieved the system would appear more stable and the VF control could be tuned more aggressively for fast response. 


\section{2: Simulation and Testing}

\subsection{1: Test 1 - High Active Power Load Imbalance}

The first test case demonstrates how the system responds to being disconnected from the main power grid with an active load that demands approximately $0.65 \mathrm{MW}$ more than is being provided by the microgrid assets at the time of islanding. Figures 5-1 and 52 show the system measurements for the PQ and Virtual Generator control modes respectively.
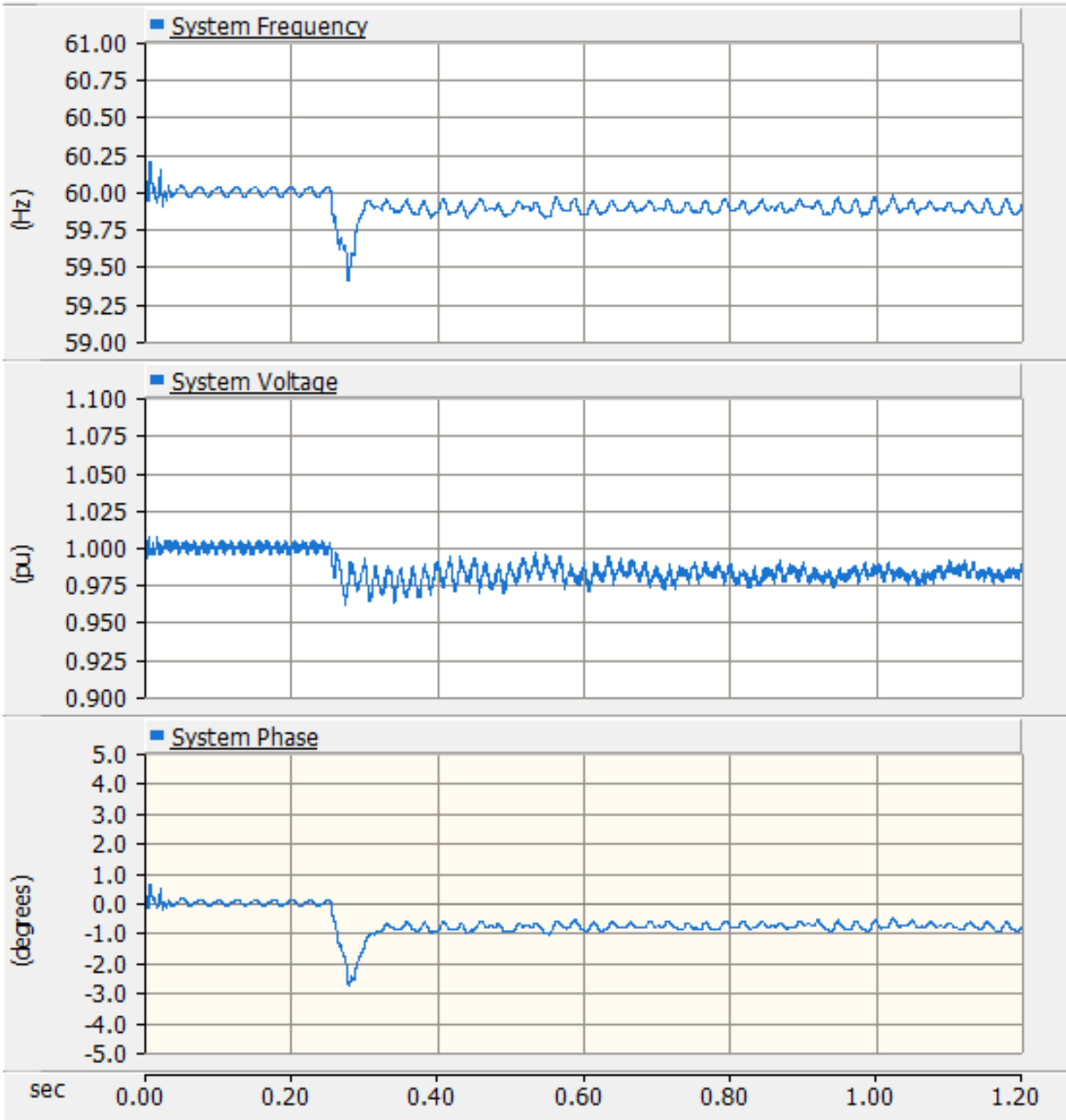

Figure 5-1: System Measurements for Test 1 Using PQ Control 


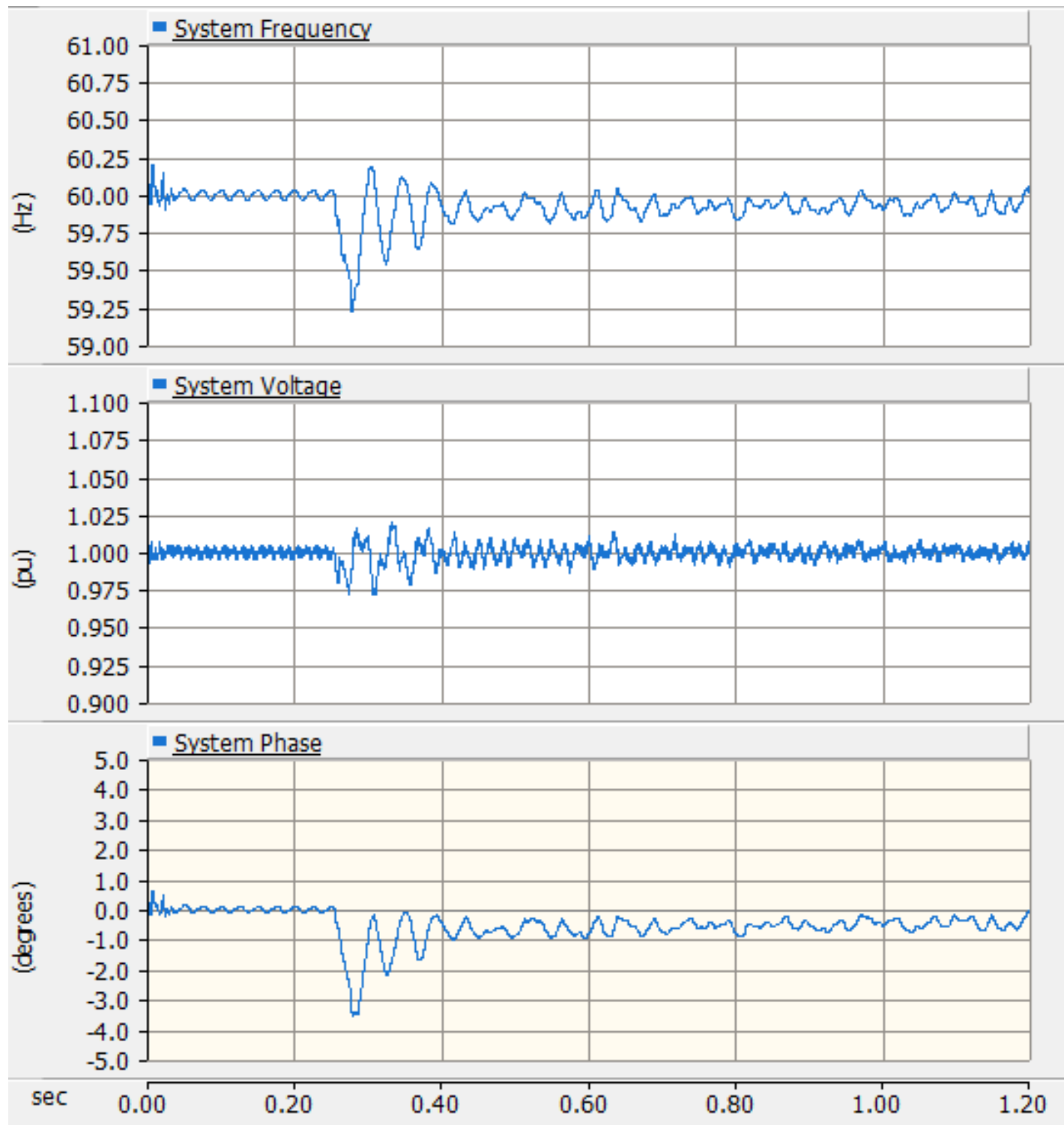

Figure 5-2: System Measurements for Test 1 Using VF Control

The system measurements for this test case show that there is not a largely noticeable difference between the two control modes. The system frequency actually appears to be slightly less stable when using the VF control mode than the PQ mode. The VF control mode does, however, demonstrate an advantage to the VF mode with respect to system voltage. Despite the fact that the load/generation imbalance is real power at the time of 
islanding, a demand for a noticeable amount reactive power is created at the time of islanding which is compensated for in the VF control mode, thus removing the voltage droop observed in Figure 5-1. The generator P and Q output graphs more clearly show the effectiveness of the compensation techniques used in the Virtual Generator Mode in Figures 5-3 and 5-4.

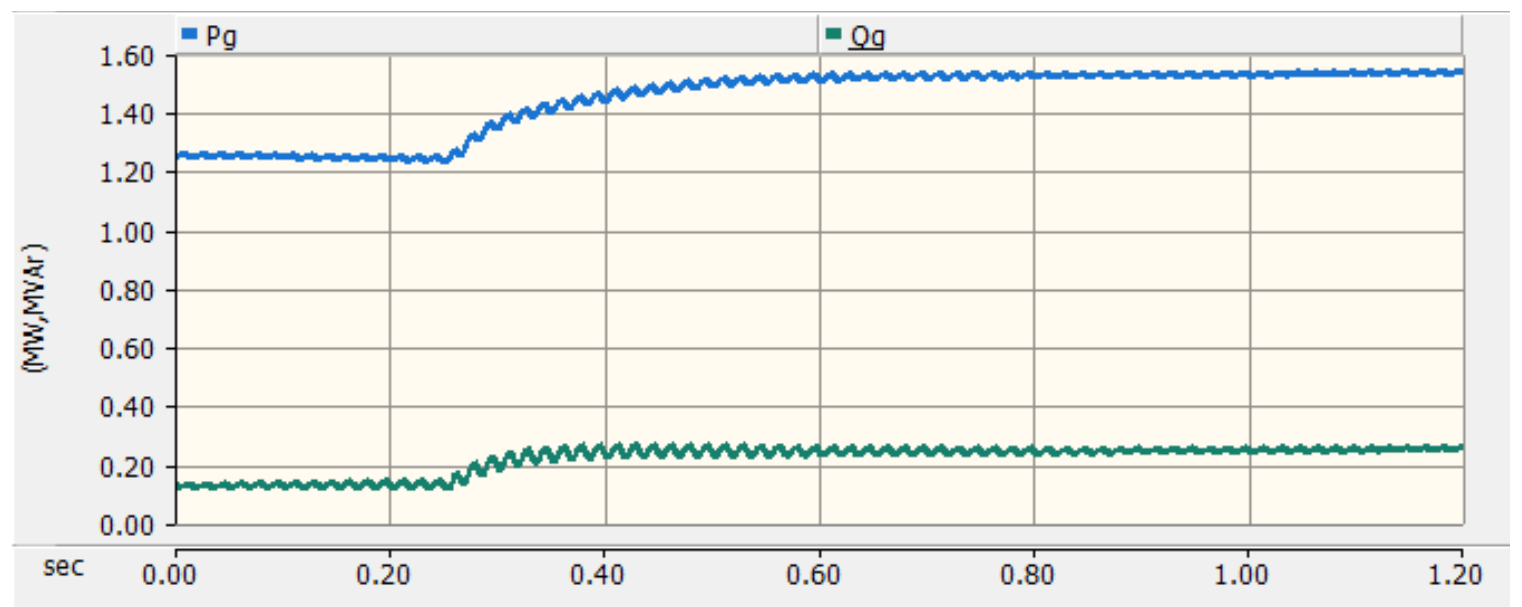

Figure 5-3: Generator P and Q Measurements for Test 1 Using PQ Control

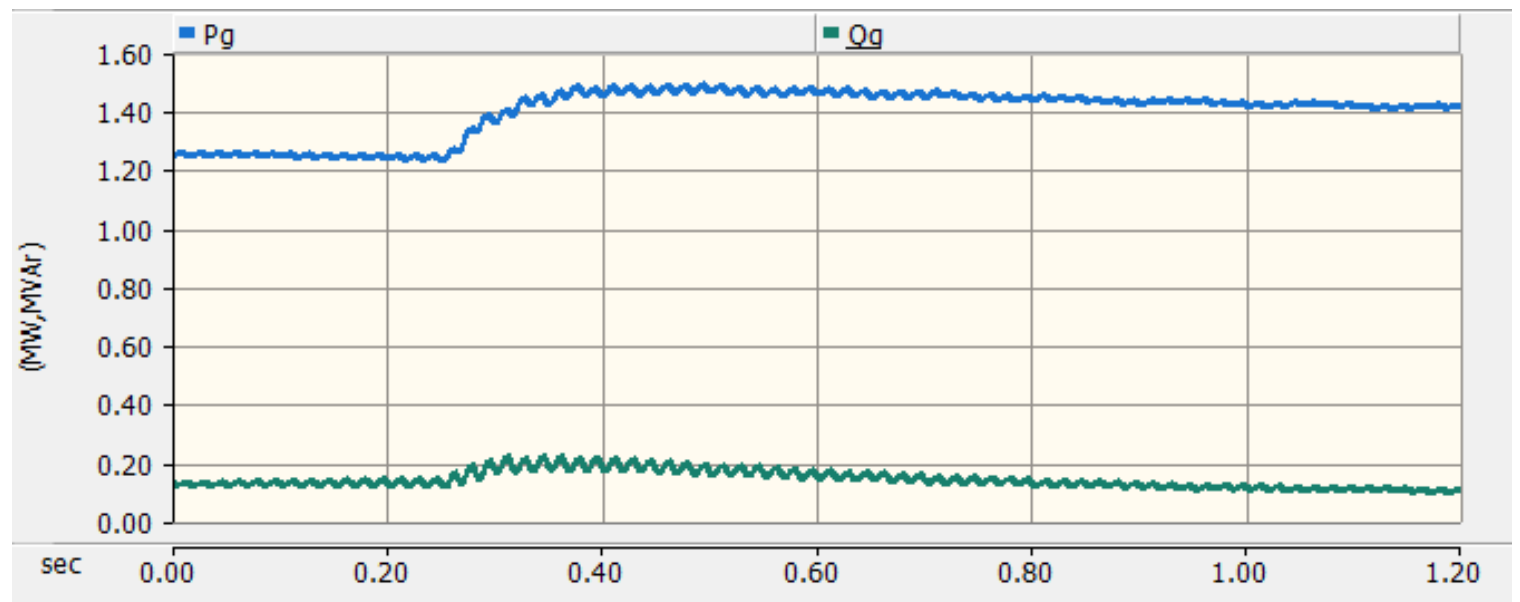

Figure 5-4: Generator P and Q Measurements for Test 1 Using VF Control 
The generator measurements show that the generators do not react as strongly to the transition to islanded mode when the aide of the energy storage is provided. More active and reactive power is demanded from the generators when they are the sole assets responsible for balancing the system.

\subsection{2: Test 2 - High Reactive Power Load Imbalance}

The second test case shows how the system responds to being disconnected from the main power grid with a reactive load that demands approximately $0.375 \mathrm{MVAR}$ more than is being provided by the microgrid assets at the time of islanding. Figures 5-5 and 56 show the system measurements for the PQ and Virtual Generator control modes respectively.

This test case demonstrates the advantage of running the energy storage systems in VF control mode much more clearly than Test 1 . The generators simply cannot compensate for the increased need for reactive power without the help of the energy storage devices. Furthermore, by mitigating the disturbance in the form of reactive power unbalance, the system frequency also experiences a much smaller disturbance. The generator measurement graphs in Figures 5-7 and 5-8 reinforce this statement. The generators hardly seem to notice the disturbance in terms of their output due to the fast response of the energy storage devices to inject the needed reactive power to the system. 

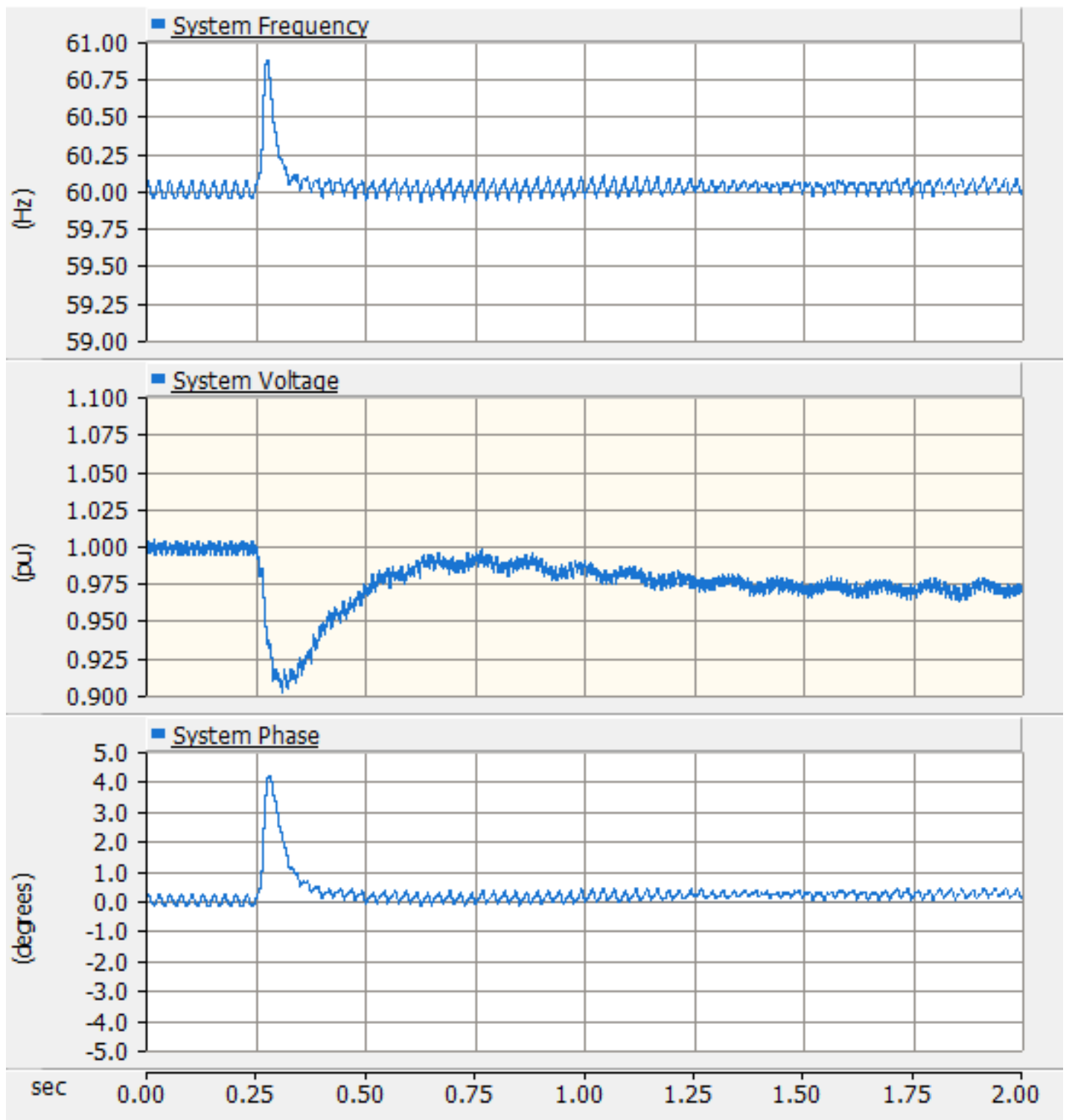

Figure 5-5: System Measurements for Test 2 Using PQ Control 


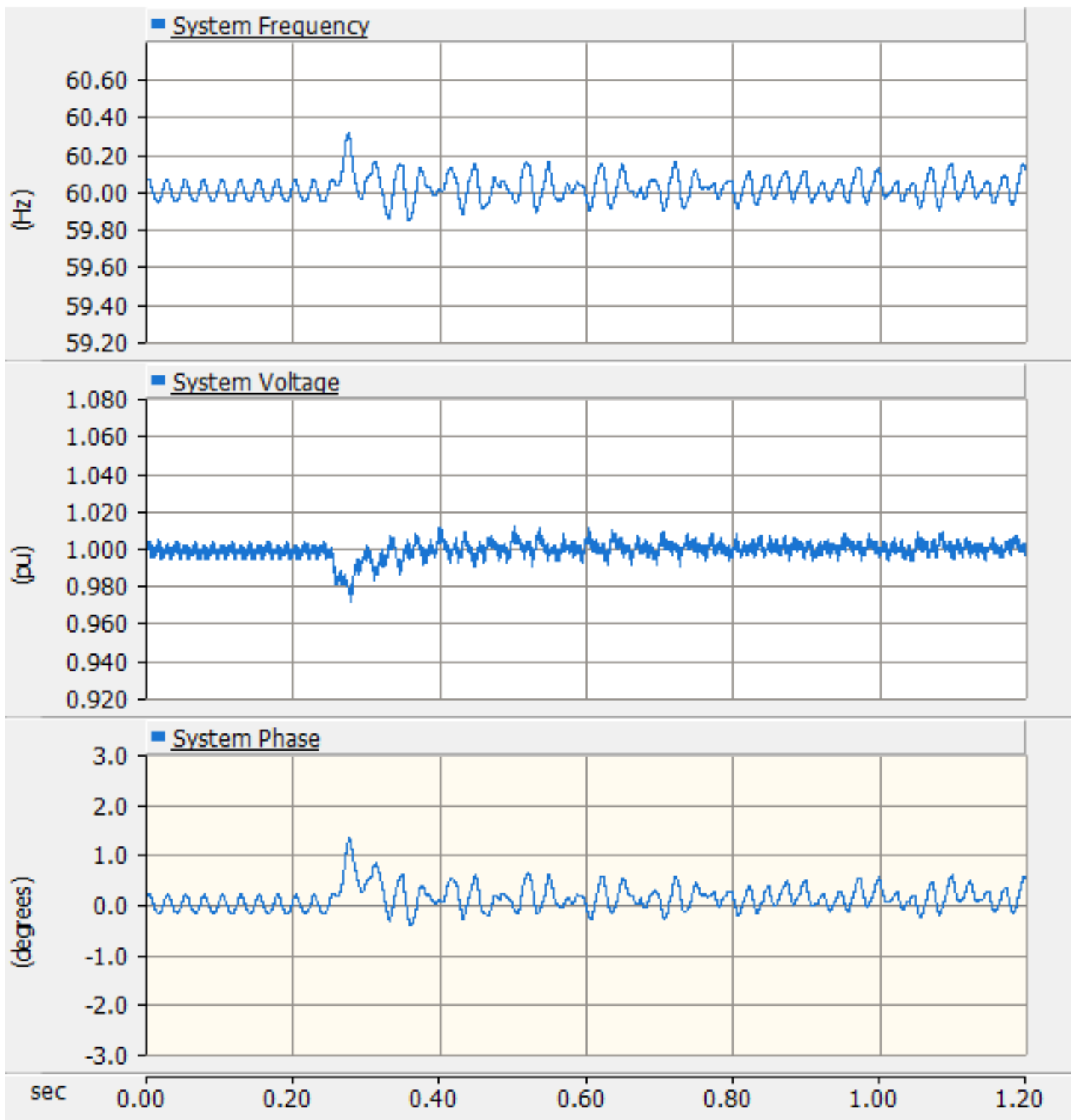

Figure 5-6: System Measurements for Test 2 Using VF Control 


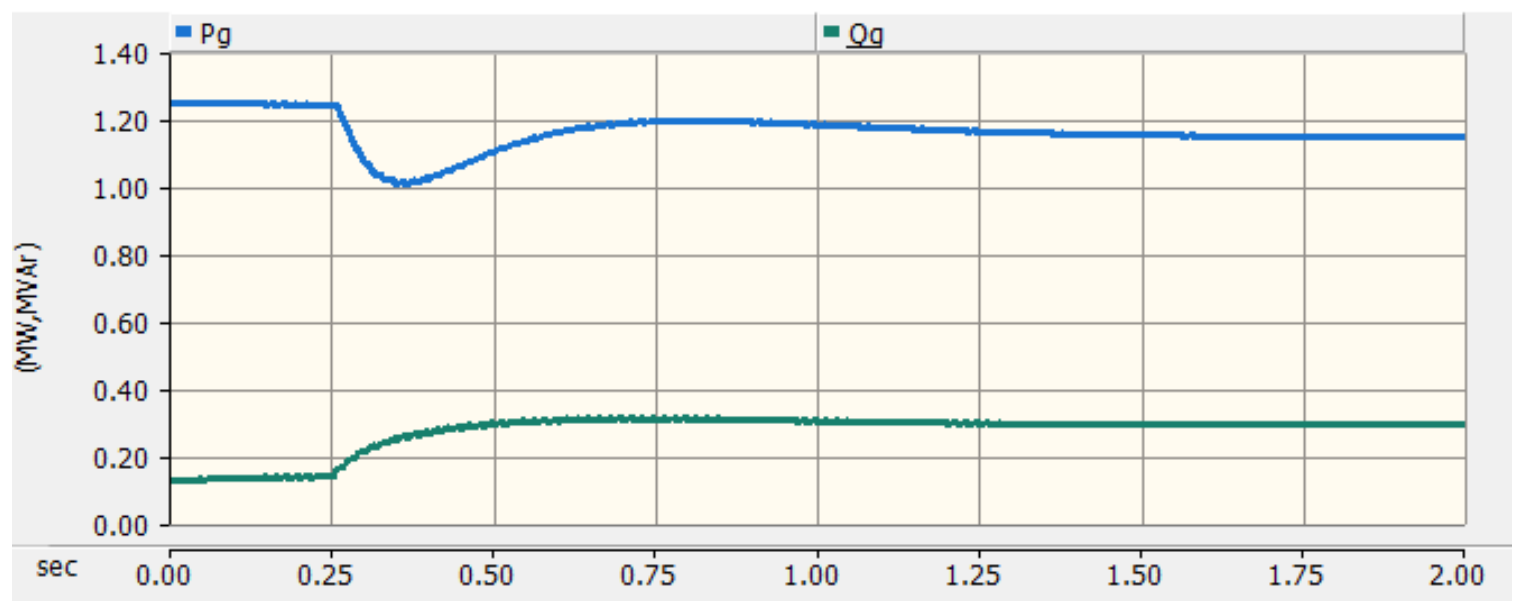

Figure 5-7: Generator P and Q Measurements for Test 2 Using PQ Control

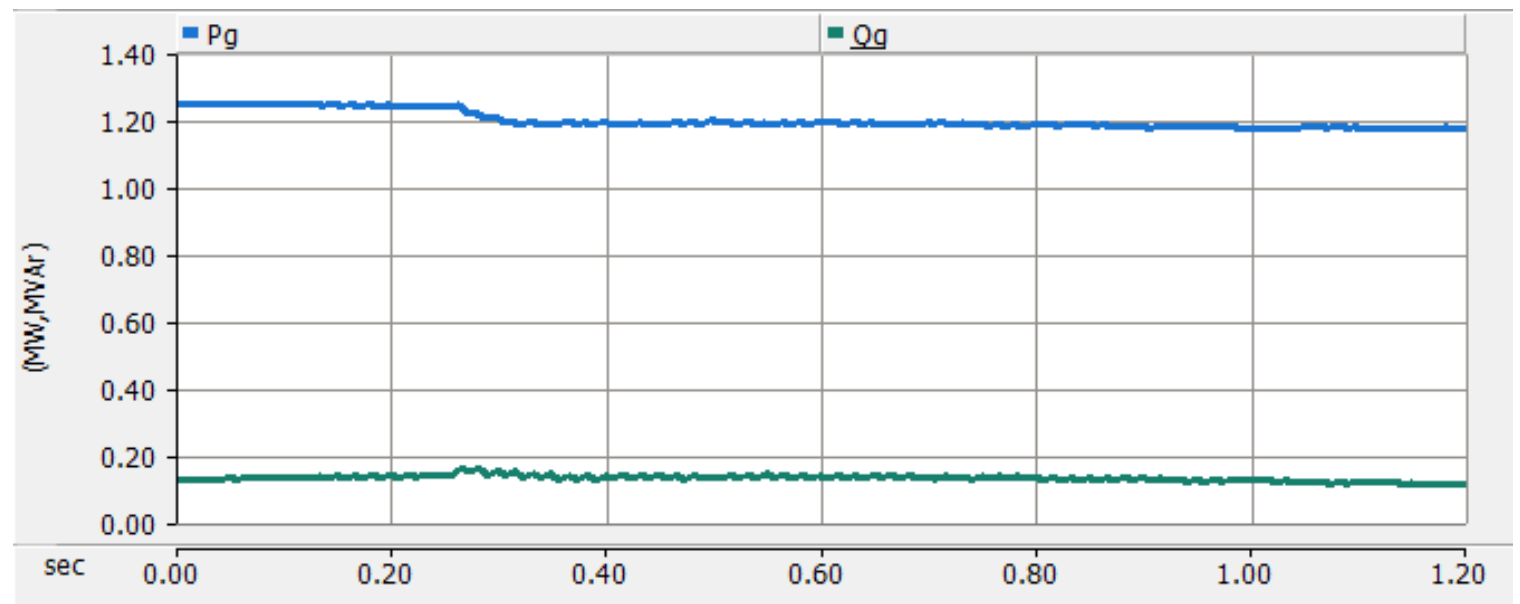

Figure 5-8: Generator P and Q Measurements for Test 2 Using VF Control

\subsection{3: Test 3 - Low Reactive Power Load Imbalance}

The third test is similar to the second one, although it showcases the voltage rise of the system when islanding occurs at a time that too much reactive power is being generated by the microgrid assets compared to the load. The reactive power demand of the load is approximately 0.3MVAR lower than the generated amount at the time of islanding. Figures 
5-9 and 5-10 show that the system experiences a sort of inverse reaction to islanding that was shown in Figures 5-5 and 5-6.

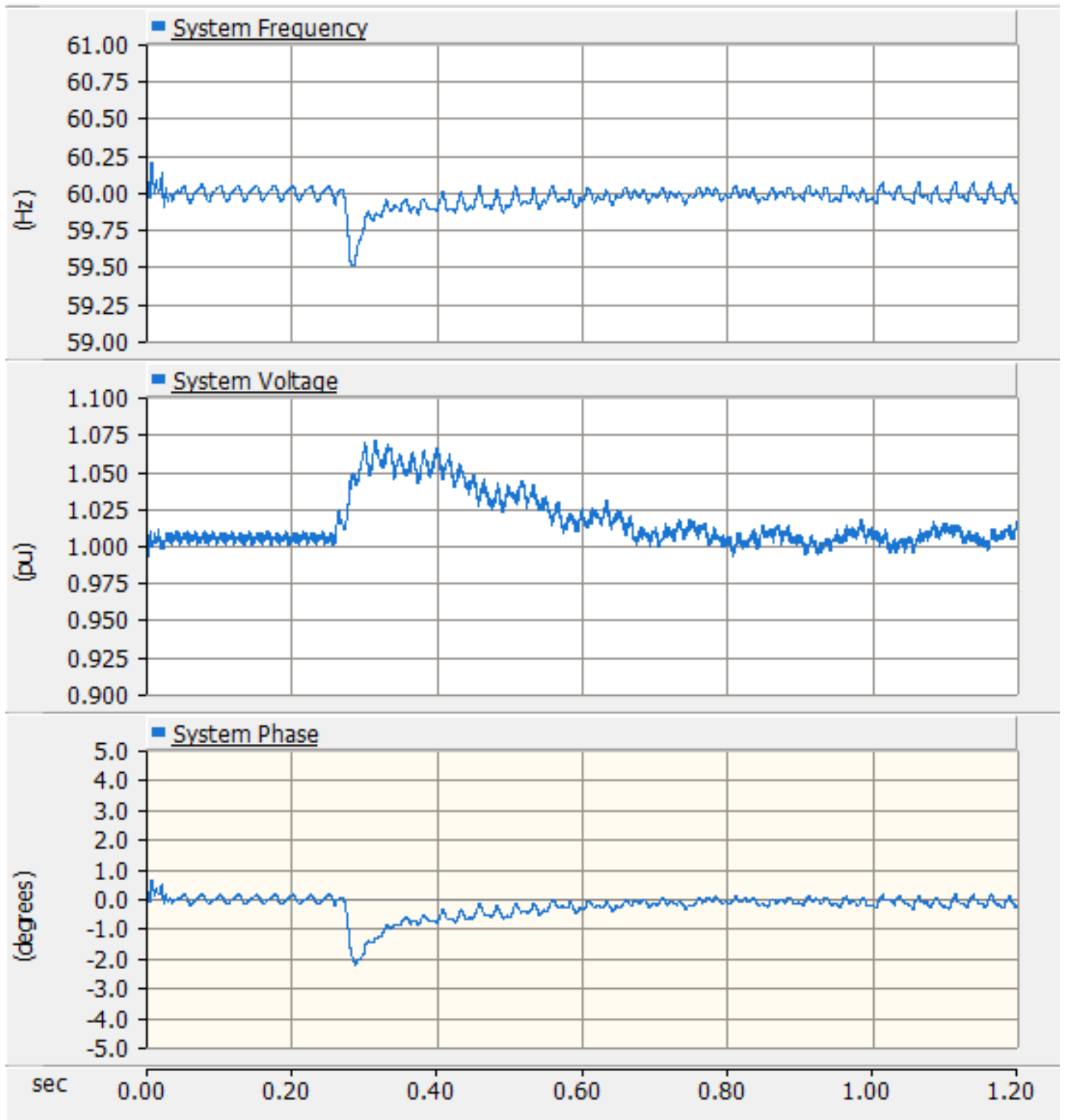

Figure 5-9: System Measurements for Test 3 Using PQ Control 

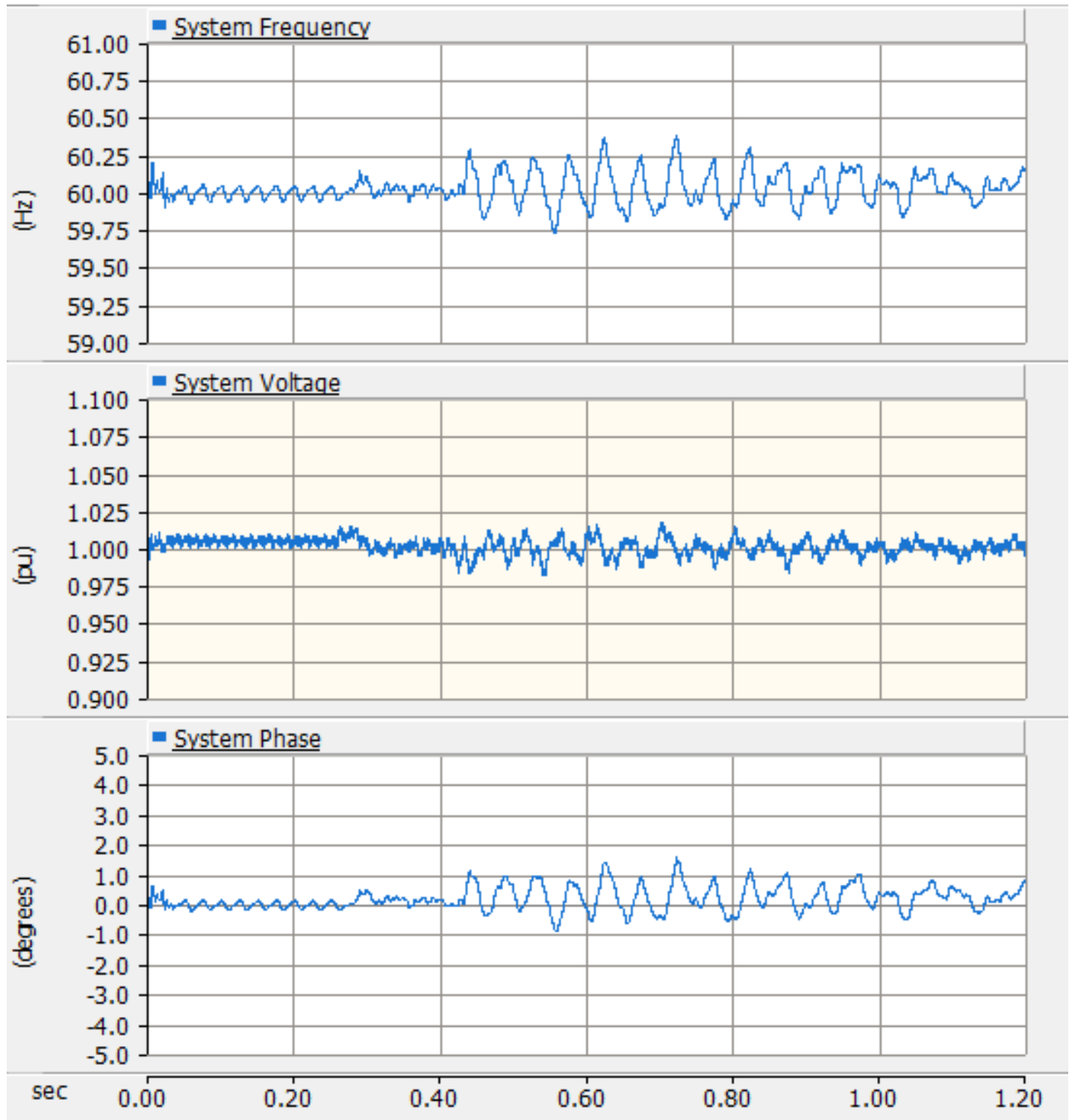

Figure 5-10: System Measurements for Test 3 Using VF Control

In addition the generator graphs in Figures 5-11 and 5-12 show that the diesel generators must experience a disturbance at the time of islanding that is virtually avoided when the Virtual Generator Mode is utilized in the energy storage assets. 


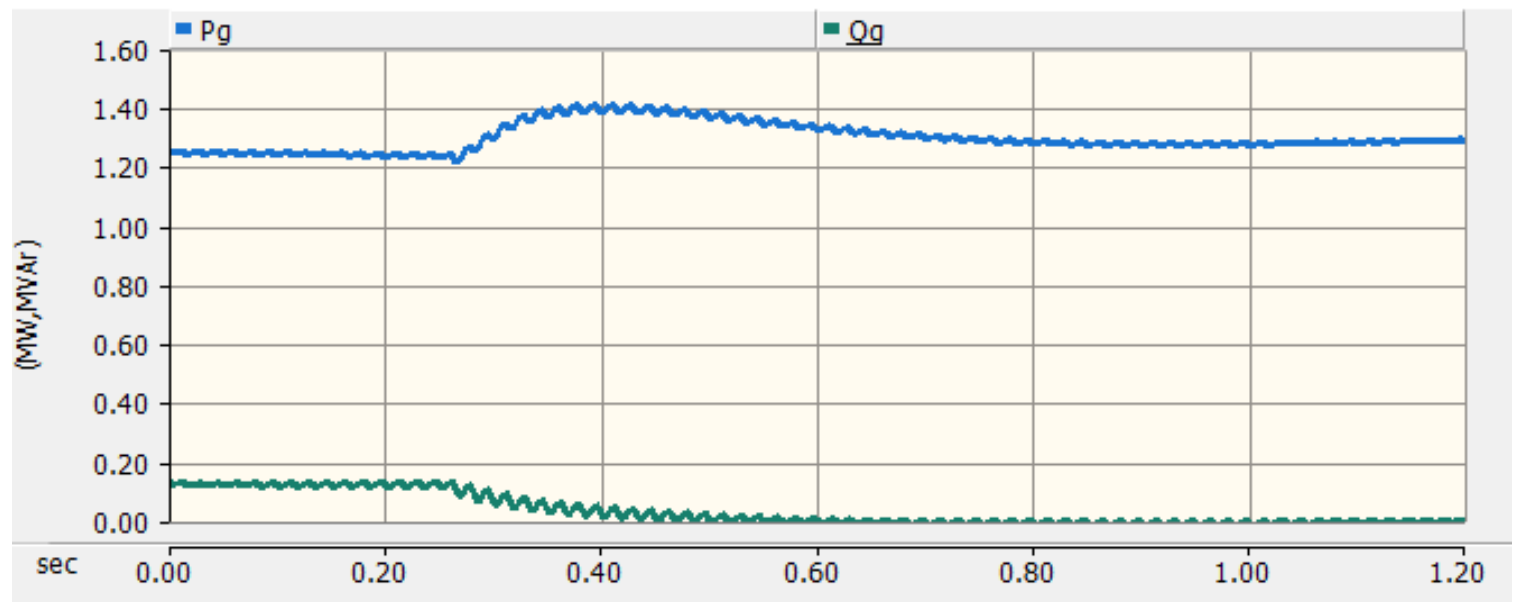

Figure 5-11: Generator P and Q Measurements for Test 3 Using PQ Control

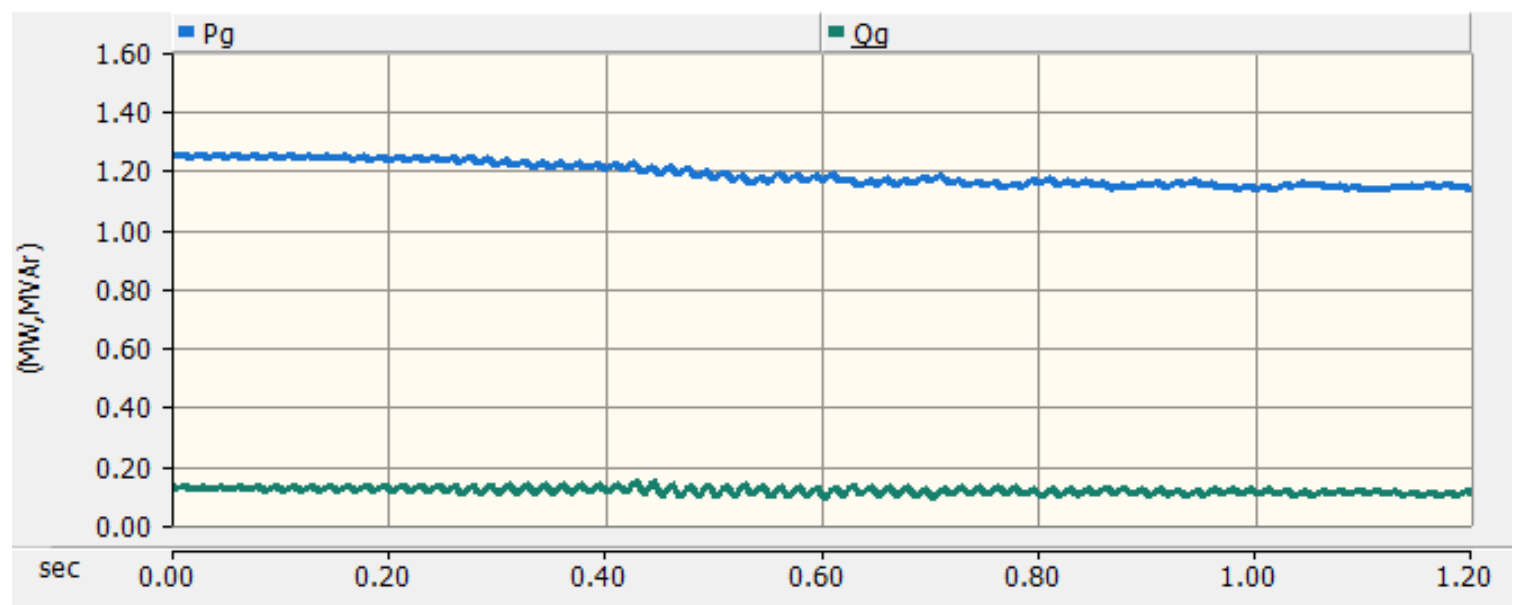

Figure 5-12: Generator P and Q Measurements for Test 3 Using VF Control

\subsection{4: Test 4 - High Active and Reactive Power Load Imbalance}

Finally the fourth and final test demonstrates the effect islanding has on the system when the load is demanding $0.7 \mathrm{MW}$ and $0.35 \mathrm{MVAR}$ more than is being generated when the microgrid transitions into islanded mode. Figures 5-13 and 5-14 show the system level response to the islanding transition. 

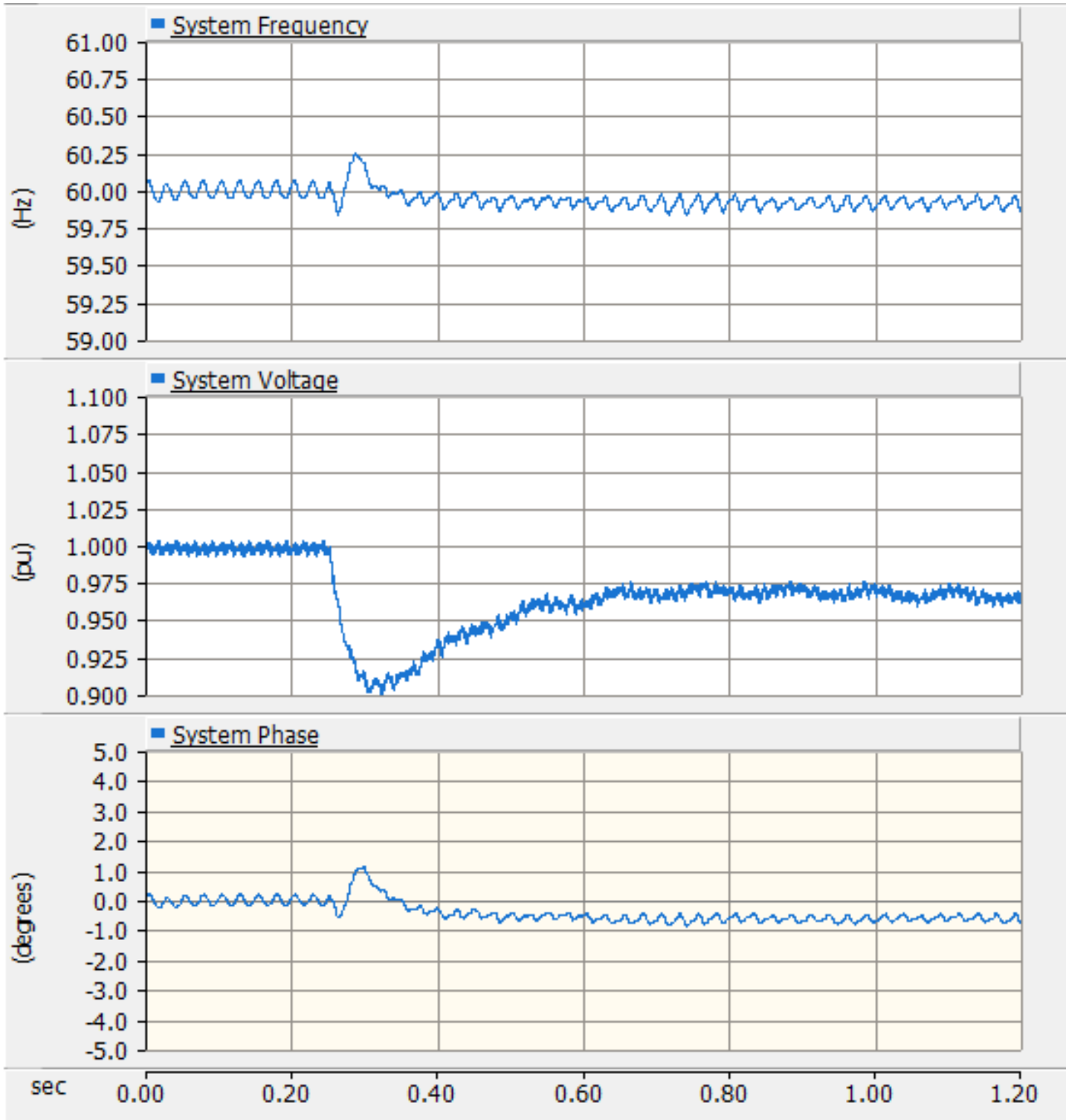

Figure 5-13: System Measurements for Test 4 Using PQ Control

The effect on system voltage level is significant and consistent with previous test, although the immediate disturbance on system frequency is relatively small. That being said, the frequency of the system does begin to droop after the initial transition. The Virtual Generator control mode helps to mitigate both of these negative effects significantly. 


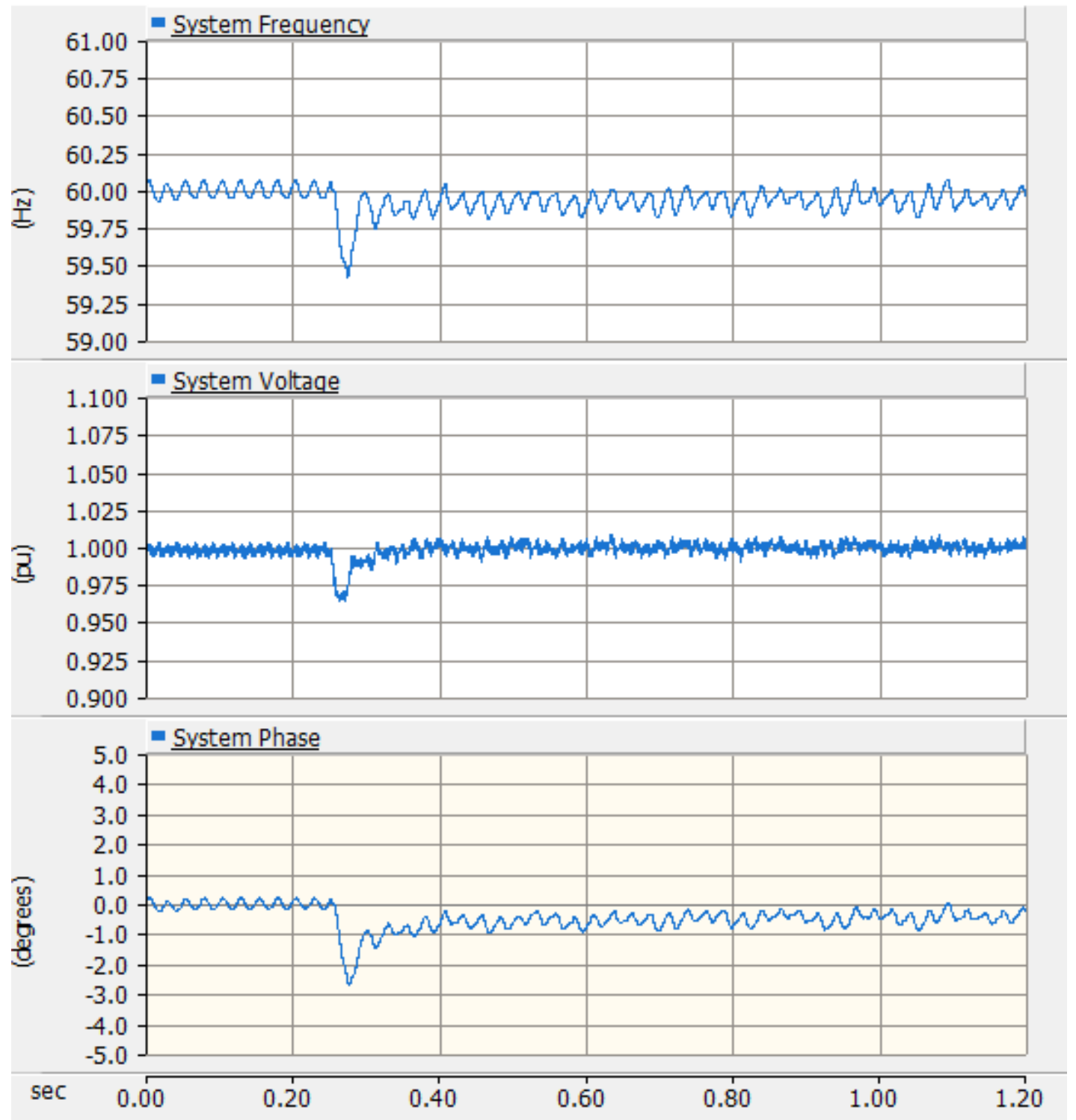

Figure 5-14: System Measurements for Test 4 Using VF Control 


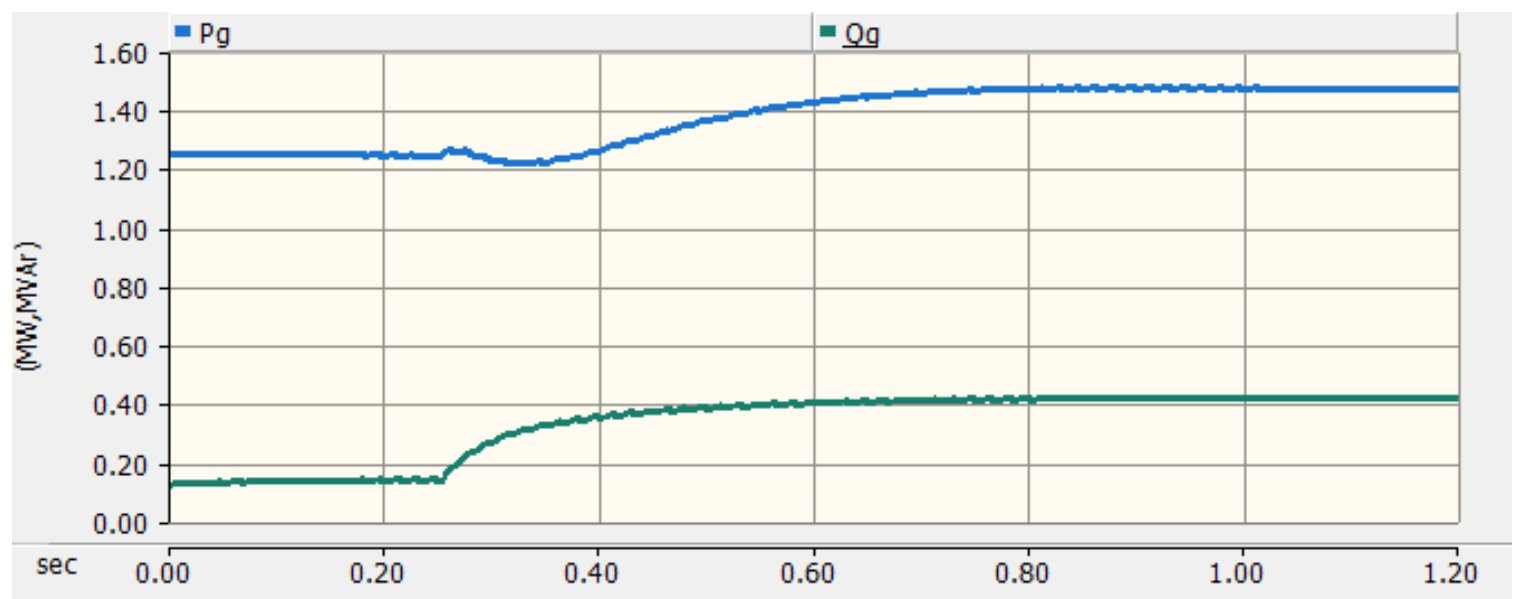

Figure 5-15: Generator P and Q Measurements for Test 4 Using PQ Control

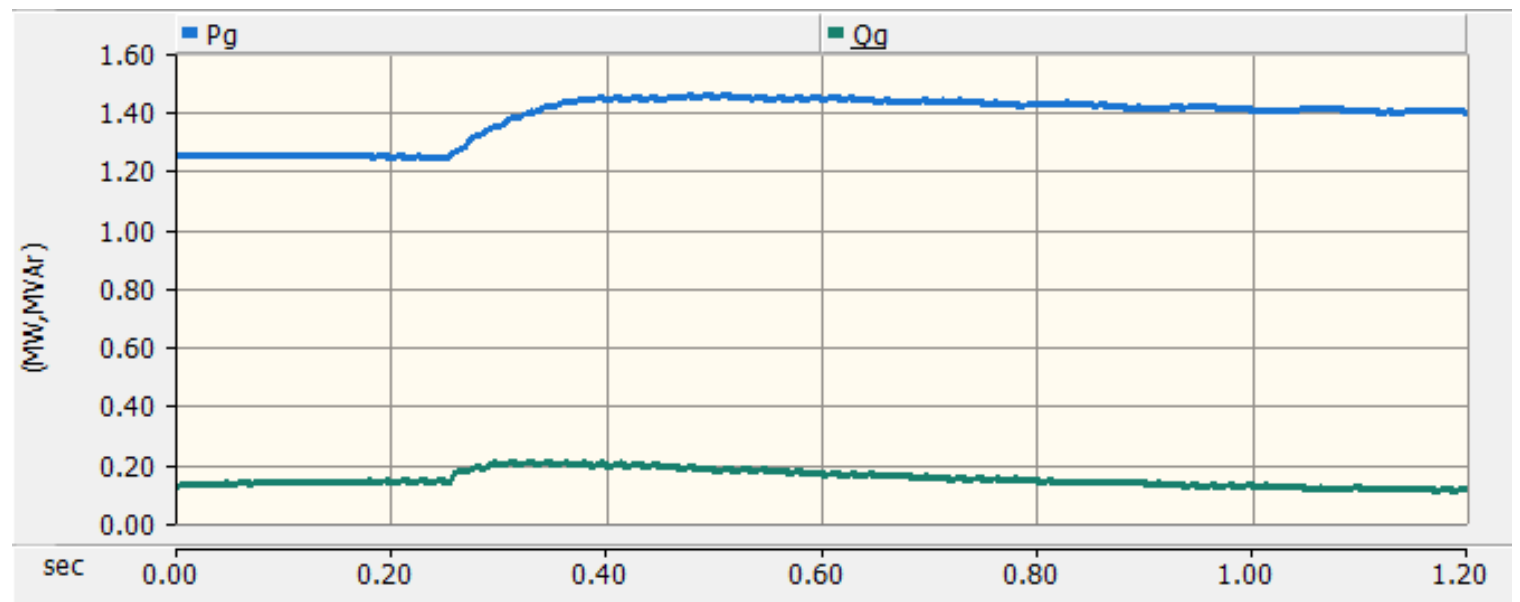

Figure 5-16: Generator P and Q Measurements for Test 4 Using VF Control

The generator graphs show that the generator experiences a significant increase in reactive power at the time of islanding when operating in the PQ control mode Due to the increase in reactive power the generator takes more time to increase the active power to the required level. The VF control mode of the energy storage assets provides reactive power compensation and allows the generator to scale up to the necessary active power level needed more quickly in order to sufficiently balance the system. 


\section{Chapter 6. Conclusions and Future Work}

This thesis study set out to create a PSCAD model of the [REDACTED] Microgrid for simulation and testing purposes to be utilized by [REDACTED]. In order to create and generate tests for the assets contained within the microgrid a deep level of understanding of PSCAD is required. In order to create a working microgrid for both grid-connected and islanded operation the appropriate methods of control were employed. Properly controlling the power output of energy storage devices can give the system user a desired result for grid-tied operation, but is unlikely to work well for islanded operation. PSCAD was useful in showing the positive effect that proper inverter control can have on system stability with respect to frequency and voltage droop levels. The voltage and frequency regulation control mode reflected the capability of the inverters used in the microgrid and showed that system frequency and voltage levels directly correspond to the balance between load and generation. Ultimately, proper control of the energy storage assets is the most effective way to create balance in an islanded microgrid. The Virtual Generator Mode is the optimal control mode for creating balance in small grids. The Virtual Generator Mode allows for quick response of the system where the largest concern for stability comes from loads and reactive power limits.

In addition the results could be reinforced, and shown with more significance, with improved filtering on the power electronics. Improved filtering would increase power quality, which would then allow for more aggressive tuning to the voltage and frequency regulation in the energy storage systems. Further studies could also be executed through the PSCAD model to achieve a higher level understanding of what capability the microgrid has in terms of stability. Tests that use more dynamic loads, more accurately reflecting a 
power system, could provide insight into the stability of the system when islanded. Dynamic Loads would also shed more light on the difference in system stability between the different islanding methods. Furthermore, other techniques of system stability improvement could be investigated to evaluate the effectiveness. Techniques that would be interesting include load shedding methods, along with reactive power compensation using DSTATCOM coordination. 


\section{REFERENCES}

[1]. P. Anderson, Power system protection, 1st ed. New York: McGraw-Hill, 1999, pp. 44-45, 97-120.

[2]. "Accommodating High Levels of Variable Generation", North American Reliability Corporation, 2009.

[3]. Microgrid: A Conceptual Solution Robert H. Lasseter, Paolo Paigi University of Wisconsin-Madison Madison, Wisconsin: http://ieeexplore.ieee.org/stamp/stamp.jsp?arnumber=1354758

[4]. "How Microgrids Work", Energy.gov, 2014. [Online]. Available: https://energy.gov/articles/how-microgrids-work. [Accessed: 05- Feb- 2017].

[5]. "Introduction to Distributed Generation", Dg.history.vt.edu, 2017. [Online]. Available: http://www.dg.history.vt.edu/ch1/introduction.html. [Accessed: 17- Feb2017].

[6]. L. Mariam, M. Basu and M. Conlon, "A Review of Existing Microgrid Architectures", Journal of Engineering, vol. 2013, pp. 1-8, 2013.

[7]. D. Dolan, "EE420 Lecture-Solar PV Operation and PV Technologies", Cal Poly SLO, 2016.

[8]. D. Dolan, "Wind Energy 101 Introduction to wind turbine technology", Cal Poly SLO, 2016.

[9]. P. Gaur and S. Singh, "Investigations on Issues in Microgrids", Journal of Clean Energy Technologies, vol. 5, no. 1, pp. 47-51, 2017.

[10]. X. Zhang, J. Chen and C. Wang, "Stability Analysis of Islanded Microgrids with Dynamic Loads", in 14th International Conference on Control, Automation, Robotics \& Vision, Phuket, Thailand, 2016, pp. 1-6.

[11]. X. Lu, K. Sun, J. Guerrero, J. Vasquez, L. Huang and J. Wang, "Stability Enhancement Based on Virtual Impedance for DC Microgrids With Constant Power Loads", IEEE Transactions on Smart Grid, vol. 6, no. 6, pp. 2770-2783, 2015.

[12]. Y. Duan, Y. Gong, Q. Li and H. Wang, "Modelling and simulation of the microsources within a microgrid", 2008.

[13]. IEEE Recommended Practice for Excitation System Models for Power System Stability Studies, 1st ed. NY: Energy Development and Power Generation Committee, 2016, pp. 49-50.

[14]. "Knowledge Base", Hvdc.ca, 2017. [Online]. Available: https://hvdc.ca/knowledgebase/v:. [Accessed: 30- May- 2017].

[15]. Introduction to Power Electronics, 1st ed. San Luis Obispo, 2016, pp. 302-303.

[16]. Y. Chen and F. Liu, "Design and Control for Three-Phase Grid-Connected Photovoltaic Inverter with LCL Filter", in 2009 IEEE Circuits and Systems International Conference on Testing and Diagnosis, Chengdu, China, 2009.

[17]. 2UCD190000E001 Rev C, PCS 100 ESS - Energy Storage Converter Operator Manual, 2012 